\title{
6. HEFTIGES WERBEN UM JAPAN BIS JUNI 1940
}

\subsection{Rückkehr zur alten Freundschaft}

Der Hitler-Stalin-Pakt stellte die Mächte-Konstellation auf den Kopf: Nach langen Verhandlungen mit dem Westen wurde Moskau zu Hitlers Partner. Frankreich und Großbritannien mußten damit rechnen, ohne eine Gegenfront an Deutschlands Ostgrenze gegen Hitler kämpfen zu müssen. Japan fand sich gedemütigt, isoliert und gefährdet wieder: Mitte August begannen die Sowjets in dem Kleinkrieg um Nomonhan an der mandschurisch-mongolischen Grenze eine große Offensive gegen Japan; seit der Kündigung des Handelsvertrages Ende Juli mußte Tokio mit wirtschaftlichen Sanktionen der USA rechnen.

Für die französische Regierung kam die deutsch-sowjetische Allianz einer Kriegsdrohung gleich. Als das Deutsche Nachrichtenbüro am 21. August kurz vor Mitternacht meldete, daß von Ribbentrop nach Moskau fliege, alarmierte Paris die Grenztruppen und mobilisierte erste Verbände. Am 25. August wurde Paris verdunkelt, Kunstwerke des Louvre wurden evakuiert. Frauen und Kinder verließen die Stadt. $\mathrm{Zu}$ diesem Zeitpunkt hatte der französische Geheimdienst bereits vom Geheimzusatz des Pakts über die Teilung Polens erfahren. Indochina mobilisierte Reservisten für die Metropole ${ }^{l}$. Die Fernostflottille wurde alarmiert, die Überwachung der Grenzen verstärkt. Ausländische Bankguthaben in Indochina wurden eingefroren. Das deutsche Konsulatspersonal in Hanoi reiste am 8. September nach Shanghai und vertraute den Schutz seines Gebäudes China an ${ }^{2}$.

In der Woche nach Abschluß des deutsch-sowjetischen Paktes vom 23. August sei Frankreichs Diplomatie eine der passivsten Europas gewesen, urteilt Jean-Baptiste Duroselle. In Asien ist das Gegenteil richtig: Keine Macht strebte intensiver eine Veränderung der Lage an als Paris. Schon am 22. August äußerten Daladier und Bonnet die Hoffnung, daß das deutsch-sowjetische Bündnis Japans Haltung verändern werde. Henry wurde angewiesen, Tokio auf gemeinsame Interessen hinzuweisen. Man müsse den Pakt in Japan aus-

\footnotetext{
${ }^{1}$ Genebrier, Septembre 1939, S. 79; Bullitt an Hull, 22.8., 23.8.1939 (FRUS 1939, I, S. 301f., SD 740.00/21 10); Brāuer an Ribbentrop, 22.8., 24.8.1939 (ADAP D VII, 184, 216); Les carnets secrets de Jean ZAY, S. 69; CRÉMIEUX-BRILHAC, Les Français, Bd. 1, S. 43; RichER, La drôle de guerte, S. 27 , S. 54; PAIllole, Services Spéciaux, S. 154; EMA.2, compte rendu, 21.10.1939 (SHAT 7 N 2516).

${ }^{2}$ EMG.3 an FNEO, T 5918, 22.8., T 5972, 23.8., T 6012, 25.8.; FNEO, compte rendu, 1.9., Colonies, note, 20.9.1939 (SHM 1 BB9 271, 1 BB4 74, SHAT 7 N 4195); Catroux an Mandel, T 1440-4I, 28.8., T 1447, T 1450, 29.8.; T 1619, 17.9.1939 (CAOM FM Tel 80, 82).
} 
nutzen, sagte Bonnet britischen Diplomaten. Daladier fürchtete, daß Japan westliche Besitzungen in Asien angriff, sobald der Krieg in Europa begann ${ }^{3}$.

$\mathrm{Da} ß$ sich Paris so intensiv um Tokio bemühte, lag nicht nur daran, daß sich Frankreich, anders als Großbritannien oder die USA, als direkter Nachbar einem deutschen Angriff sofort stellen und deshalb besonders rasch neue Freunde finden mußte. Wichtigste Ursache für die geradezu instinktive Hinwendung Daladiers und Bonnets zu Japan war die jahrzehntelange Erfahrung gemeinsamer Interessen. Weil das französisch-japanische rapprochement an eine bewährte, nur zwischenzeitlich etwas erkaltete Freundschaft anknüpfte, mußten vor einer Wiederbelebung der Verbindung weder in Paris, noch in Tokio große mentale Barrieren eingerissen werden. Im August 1939 stand auch kein aktueller Konflikt einer Annäherung unüberwindlich entgegen.

Am 23. und 24. August gingen im Quai d'Orsay Nachrichten ein, wonach eine Aussöhnung von Sowjets und Japanern möglich sei. Daß Bonnet Belgiens Botschafter versicherte, dies sie unrealistisch, sollte nur Brüssel beruhigen. Léger sagte später, daß sich Paris vor allem aus Angst vor einem deutschsowjetisch-japanischen Pakt um eine Annäherung an Japan bemüht habe. Paris kam entgegen, daß sich in Tokio Diplomatie und Militär über den HitlerStalin-Pakt empörten. Mehrere Kreise dort signalisierten, daß sie mit Frankreich ins Gespräch kommen wollten. Vize-Außenminister Sawada Renzo schlug am 24. August die Einrichtung von Direktflugverbindungen zwischen Paris nach Tokio vor; kurz darauf hieß es, der japanische Schiffsverkehr mit Europa werde auf Marseille konzentriert. Wellington Koo befürchtete bereits, Japan könne sich dem britisch-französischen Lager an den Hals werfen. Daladier und Bonnet sagten Botschafter Phipps, sie hofften, daß sich London energisch bemühe, den Hitler-Stalin-Pakt in Japan diplomatisch auszunutzen ${ }^{4}$.

Am Tag darauf wurde Henry angewiesen, dem Gaimusho zu erklären, daß Japan der Weg zur Annäherung an den Westen offenstehe. Japans Botschaft in Paris signalisierte Verständigungsbereitschaft: Sie wolle gern Probleme lösen, vor allem das der Ernennung eines japanischen Botschafters. Bonnet forderte das Foreign Office auf, in London zu britisch-französisch-japanischen Gesprächen einzuladen. Er könne das nicht, weil in Paris kein japanischer Bot-

\footnotetext{
${ }^{3}$ DuRoselle, Décadence, S. 472; Anmerkung Daladier zu: Noël an Bonnet, T 1228, 22.8., Bonnet an Henry, T 378, 22.8.1939 (DDF XVIII, 217, 243); Bullitt an Hull, 22.8.1939 (FRUS 1939, I, S. 301f.); Campbell an Halifax, 22.8., 23.8.1939 (FO 371/22976, C 11780, 11812/15/18).

${ }^{4}$ Saint-Quentin an Bonnet, T 1333, 23.8., François-Poncet an Bonnet, T 3418, 24.8., Garreau an Bonnet, T 41, 24.8.; Coulondre an Bonnet, T 2405, 27.8.1939 (DDF XVIII, 320, 349, 353; XIX, 62); Pol Le Tellier an Hubert Pierlot, 25.8.1939 (DDB V, 116); Léger, note pour l'ambassadeur [Corbin], 10.10.1939 (MAEN Londres C 487); Henry an Bonnet, T 506-8, 23.8., T 512-13, 24.8.1939 (DDF XVIII, 290, 361); Havas, déclarations d'un amiral, 24.8., Henry an Bonnet, T 514-15, 24.8.1939 (MAE Japon 104, 129); EMA.2, compte rendu, 1.10., note de la sous-direction d'Asie, 24.8.1939 (SHAT 7 N 2516, DDF XVIII, 392); Phipps an Halifax, 25.8.1939 (FO 371/23561, F 9402/456/23).
} 
schafter akkreditiert sei. Chauvel sagte Phipps, da ein Krieg in Europa drohe, müsse man die Neutralisierung Ostasiens anstreben, indem man Japan und China zu einer vorübergehenden oder dauerhaften Übereinkunft bringe. Man müsse schnell handeln, überlegen, ob und wie man Washington einbeziehe und den Eindruck vermeiden, daß man Chiang Kai-shek im Stich lasse - eine Erwägung, die wohl auch mit Rücksicht auf Washington entstand.

London reagierte zurückhaltend auf die Vorschläge aus Paris: Man dürfe in Tokio nicht übereifrig auftreten. Allein Staatssekretär Butler riet, sich notfalls ohne Rückendeckung der USA Japan zuzuwenden. Herrschende Meinung im Foreign Office war, den Beziehungen zu Amerika unbedingt Vorrang vor einem besseren Klima mit Japan einzuräumen. Mit zahlreichen Gegenvorschlägen bremste das Foreign Office den Quai d'Orsay: Man müsse erst die Tientsingespräche abschließen, hieß es am 25. August. Am Tag darauf forderte London, praktische Schritte in Tokio sorgfältig abzuwägen. Man müsse zudem Washington überzeugen und sich darauf einstellen, daß jede Lösung des Fernostkonflikts Opfer der Mächte, also auch Frankreichs, erfordern werde. Die durch den Hitler-Stalin-Pakt ausgelöste Regierungskrise in Tokio gebe dem Westen Zeit, argumentierte das Foreign Office. Bonnet hielt es für möglich, daß Briten, Franzosen und Amerikaner vermittelten, denn Japan fürchte seine Isolierung und China ein Zusammengehen des Westens mit Japan. Henry stützte Bonnets Annahme: Die prowestlichen Kräfte in Japan seien im Aufwind. Das im Konflikt stets um Neutralität bemühte Paris habe die besten Chancen zu vermitteln. Man könne Tokio sogar für eine Allianz mit dem Westen gewinnen. London und Paris müßten sich nur einigen, was sie Japan anböten. Wellington Koo sagte am 26. August, China akzeptiere eine Vermittlung nur, wenn die USA beteiligt seien. In Paris besuchte Japans Heeresattaché Oberstleutnant Hikasa nach langer Zeit wieder den französischen Generalstab. Die japanische Armee in China versprach, Zwischenfälle in den Konzessionen zu vermeiden. China setzte gleich auf beide Seiten und drückte auch in Berlin die Hoffnung auf verbesserte Beziehungen aus ${ }^{5}$.

Bonnet nahm sich am Sonntag, 27. August, vor, die folgende Woche solle eine Annäherung an Japan bringen. Er teilte Henry mit, daß Paris Tokio in vier

\footnotetext{
${ }^{5}$ Bonnet an Henry, T 385, 25.8., Bonnet an Corbin, T 1823-24, 25.8., note de la sous-direction d'Asie-Océanie, 25.8.1939 (DDF XVIII, 406, 409, 458); BEST, Britain, Japan and Pearl Harbor, S. 89; LowE, Great Britain and the Origins, S. 134; Phipps an Halifax, 25.8., Clarke, Memorandum, 22.8.1939 (FO 371/23562, F 9450/456/23, 371/23460, F 9369/87/10); Corbin an Bonnet, T 2722-23, 25.8., T 2732, 25.8., T 2737-38, T 2739-43, T 2748, T 2744-45, 26.8.; T 2746-47, 26.8.1939 (DDF XVII, 420, 436, XIX, 16, 18, 20, 27, MAE Japon 123); Bonnet an Corbin, T 1860-63, 26.8., Henry an Bonnet, T 517-18, T 519-20, 26.8.; Note de la sous-direction d'Asie-Océanie, 26.8., Cosme an Bonnet, D 298, 28.8.1939 (DDF XIX, 25, 45, 46, 49, 143); EMA.2, compte rendu, 26.8.1939 (SHAT 7 N 3301); Aufzeichnung von Weizsäcker, 26.8.1939 (ADAP D VII, 327).
} 
Punkten entgegenkomme: Einer japanischen Fluggesellschaft wurde erlaubt, eine Direktverbindung nach Paris aufzubauen, Japan durfte zusätzliche 40000 Tonnen Eisenerz in Indochina kaufen und als einziges Land ein Konsulat in Nouméa auf Neukaledonien eröffnen. Paris akzeptiere als Botschafter jeden von Tokio vorgeschlagenen Diplomaten. Am Tag darauf lobte Chauvel bei Geschäftsträger Miyasaki das neue Klima in den Beziehungen. Daladier sprach gegenüber Bullitt von einer deutlichen Verbesserung der französischjapanischen Beziehungen, verschwieg aber die Details. Für Anstrengungen, Japan in den französisch-britischen Orbit zu ziehen und den Krieg in China zu beenden, habe Paris leider keine Zeit gefunden, erklärte Daladier ${ }^{6}$.

Die Annäherung an Japan war dem Quai d'Orsay so wichtig, daß er schwere Grenzverletzungen überging: Vom 16 . August bis 6 . September drangen japanische Flugzeuge bei Angriffen auf China sechs Mal in Indochinas Luftraum ein, dreimal fielen Bomben auf indochinesisches Territorium. Der MilitärGeheimdienst Section d'études de Hanoi fürchtete eine Landung Japans in Haiphong. Zwei Bombenabwürfe gingen glimpflich aus, doch am 28. August warf ein japanisches Flugzeug zwei Bomben auf das 30 Kilometer von der Grenze entfernte Dorf That-Kê. Eine große Zahl an Zivilisten, die der britische Konsul mit 68, Decoux mit mehr als 100 und Bauchar mit 200 angeben, kam ums Leben. Henry protestierte gegen das Bombardement. Mehr unternahm Paris nicht, um die Beziehungen zu Japan nicht zu gefährden. Auch Tokio wollte den Zwischenfall beilegen und zahlte eine Entschädigung?

Über Corbin und Phipps drängte Bonnet am 28. August das Foreign Office, mit aller Kraft Japan ins westliche Lager hineinzuziehen. Dazu solle der Westen im Fernostkonflikt diskret vermitteln. Nicht über kleine Fragen, wie die der Silberreserven oder der Verbreitung des Fapi, solle man verhandeln, sondern über die Beendigung des Krieges. Wegen der japanischen Vorbehalte gegenüber Großbritannien sei Paris der beste Ort für Verhandlungen, so Bonnet. Chauvel erklärte einem britischen Diplomaten, der Westen sei daran interessiert, daß die Lage in Asien stabil bleibe. Das Verhalten Tokios und Chungkings zeige, daß die Neutralisierung des Fernen Ostens möglich sei: Japan wolle sich den USA und Frankreich annähern, China fürchte die Einigung Japans mit dem Westen. Ein französisch-japanisches Bündnis finde

\footnotetext{
${ }^{6}$ Bonnet an Henry, T 390-93, 27.8., notes de la sous-direction d'Asie, 28.8.1939 (DDF XIX, 55, 134); Bullitt an Hull, 27.8.1939 (SD 760c.62/1069).

${ }^{7}$ Brévié an Mandel, T 1363-64, 19.8., Graffeuil an Mandel, T 1387, 25.8.; T 1448, 31.8.; Troupes de l'Indochine, note, 30.9., SEH, renseignement, 19.9.1939 (CAOM FM Tel 80, 82, CM 818); Walsh an Halifax, 13.9.1939 (FO 371/22921, C 16180/249/17); FNEO, compte rendu, 1.9.1939 (SHM 1 BB4 74); BAUCHAR, Rafales sur l'Indochine, S. 30. Japan zahlte im November 1939 für 76 Tote und 89 Verletzte 625000 Francs Entschädigung. Catroux erklärte die Sache damit für erledigt (Business Report of 1939 by the Board of South Seas, TWCT, III, S. 6814f.).
} 
in der Bevölkerung und bei Bonnet große Resonanz. Doch diese Allianz könne China in das deutsch-sowjetische Lager treiben. Deshalb müsse man diskret versuchen, Japan und China zur Einigung zu bringen. Eine naheliegende Überlegung äußerte Chauvel aber nicht, nämlich, daß man Tokio gegen Moskau in Stellung bringen könnte. Dabei hatte am 25. August die Unterdrückung kommunistischer Aktivitäten in Frankreich begonnen, der Ton gegenüber den Sowjets verschärfte sich. Wellington Koo nahm an, daß die Westmächte versuchten, Japan zum Gegengewicht gegen Rußland zu machen. Auch Chauvels Urteil, daß für Frankreich eine Waffenruhe in China besser sei als andauernde Kämpfe (in denen China japanische Kräfte absorbierte), könnte darauf beruhen, daß der sous-directeur wünschte, Japans Kraft gegen Moskau zu lenken. Immerhin dauerte der japanisch-sowjetische Grenzkonflikt noch an.

Das Foreign Office blieb skeptisch. Staatssekretär Mounsey versicherte, London und Paris wollten Tokio von Berlin trennen und den Fernostkonflikt entschärfen, doch eine Vermittlung sei verfrüht, da die Differenzen zwischen Japan und Großbritannien fortbestünden. Am besten sei es, wenn die USA Vermittlungsvorschläge unterbreiteten. Die Antwort enttäuschte Chauvel so sehr, daß er intern vorschlug, Paris solle allein diskret in Tokio, Chungking und Washington vorfühlen, wenn London dies dulde. Der Quai d'Orsay konzentrierte sich zunächst auf die USA und spannte Bullitt am 28 . August für seine Idee ein: Der US-Botschafter regte bei Roosevelt an, Chiang Kai-shek zu erklären, daß ein Friedensschluß in seinem Interesse liege. Am Folgetag bat Bonnet die US-Regierung, Japan eine Verbesserung der Beziehungen anzubieten. Washington solle sich auch an einer Vermittlung in China beteiligen, da Berlin Japan in das deutsch-sowjetische Lager ziehen wolle ${ }^{8}$.

Die japanische Innenpolitik entwickelte sich wie vom Westen gewünscht: Am 28. August trat Ministerpräsident Hiranuma mit dem Satz zurück, die europäische Welt sei kompliziert und rätselhaft. Intern machte er das heftige Drängen der Armee nach einem Bündnis mit Deutschland für Japans prekäre Lage verantwortlich. Der neue Regierungschef General Abe Nobuyuki, der am 30. August ins Amt kam und zunächst auch das Außenministeriums führte, versicherte den Mächten, er werde sie freundschaftlich behandeln, wenn diese sich freundschaftlich zu Japan verhielten. Was der Westen nicht erfuhr, war die Anweisung, die der Kaiser dem neuen Regierungschef gegeben hatte: Abe solle die Zusammenarbeit mit Briten und Amerikanern suchen. Erst jetzt, am

\footnotetext{
${ }^{8}$ Bonnet an Corbin, T 1879, T 1888, 28.8., Bonnet an Corbin, T 1881-85, Saint-Quentin T 1153-57, Henry T 409-13, 28.8.; Corbin an Bonnet, T 2782-85, 28.8., notes de la sous-direction d'Asie, 28.8., 26.8.1939 (DDF XIX, 93, 119, 95, 107, 135, 49); Bräuer an Ribbentrop, 26.8., 27.8.1939 (ADAP D VII, 310, 348); Mounsey, Note, 28.8., Phipps an Halifax, 28.8.1939 (FO 371/23551, F 9599/4027/61); Bullitt an Hull, 28.8., 29.8.1939 (SD 851.00/1947; FRUS 1939, III, S. 213, S. 58f.); Bonnet an SaintQuentin, T 1169-70, 29.8., Coulondre an Bonnet, T 2424-25, 29.8.1939 (DDF XIX, 159, 177).
} 
28. August, fragte der Quai d'Orsay seinen Botschafter in Shanghai, wie Chungking auf den Hitler-Stalin-Pakt reagiere. Dies zeigt, welch geringen Wert Paris China nun einräumte. Cosmes Analyse, die Anhänger eines Friedens mit Japan seien in der Offensive, traf die Lage genauer, als Cosme ahnte: Chiang Kai-shek bat Roosevelt am 1. September über Koo und Bullitt um Vermittlung im Fernost-Konflikt. Bei England und Frankreich bestehe die Gefahr einer Einigung mit Japan auf Chinas Kosten, schrieb Chiang'.

Bonnet forderte am 29. August von Halifax erneut Bemühungen um Japan. Halifax erwiderte, es strebe die Einigung mit Japan an, doch bevorzuge er ein graduelles Vorgehen, bei dem London und Tokio zuerst den Tientsinkonflikt lösten. Eile sei unnötig, da eine deutsch-japanische Militärallianz ausgeschlossen sei. Zudem sollten die USA bei den Gesprächen eine Führungsrolle einnehmen. Daß Hornbeck die Briten gewarnt hatte, es könne keinen sinnvollen Kompromiß mit Japan geben, teilte London Paris nicht mit. Auch in Washington erhielt der Quai d'Orsay eine Abfuhr: Welles erklärte St. Quentin am 30. August, das State Department lehne jede Intervention in Asien ab. Japan müsse sich ohnehin auf den Westen zubewegen, da es die Brücken nach Berlin abgebrochen habe. Für eine Allianz zwischen Moskau, Berlin und Tokio gebe es keine Hinweise. Man dürfe Japan nicht hinterherlaufen ${ }^{10}$.

Nach Welles' kühler Reaktion wandten sich Bonnet und Léger wieder London zu. Daß der japanische Militärattaché ausgerechnet am Tag des deutschen Angriffs auf Polen, am 1. September, eine französisch-japanische Annäherung vorschlug, bestätigte sie in ihrer Annahme, daß Paris im Fernen Osten seine Position verbessern konnte. Bonnet und Léger wiesen Henry an, auf Japans Militär positiv einzuwirken und reichlich Orden zu verteilen. Die französische Bürokratie hielt die Ordensverleihung aber noch bis Mitte Oktober 1939 auf. Am 2. September billigten der französische Außenminister und der Generalsekretär den britischen Plan, zunächst mit Japan über den Tientsinkonflikt zu verhandeln. Die USA baten sie um ein paralleles diplomatisches Vorgehen, doch sei Frankreich auch bereit, erklärte Léger Phipps, notfalls ohne die USA zu handeln. Léger erwartete, daß Japan Paris um Vermittlung bitten werde. Für die Briten war ein Vorgehen gegen den Wunsch der USA allerdings

\footnotetext{
${ }^{9}$ TANAKA, Les relations, S. 98; Henry an Bonnet, T 528, 30.8., T 530, 31.8.1939 (DDF XIX, 213; MAE SDN 2143); Maurice PERNOT, L'accord germano-russe et ses incidices, in: Politique étrangère 4 (1939), S. 473-487 (S. 477); FeIs, Road to Pearl Harbor, S. 34; IMAI, Cabinet, S. 72; Chauvel an Cosme, T 388, 28.8., Cosme an Bonnet, T 939, 30.8.1939 (MAE Japon 123, MAEN Londres C 487); Bullitt an Hull, 1.9.1939 (FRUS 1939, III, S. 221f.).

${ }^{10}$ Bonnet an Corbin, T 1892-94, 29.8., Corbin an Bonnet, T 2806-9 très secret, T 2810-13, 29.8., T 2842, très secret, T 2843 très secret, $T$ 2846 47 très secret, 30.8., Saint-Quentin an Bonnet, T 1387-90, 30.8.1939 (DDF XIX, 160, 164, 172, 217, 218, 220, 226); Memorandum of Conversation, 30.8., Lord Lothian an Halifax, 31.8.1939 (SD 740.0011 Eur. War, 1939/136, DBFP, $3^{\text {rd }}$ series, IX, 607).
} 
undenkbar. Bonnet ärgerte sich sehr, daß London und Washington auf seine Vorschläge nur mit »totaler Gleichgültigkeit« reagierten ".

Der Kriegsausbruch in Europa änderte die Lage in Asien zunächst kaum. Japan erklärte am 4. September seine Neutralität. Chinas Presse ergriff Partei für den Westen; Chiang Kai-shek bot London und Paris an, militärisch gemeinsam gegen Berlin und Tokio vorzugehen, doch diese Idee redeten Cadogan und Léger Chinas Botschaftern aus. Henry sprach am 6. September mit Regierungschef Abe, fünf Tage später empfing Bonnet Japans Geschäftsträger. Abe versicherte Henry, es gebe keine großen Differenzen zwischen ihren Ländern, er wünsche eine gute Zusammenarbeit. Um Herzlichkeit bemühten sich auch Bonnet und Miyasaki am 11. September. Konkrete Ergebnisse hatten die Treffen nicht. Daß in Paris das Gerücht umging, Bonnet habe Miyasaki einen Nichtangriffspakt angeboten, was definitiv nicht der Fall war, zeigt, wie sehr die Öffentlichkeit in Paris Japans Freundschaft wünschte ${ }^{12}$.

Léger, Chauvel und Bonnet bemühten sich am 13. September erneut, London und Washington zur Annäherung an Japan zu bewegen, denn aus Tokio, Moskau und Shanghai kamen Hinweise, daß Japan und die Sowjetunion ein Bündnis anstrebten. Die Briten glaubten jedoch nicht an einen japanisch-sowjetischen Interessenausgleich, Hull argumentierte, Japan werde sich vor allem dann auf den Westen zubewegen, wenn man es allein lasse ${ }^{13}$.

Am 13. September bildete Daladier sein Kabinett um. Die neue Regierung sollte Entschlossenheit vermitteln. Bonnet, die Verkörperung des apaisement in Europa, konnte kaum Chef der Diplomatie bleiben. Als Pétain, dessen Berufung zum Kriegsminister Daladier im März 1939 erwogen hatte, und Herriot das Amt des Außenministers ablehnten, übernahm der Regierungschef selbst die Führung des Ministeriums. Als Staatsekretär sollte der bisherige Pensionsminister Auguste Champetier de Ribes Daladier in der Leitung des Quai

${ }^{11}$ EMA.2, compte rendu, 1.9.; Henry an Daladier, T 612, 29.9., notes de la sous-direction d'AsieOcéanie pour le service du protocole, 8.10., 11.11.1939 (MAE Japon 129, 98); Auriti an Ciano, 5.9., 25.9., Guraiglia an Ciano, 2.10.1939 (DDI 9, I, 29, 427, 566); Daladier an Cosme, L 67, 26.11.1939 (MAE Chine 522); Bonnet an Corbin, T 1950-51, 2.9.1939 (DDF XIX, 361); Léger an Saint-Quentin, T 1203-5, 2.9.; Halifax an Phipps, T, 5.9.1939 (MAE Chine 738, 761); Phipps an Halifax, 3.9., Halifax an Phipps, 5.9 .1939 (FO 371/23444, F 9790/69/10); BONNET, Le Quaj d'Orsay, S. 309.

${ }^{12}$ Henry an Bonnet, T 535, 4.9., T 551-53, 7.9.1939 (MAE Japon 124, 129); Cosme an Bonnet, T 984, 9.9., Bonnet an Henry, T 443, 6.9., note de la sous-direction d'Asie-Océanie, 13.9.; 16.9.1939; Bonnet an Henry, T 459, 14.9. 1939 (MAE Chine 738, Japon 124, RFD 28).

${ }^{13}$ Chauvel an Henry, nicht abgesandtes T, 6.9., Payart an Bonnet, T 208, 6.9., Léger an Saint-Quentin, T 1289-90, 11.9.; Bonnet an Corbin, T 2133, 14.9., Corbin an Daladier, T 3183-87, 16.9.; Bonnet an Saint-Quentin, T 1304-11, 13.9., Henry an Bonnet, T 554-55, 8.9., Payart an Bonnet, L 208, 6.9., T 1048-49, 15.9., T 1055, 16.9., Cosme an Daladier, T 1025-27, 20.9., Note Corbin, 20.9., SaintQuentin an Daladier, T 1623, 21.9 .1939 (MAE Japon 124, Chine 738, MAEN Londres C 487); Phipps an Halifax, 13.9.; Bullitt an Hull, 11.9., 13.9., 26.9., Hull an Bullitt, 29.9.; Colonies, note, 30.9.1939 (FO 371/23460, F 10151/87/10; FRUS 1939, III, S. 242f., S. 247, SD 893.0146/704, SHAT 11 H 62). 
d'Orsay unterstützen, aber Champetier blieb blaß und war seinem Amt nicht gewachsen. Daladier führte die Regierung aus dem Kriegsministerium in der Rue Saint-Dominique ${ }^{14}$. Léger, der täglich mit Daladier sprach, nahm in der Fernostpolitik das Heft noch fester in die Hand. Mit dem Regierungschef war er sich über das Ziel der Annäherung an Japan einig.

Da Briten und Amerikaner abwarteten, setzten die Franzosen ihre Bemühungen um Japan allein fort. Am 15. September wies Léger Henry an, Felder für Kooperationen mit Japan zu suchen. Strittige Fragen sollten ausgeklammert bleiben; französische Interessen dürften nicht aufgegeben werden. Henry solle sich vor allem um eine bessere Atmosphäre und um Vertrauen bemühen und der Regierung klar machen, daß Paris einen Beitrag zur Verbesserung der Beziehungen Tokios zu Washington und London sowie zur Regelung des Fernostkonflikts leisten könne. Von Chinas Klagen bei britischen Diplomaten über den neuen französischen Kurs ließ sich Paris nicht beirren. Die Bitte der Chinesen, Cosme möge nach Chungking kommen, lehnte der Botschafter höflich ab. Tokio signalisierte die Bereitschaft zur Annäherung, als es Vize-Außenminister Sawada, den Chauvel für einen einflußreichen Freund Frankreichs hielt, als Botschafter in Paris berief. Von 1918 bis 1922 war Sawada Botschaftssekretär in Paris gewesen. Die Berufung zeige, daß Japan seine traditionellen Beziehungen zu Frankreich wiederbeleben wolle, schrieb Chauvel. Man wisse nicht, wie die Gespräche mit Japan endeten, aber daß Tokio einen Botschafter benenne, um zu sprechen, sei ein gutes Zeichen. Auch Henry setzte große Hoffnungen auf Sawadas Berufung. Als Freund des Westens sah Cosme den neuen Außenminister Admiral Nomura Kichisaburo. Der ehemalige Marineattaché in Washington war tatsächlich bewußt als Geste an die USA ausgewählt worden. Léger wies Henry an, dem neuen Chef des Gaimusho Frankreichs Wunsch nach Wiederaufnahme der traditionell vertrauensvollen Zusammenarbeit mit Japan zu übermitteln ${ }^{15}$.

Auch dem neuen Vize-Außenminister Tani, der wegen seiner Ablehnung als Botschafter sicher nicht ohne Ressentiments gegen Frankreich war, übermittelte Léger seinen Wunsch nach Verständigung. Henry glaubte jedoch, daß sich Tani nicht sehr freundlich verhalten werde, und hoffte deshalb, daß dieser

\footnotetext{
14 Jeanneney, Joumal, S. 9; PertinaX, Les fossoyeurs, Bd. 1, S. 128; Chauvel, Commentaire, S. 61; Bullitt an Hull, 23.3., Phipps an Halifax, 14.9 .1939 (SD 740.00/668, FO 371/22910, C 13909/25/17); CrÉmieuX-BrilhaC, Les Français, Bd. 1, S. 145; HeIMSOETH, Der Zusammenbruch, S. $271 \mathrm{f}$.

${ }^{15}$ Léger an Henry, T 462-63, 15.9., T 491, 24.9., Cosme an Daladier, T 999-1000, 15.9., Léger an Corbin, T 2156, 15.9., note de la sous-direction d'Asie-Océanie, 19.9.1939 (MAE Chine 738); ClarkKerr an Halifax, 13.9., 14.9.1939 (FO 371/23444, F 10173/69/10, FO 371/23461, F 11601/787/10); Léger an Henry, T 482-83, 20.9., note de la sous-direction d'Asie-Océanie, 24.9.1939 (MAE Japon 129); Auriti an Ciano, T 720, 25.9.1939 (DDI Serie 9, I, 427); Cosme an Daladier, T 1042, 23.9.1939 (MAEN Londres C 487); Clavery, Extrême-Orient, S. 347; JonES, Japan's New Order, S. $155 f$.
} 
über den Streik zu Fall käme, der Japans Außenministerium im Oktober lähmte. Der Ausstand, der sich gegen den Aufbau eines Ministeriums für Außenhandel richtete und an dem auch Miyasaki in Paris teilnahm, zeigte, daß Abe und Nomura keiner starken Regierung vorstanden.

Im ersten Gespräch am 28. September versicherte Nomura Henry, daß Japan in Europa neutral bleibe. Tokio erwarte aber, daß Frankreich jegliche Hilfe an China einstelle. Henry urteilte, daß Japan sich auf den Krieg in China konzentriere und dort Zugeständnisse der Mächte erwarte. Nomura strebe bessere Beziehungen zu allen Mächten an. Daladier versicherte Nomura umgehend, daß Frankreich nicht beabsichtige, Japan in Europa gegen Deutschland auf seine Seite zu ziehen. Paris wünsche lediglich eine friedliche Regelung des Krieges in China. Als gutes Zeichen sah Paris Ende September, daß sich in den Konzessionen das Klima zwischen den westlichen und den japanischen Truppen verbesserte und daß Japan von Hainan die meisten Verbände abzog. Die französische Regierung, so wollte der italienische Botschafter in Paris erfahren haben, wies die Behörden in Indochina an, Japaner zuvorkommend zu behandeln. Dem Auswärtigen Ausschuß der Kammer berichtete Daladier am 4. Oktober, die Beziehungen zu Japan hätten sich deutlich verbessert ${ }^{16}$.

Um Japans Freundschaft zu gewinnen, war der Quai d'Orsay sogar bereit, die Truppen in China zu reduzieren. Am 5. September hatte Japans Regierung mit einem "freundschaftlichen Rat» Briten und Franzosen aufgefordert, ihre Heeres- und Marineverbände aus China abzuziehen, „um Komplikationen zu vermeiden«. Tokio machte die Forderung, die Paris und London kaum überraschte, nicht öffentlich, um die Demokratien nicht zu sehr unter Druck zu setzen. Der Begriff »freundschaftlicher Rat« hatte in Japans Geschichte keine positive Bedeutung: Frankreich, Deutschland und Rußland hatten 1895 so ihren Druck auf Japan genannt, China die Liaotung-Halbinsel abzutreten; auch Japans Forderung an Deutschland 1914, Tsingtao zu räumen, firmierte als freundschaftlicher Rat. Craigie und Henry sahen Tokios Forderung als nicht drängend und nicht, wie dies Italiens Botschafter Auriti tat, als Beweis einer feindseligen Haltung. London und Paris erwiderten, man begrüße Japans Wunsch, Zwischenfälle zu vermeiden, sehe aber nicht, wie die Präsenz der Truppen zu Spannungen führen solle. Die Gespräche, die Premierminister Abe

\footnotetext{
${ }^{16}$ Henry an Daladier, T 604, 25.9., Léger an Henry, T 500-2, 26.9.; Daladier an Henry, T 517-19, 5.10., Henry an Daladier, T 631-32, 10.10.1939 (MAE Chine 738, 739); Henry an Daladier, T 60911, 28.9., T 627-28, 5.10., T 628, 8.10.1939 (MAEN Londres C 487); Henry an Daladier, T 609-I1, 28.9., note de la sous-direction d'Asie-Océanie, 12.10.1939 (MAE Japon 124); Henry an Cosme, T 328, 8.10., T 330-31, 13.10., T 333, 14.10.; Simon an Cosme, L, 28.9.1939 (MAEN Pékin A 311, A 494); Henry an Catroux, T 6, 29.9.1939 (CAOM CM 818); Altenburg an Ribbentrop, 18.11.1939 (AA Botsch Peking Pol 5-10); Yvon an EMA.2, L 105, 14.9 .1939 (SHAT 7 N 3292); Guariglia an Ciano, 2.10.1939 (DDI Serie 9, I, 567); Bulletin de commissions, Bd. IV, $2^{e}$ partie, Paris 1946.
} 
mit Craigie und ein Abteilungsleiter im Gaimusho mit dem französischen Botschaftsrat Fain führten, bestärkten Henry und Craigie in der Ansicht, daß Tokio den Truppenabzug nicht erzwingen werde. Abe sagte, der Abzug sei nicht besonders dringlich. Nur Cosme riet zum Rückzug, weil dies Gespräche mit Japan erleichtere. Es sollten aber genügend Polizeikräfte in den Konzessionen verbleiben - um chinesische Aktivitäten zu unterdrücken! $!^{17}$

Die britische Regierung schlug Paris vor, fast das gesamte Militär aus China abzuziehen, wie dies London ohnehin geplant hatte. Der Rückzug entspanne die Beziehungen zu Japan. Man müsse die Truppe ohnehin früher oder später zurückziehen. Der Abzug könne nur verschoben werden, wenn Amerika interveniere. Prompt warnten Roosevelt, Hull und Welles Japans Regierung, es schade den japanisch-amerikanischen Beziehungen, wenn Tokio London und Paris zum Abzug dränge. Die Äußerungen sollten nicht nur Tokio, sondern auch London und Paris beeindrucken, die mit deutlichem Nachdruck informiert wurden. Die US-Diplomaten Hornbeck und Bullitt empfahlen "privat« den Briten und Franzosen, die Truppen nicht abzuziehen ${ }^{18}$.

Léger und Chauvel sprachen sich Mitte September gegenüber Briten und Amerikanern für den Verbleib der Truppen aus. Gebe man Japan nach, bedeute dies die endgültige Verdrängung des Westens aus China, neue Forderungen würden folgen. Vor allem dürfe man Washington nicht zeigen, daß man bereit sei, Positionen in Asien zu räumen. Falls die USA aber keine Verantwortung in Asien übernähmen, müsse man über einen Abzug reden, so Léger ${ }^{19}$.

Das Foreign Office erklärte Corbin, es rechne nicht mit amerikanischer Unterstützung; doch ein Truppenrückzug sende ein wichtiges Signal der Entspannung an Japan. Vermutlich setzte auch Léger kaum Hoffnungen auf die USA, wollte aber sicher gehen, daß der Abzug als Element der Annäherung an Japan nicht für Unmut in Washington sorgte. Am 14. September erklärte Botschafter Saint-Quentin Sumner Welles, ohne amerikanische Unterstützung könnten Franzosen und Briten ihre Truppen kaum in China belasssen. Welles

\footnotetext{
${ }^{17}$ Henry an Bonnet, T 542-46, 5.9., T 547-49, 6.9., T 567-69, 10.9., Corbin, Note, 7.9.1939 (MAEN Londres C 487); Dooman an Hull, 6.9.1939 (SD 793.94/15349); Auriti an Ciano, 7.9.1939 (DDI Serie 9, I, 69); Phipps an Halifax, 7.9., Craigie an Halifax, 6.9., 9.9., 14.9., 18.9., Halifax an Craigie, 10.9.1939 (FO 371/23460, F 9869, 9903, 9944, 10163, 10259, 9869/87/10); Henry, aide-mémoire, 12.9.1939 (FO 371/23461, F 11424/87/10); Henry an Daladier, T 575-76, 14.9., Corbin an Daladier, T 3183-87, 16.9., Cosme an Bonnet, T 964, 6.9.1939 (MAE Chine 738).

${ }^{18}$ Corbin an Bonnet, T 2994-99, 7.9.; Saint-Quentin an Bonnet, T 1497, 9.9., Bonnet an SaintQuentin, T 1264-67, 10.9., Chauvel, Note, 17.9.1939 (MAE RFD 28, MAEN Londres C 487); War Cabinet Conclusions, 8.9., Halifax an Phipps, 9.9., Lothian an Halifax, 7.9., 8.9., Brenan, Note, 14.9., Note, 18.9.1939 (FO 371/23460, F 10078, 9846, 9920, 9943, 10193, 10292/87/10); Hull an Dooman, 6.9., Johnson an Hull, 8.9., Hull an Bullitt, 16.9 .1939 (SD 793.94/15348, 893.0146/698, 696C).

${ }^{19}$ Phipps an Halifax, 11.9., 12.9.1939 (FO 371/23460, F 10109, F 10133/87/10); Bullitt an Hull, 11.9., 13.9., 9.10., 26.9.1939 (FRUS 1939, III, S. 242f.; S. 247; S. 282f.; SD 893.0146/704).
} 
gab keine Antwort. Saint-Quentin und sein britischer Kollege Lord Lothian waren sich sicher, daß die USA keine Verpflichtungen eingehen würden. Beide hielten es für wichtig, daß England und Frankreich ihre Truppen in China behielten, solange die USA dies auch täten, um in der amerikanischen Öffentlichkeit den Eindruck zu vermeiden, man lasse die USA im Stich. Auch für die Asienabteilung im Quai d'Orsay war der Eindruck, den der Abzug auf die USA machen könnte, von überragender Bedeutung ${ }^{20}$.

Das State Department erklärte am 27. September, daß die USA ihre Truppen in China beließen, aber London und Paris nicht mit ihrer Hilfe rechnen dürften; Hull nahm den Vorschlag vom 19. September zurück, eine internationale Konferenz über die Zukunft Shanghais einzuberufen. Léger nahm die Absage nicht hin. Er sagte Bullitt, Frankreich werde alle Verbände aus China zurückziehen. Hull blieb bei seiner Zurückhaltung. Schon bevor Hulls Antwort vorlag, hatten Paris und London für den Fall einer negativen Reaktion der USA Pläne entworfen: Halifax empfahl am 22. September dem War Cabinet, alle Truppen aus China abzuziehen, bis auf die in Shanghai, die man mit Rücksicht auf die USA beibehalte. Zwei Tage später erteilte das französische Außenministerium der Armée de terre den Auftrag, einen Abzug zu planen. Das Heer schlug vor, die Garnisonen in Tientsin und Shanghai zu belassen und an den anderen Posten nur kleine, symbolische Kontingente zu stationieren ${ }^{21}$.

Die britische und die französische Regierung versicherten einander, sie hätten noch nicht über den Abzug entschieden, planten den Rückzug aber weiter. Am 3. Oktober erfuhr London von seinem Botschafter in China, daß Paris erwog, aus Shanghai 400 von 1700 Soldaten, in Tientsin 1600 von 2000 Mann sowie die Garnisonen in Hankou und Kanton ganz abzuziehen. Tokio drängte nicht weiter auf den Abzug. Für wie gering die Franzosen die Gefahr für ihre Kontingente in China hielten, zeigte sich daran, daß die Regierung bis zum Ende der Dritten Republik keinen Befehl über das Verhalten bei einem japani-

${ }^{20}$ Brenan, Minute, 14.9., Halifax an Phipps, 16.9., Lord Lothian an Halifax, 16.9., Phipps an Halifax, 17.9.1939 (FO 371/23460, F 10193, 10133, 10246, 10257/87/10); Bressy an Saint-Quentin, T 1301-3, 14.9., Saint-Quentin an Daladier, T 1576, 16.9., Corbin an Daladier, T 3145-47, 14.9., T 3188, 16.9.1939 (MAEN Londres C 487); Saint-Quentin an Daladier, T 1537-40, 14.9., note de la sousdirection d'Asie-Océanie, 19.9.; Léger an Saint-Quentin, T 1344-48, 17.9.1939 (MAE Chine 738, 761); Bullitt an Hull, 15.9.1939 (SD 893.0146/695); Lothian an Halifax, 19.9., 28.9.1939 (FO 371/23461, F 10549, F 10334/87/10); Saint-Quentin an Hull, 20.9.1939 (FRUS 1939, III, S. 258f.).

${ }^{21}$ Welles an Saint-Quentin, 27.9., Bullitt an Hull, 30.9.1939 (FRUS 1939, III, S. 267, S. 272); SaintQuentin an Daladier, T 1640, 22.9., T 1677-80, 28.9.; Léger an Cosme, T 469-70, 3.10.1939 (MAE Chine 1064, 739); Halifax, Memorandum, 22.9.1939 (FO 371/23522, F 10454/3918/10); Analyse, EMA, 29.9.1939 (SHAT 11 H 64); Hull an Bullitt, 6.10.1939 (SD 893.0146/706); Léger an Corbin, T 2414-18, 1.10.1939 (MAEN Londres C 487). 
schen Angriff herausgab. Die britischen Verbände hingegen wurden Mitte Dezember 1939 angewiesen, sich bei einem Angriff kampflos zu ergeben ${ }^{22}$.

Mitte Oktober teilte das Foreign Office Washington, aber nicht Paris mit, $\mathrm{da} ß$ London seine Truppen aus Nordchina so rasch wie möglich zurückziehen wolle. Die Lage sei so stabil, daß das Militär ohne Prestigeverlust abziehen könne. Als Außenminister Hull erklärte, er sehe angesichts der andauernden sowjetisch-japanischen Spannungen keinen Grund, warum Großbritannien und Frankreich Japan eine bessere Position in China einräumen sollten, und seine Hoffnung äußerte, daß die Briten wenigstens kleine Kontingente zurückließen, beschloß das Kabinett in London, symbolische Kräfte in Tientsin und Peking zu belassen. Aus Washington erfuhren Léger und Chauvel von den britischen Entscheidungen. Das Foreign Office entschuldigte sich, man habe mit dem Vorstoß nur die Meinung des State Department herausfinden wollen. Die britische Regierung informierte Paris am 31. Oktober, daß sie bis auf ein symbolisches Kontingent von 175 Soldaten definitiv alle Truppen aus Nordchina abziehe. Die Abstimmung zwischen den Rückzügen der britischen und der französischen Truppen solle vor Ort erfolgen ${ }^{23}$.

Am 5. oder 6. November einigten sich in Paris das Außen- und das Kolonialministerium, von den 4000 Soldaten 400 Mann in Nordchina und 1000 Mann in Shanghai zu belassen. In Hankou und Kanton wurden 50 und 20 vietnamesische Soldaten der Polizei zugeordnet. Am 13. November wurde der Teilabzug bekanntgegeben. Der Quai d'Orsay sprach nicht von einem Abzug, sondern von einer vorübergehenden Veränderung der Kontingente. Auf britischen Schiffen wurden die Truppen Ende November aus Shanghai und Ende Dezember aus Tientsin nach Indochina verlegt. Das französische Hauptquartier zog von Tientsin nach Shanghai. Als die französische Regierung Chungking über den Abzug informierte, verband sie dies mit dem Hinweis, daß Frankreich genügend Kräfte in China belasse, um seine Rechte zu verteidigen. Nach Ende der Umgruppierungen Ende Januar 1940 befanden sich je 1600 britische und amerikanische, 1400 französische und 400 italienische

\footnotetext{
${ }^{22}$ Corbin an Daladier, T 3484-86, 2.10., Cosme an Daladier T 1019-20, 19.9.1939 (MAEN Londres C 487); Hull an Bullitt, 2.10.1939 (SD 893.0146/707); Clark Kerr an Halifax, 3.10.1939 (FO 371/23522, F 10753/3918/10); Corbin an Daladier, T 3501, 3.10.; Léger an Cosme, T 444, 21.9., Cosme an Daladier, T 1003, 15.9., T 1036-37, 22.9.1939 (MAE Chine 739, 1064); General Officer Commanding (GOC) Hongkong an War Office, 15.12 .1939 (FO 371/23518, F 12825/3139/10).

${ }^{23}$ Corbin an Bonnet, T 3058, 11.9., Léger an Corbin, T 620-621, 21.10., Corbin an Daladier, T 3637, 12.10., T 3281, 30.10.; T 3783-88, 26.10., T 3863-64, 3.11.1939 (MAEN Londres C 487, MAE Chine 761, 564); War Cabinet Conclusions 46, Min. 8, 13.10.1939, Conclusions 57, Min. 9, Halifax an Phipps, Draft, Oct 1939, Cadogan an Campbell, 29.10., Campbell an Halifax, 1.11., Halifax an Campbell, 3.11.1939 (FO 371/23522, F 10996, F 11242, F 11366, F 11436/3918/10); Halifax an Lothian, 18.10., Lothian an Halifax, 20.10., Campbell an Halifax, 24.10.1939 (FO 371/23461, F 10549, F 11153, F 11237/87/10); Direction politique, note, 2.11.1939 (MAE Chine 563).
} 
Soldaten in China. Damit hatte Paris, das stets so energisch das Corps d'occupation en Chine verteidigt hatte, die Kontingente stärker reduziert als London ${ }^{24}$.

Der Rückzug betraf auch die canonnières auf dem Jangtse. Schon im Januar 1939 hatte Darlan den Rückzug der Kanonenboote vom Oberen Jangste verlangt. Anfang September 1939 entschied die Marineführung in Paris, alle Kanonenboote zu entwaffnen, um Hilfskreuzer im Pazifik zu bewaffnen. Diese Anordnung revidierte Marineminister Campinchi: Anfang Oktober sollten nur noch zwei der vier Kanonenboote, später dann keines abgerüstet werden. Ende Oktober, als die Briten bereits fünf ihrer zehn Kanonenboote vom Jang-tse nach Hongkong verlegt hatten, drohte Japans Generalstab, die vor Hankou liegende Francis Garnier gewaltsam zu entwaffnen, falls sie nicht abfahre. Gegen Cosmes Widerstand zog Paris die Garnier am 13. Dezember ab. Anfang 1940 wurde die Doudart de Lagrée abgerüstet, die Francis Garnier blieb vor Shanghai, die Argus wurde in Hongkong stationiert. Auf dem Oberlauf des Jangtse blieb die Balny, wo sie im September 1940 entwaffnet wurde . $^{25}$.

Frankreich hatte damit zum Jahreswechsel 1939/40 den größten Teil seiner Militärpräsenz in China geräumt. Paris gab diese semikolonialen Rechte nicht auf, um dem Selbstbestimmungsrecht der Chinesen entgegenzukommen, sondern letztlich zugunsten eines stärkeren Zugriffs der Japaner auf China. Das politische Signal des Abzugs war deutlich: Der Rückzug müsse als ein Mittel zur Annäherung an Japan gesehen werden, kommentierte Italiens Botschafter in Shanghai. Champetier de Ribes versicherte Bullitt treuherzig, mit der Reduzierung habe man allein Zusammenstöße in China vermeiden wollen. Geheime Verhandlungen mit Japan gebe es nicht ${ }^{26}$. Der Abzug bewies, daß Paris bereit war, für die Annäherung an Tokio in China Opfer zu bringen.

Auf einen Weg, den von Paris gewünschten Ausgleich zwischen Japan und China herbeizuführen, schien die im Herbst 1939 bevorstehende Etablierung

\footnotetext{
${ }^{24}$ Colonies an Marine, L 1297, 6.11.; Direction politique an Campbell, 8.11., Léger an Cosme, T 57172, 11.11., Léger an Saint-Quentin, T 1754-58, 12.11.1939 (MAE Chine 563, 564); Corbin an Daladier, T 3926, 10.11., Léger an Henry, T 587-89, 11.11., Henry an Daladier, T, 13.11.1939 (MAEN Londres C 487); Colonies an Casseville, T 218, 7.11., FTFC, Note de Service, 14.11.; Diplomatie an Guerre, L 5475, 15.11., Tientsin an Guerre, T 200, 15.11.1939 (SHAT 11 H 79, 64; 7 N 3249, 3292); Chauvel an Cosme, T 10, 10.1.; Georges-Picot an Daladier, T 101, 26.1.1940 (MAE Chine 799, 795); Division of Far Eastem Affairs, Note, 29.1.1940 (SD 893.0146/764). RoTH, Japan Strikes South, S. 42. Im August 1940 zogen die Briten alle Soldaten aus China ab. Die französischen Soldaten - im Juli 1940 noch 1300 Mann - wurden erst im März 1945 von Japan entwaffnet.

${ }^{25}$ Darlan an Bonnet, L 20, 9.1.; Léger an Corbin, L 1848, 31.10.1939 (SHM 1BB2 182, MAEN Londres C 487); Diplomatie an Marine, L 1559, 12.10.1939; Chauvel an Cosme, T 517, 21.10., Cosme an Daladier, $\mathrm{T}$ 1202, 28.10., T 1212-13, 29.10., Léger an Cosme, $\mathrm{T}$ 580, 14.11., Cosme an Daladier, T 1276-78, 19.11.1939 (MAE Chine 766); Spiker an Hull, 13.12.1939 (SD 893.0146/758); Yvon an EMA.2, L 39, 14.1.1940 (SHAT 7 N 3292); Bernard ESTIVAL, Les canonnières de Chine, in: Revue internationale d'Histoire militaire 75 (1995), S. 97-109 (S. 103).

${ }^{26}$ Taliani an Ciano, 19.11., Bullitt an Hull, 14.11.1939 (DDI Serie 9, II, 263; FRUS, III, S. 318f.).
} 
des Regimes von Wang Ching-wei hinzudeuten. Im Sommer war der Versuch des mit Japan kollaborierenden Kuomintang-Politikers, eine Regierung $\mathrm{zu}$ bilden, noch gescheitert. Cosme beobachtete Wangs Bemühungen abwartend. Die französischen Behörden in Shanghai, Kanton und Tientsin kooperierten mit den Marionetten-Stadtverwaltungen, ohne diese aber, etwa durch Briefe, implizit anzuerkennen. Die Briten verhielten sich ähnlich. Der Krieg in Europa bot Japan eine neue Chance, eine chinesische Zentralregierung zu installieren. Als Wang am 28. August in Shanghai die Bildung einer Regierung ankündigte, erwog Chauvel, zu Wangs Gunsten die Kontakte mit Chungking abzubrechen. Am 7. September erklärte Wang, er bilde seine Regierung noch im September. Der japanische Regierungschef Abe äußerte sich ähnlich ${ }^{27}$. Henri Cosme drängte den Quai d'Orsay, »die große Chance der Zusammenarbeit mit Wang Ching-wei« zu nutzen. In Telegrammen, die er vom 4. bis 7. September täglich an Bonnet richtete, argumentierte der Botschafter, Frankreich könne Japan nur gewinnen, wenn Paris seine China-Politik ändere und Japan beim Aufbau einer neuen Ordnung unterstütze. Falls Frankreichs Versuch scheitere, Wang und Chiang zusammenzubringen, habe Paris jeden Grund, sich von Chiang ab- und Tokio zuzuwenden. Die Hinwendung zu Japan sichere die Konzessionen und Frankreichs Einfluß in Südchina. Paris müsse die Chinapolitik aber rasch ändern, um davon zu profitieren. Sonst gerate man unter Druck. Dem italienischen Botschafter erklärte Cosme, er sei überzeugt, daß die neue Regierung rasch von Paris und London anerkannt werde. Nach Frankreichs Kollaps im Juni 1940 schrieb Cosme, eine Kollaboration mit Wang hätte französische Interessen in Asien bewahrt.

Chauvel folgte Cosme nicht. Wangs Regierung werde vermutlich schwach sein, zudem wolle Wang das Ende der ungleichen Verträge. Auch Japans Forderung nach Truppenabzug zeige geringen Respekt vor den Konzessionen. Im Fall einer japanisch-chinesischen Einigung bestehe die Gefahr, daß Chiang Frankreich aus Südchina herausdränge. Vor allem, so betonte Chauvel intern, könne Paris die Chinapolitik nur mit Zustimmung Londons und Washingtons ändern. Auch Henry nannte die USA den entscheidenden Faktor in Asien. Léger und Daladier fragten sich jedoch, ob Wang nicht doch Aussicht auf Erfolg habe. Sie ließen Cosmes Anregungen zwei Wochen lang unbeantwortet und telegraphierten dem Botschafter am 24. September, Frankreich wolle die Beziehungen zu Japan verbessern und denke deshalb über eine Zusammenar-

\footnotetext{
${ }^{27}$ Myers an Hull, 14.6.1939 (SD 793.94/15213); Boissezon an Bonnet, T 738, 25.6.1939 (MAE Chine 773); Cosme an Bonnet, T 768, 4.7., L 248, 30.7., T 880-81, 9.8.1939 (MAE RFD 28, Chine 737, MAEN Londres C 480); LANGER, GLEASON, The Challenge, S. 581f; Altenburg an Ribbentrop, 28.8.1939 (ADAP D, VII, 368); Note de la sous-direction d'Asie-Océanie, 31.8., Henry an Daldier, T 573-74, 14.9.1939 (DDF XIX, 286; MAE Chine 738); L. RoBERT, Aspect fondamental du conflit sino-japonais, in: Revue des questions de défense nationale (1940), S. 499-516 (S. 509).
} 
beit mit Wang nach. Paris müsse aber Rücksicht auf die USA und wegen der Kontrolle über Indochinas Nachbarprovinzen auch auf Chiang Kai-shek nehmen. Man müsse Tokio, das die Konzessionen kontrolliere, und Chungking, das Indochina gefährlich werden könne, gleichermaßen beachten. Léger hielt Wangs Versuche der Regierungsbildung für schädlich: Solange Japan nicht wisse, wie sich Wang etabliere, nehme es keine Friedensgespräche mit Chiang auf. Cosme hielt weiter Kontakt zu Wang. Dieser und Japans Diplomatie erklärten wiederholt, die Regierungsbildung stehe unmittelbar bevor ${ }^{28}$.

Die Aufnahme von Friedensgesprächen zwischen Chiang Kai-shek und Japan hielt Paris für dringlich. Um den 24. September empfahl Chauvel Koo, Chiang solle mit Japan Frieden schließen und mit Wang kooperieren, um bessere Bedingungen als von Tokio zu bekommen. Chauvel sagte Koo, Finanzminister Kung arbeite womöglich mit Wang zusammen, vielleicht sei auch Chiang zu schwach, um den Widerstand fortzusetzen.

Die chinesische Regierung reagierte heftig auf die französische Anregung: Sie warf Paris öffentlich vor, mit Tokio zu paktieren, und lancierte Berichte, wonach sich Frankreich um Frieden zwischen Japan und China bemühe. Über die Agentur United Press verbreitete Chungking, ein Verantwortlicher in Paris habe China geraten, mit Wangs Hilfe Frieden mit Japan zu schließen. Französische Diplomaten hätten eine Parade von Marionettentruppen in Shanghai besucht. Tatsächlich hatten nur Vertreter der westlichen Stadtverwaltungen an einem Empfang teilgenommen, wie dies üblich war. Die Berichte zielten auf die US-Öffentlichkeit ab. Chauvel dementierte die Meldungen sofort. Auch im Foreign Office beschwerten sich die Chinesen über einen französischen Kurswechsel. Chauvel erklärte den Briten, Chinas Botschaft, die ihn oft um Rat frage, habe wissen wollen, wie sie sich gegenüber Wang verhalten solle. Er habe das Problem dargelegt, ohne einen Rat zu geben, so Chauvel. Die Mitarbeiter im Foreign Office glaubten Chauvel. In einem Telegramm an Cosme bestätigte Léger jedoch, man habe Koo erklärt, daß die Einbeziehung Wangs die einzige Möglichkeit sei, mit Japan Frieden zu schließen und daß die Mächte in eine schwierige Lage kämen, wenn Wang die Kontrolle über die japanisch besetzten Gebiete mit den Konzessionen übernehme. Gleichzeitig versicherte Léger den Briten, Paris bleibe auf Chinas Seite. Nur wegen der Koinzidenz von vier Faktoren - dem Abzug der französischen Militärmission,

${ }^{28}$ Cosme an Bonnet, T 953-55, 4.9., T 957, 5.9., T 964, 6.9., T 972-73, 7.9.1939 (MAE Japon 124, MAEN Pékin A 311, MAE Chine 738, Japon 124); NOLDE, Mission, S. 982; Taliani an Ciano, T 230, 30.9.1939 (DDI Serie 9, I, 522); Cosme an Baudouin, T 478-82, 3.7.1940 (MAEN Pékin A 312); Notes de la sous-direction d'Asie-Océanie, 7.9., 2.10.1939 (MAE Chine 784, Japon 124); Daladier an Cosme, T 449-54, 24.9., Note de la sous-direction d'Asie-Océanie, 4.10.1939 (MAE Japon 129); Corbin an Bonnet, T 2973, 6.9., Cosme an Daldier, T 1002, 14.9.1939 (MAE Chine 738); Henry an Daladier, T 587-88, 19.9., Léger, note pour l'ambassadeur, 10.10.1939 (MAEN Londres C 487). 
dem irrtümlichen Anschein eines französischen Flirts mit Wang Ching-wei, der verspäteten Reise Cosmes nach Chungking und einer vorübergehenden Einschränkung des Warentransits durch Indochina - habe Chiang einen falschen Eindruck gewonnen. Die Mißverständnisse seien aber ausgeräumt ${ }^{29}$.

Die französische Haltung zu Wang, der Abzug der Militärmission und vor allem der reduzierte Waffentransit durch Indochina verbitterten Chiang. Er warnte die abreisenden französischen Offiziere, er starte eine antifranzösische Kampagne in Kwangsi, falls sich Frankreichs Verhalten nicht ändere. Chiangs Frau kündigte an, sie stelle das Studium der französischen Sprache ein. Chiang sagte Botschafter Clark Kerr, die Chinesen kämen eines Tages nach Indochina und holten sich die dort für sie lagernde Ware. Chiang dementierte, daß es Friedensgespräche mit Tokio gebe. Er sei entschlossen, Japan weiter Widerstand zu leisten. Mitte Oktober hatte die französische Regierung die Hoffnung auf Wang noch nicht aufgeben, doch Wangs Stern fing an zu sinken: Die Annäherung zwischen Wang und Chiang war gescheitert, Japan distanzierte sich von Wang. Dennoch unterhielt Cosme weiter geheime Kontakte zu Wangs Emissär, dem früheren Kuomintang-Politiker Dr. Chu Min-yi. Paris hielt sich die Option für Wang offen. Noch Mitte November 1939 kursierten Gerüchte in Hanoi, Cosme wolle zwischen beiden Lagern vermittel ${ }^{30}$.

Ab Mitte November bemühte sich der Quai d'Orsay mit Rücksicht auf Washington mehr als zuvor, Chiang nicht weiter zu brüskieren. Daladier nahm in den ersten Wochen des Krieges in Europa an, daß Japan die einzige Macht sei, die ihr Gewicht sofort gegen die Sowjetunion richten konnte. Doch in einem langen Krieg hielt der Ministerpräsident die Hilfe der USA für entscheidend. Als der US-Kongreß am 3./4. November die Neutralitätsgesetze mit der "Cash and carry-Klausel« erleichterte, setzte die französische Regierung noch stärker auf Amerika. Die Verantwortlichen in Paris glaubten, daß Washington die französische Annäherung an Japan tolerieren könne, aber keine Politik auf Kosten Chiang Kai-sheks. Cosme sagte US-Diplomaten Anfang Dezember in Chungking, mit Rücksicht auf die französisch-amerikanischen Beziehungen und die Lage Indochinas unterstütze Frankreich Chinas Widerstand gegen Ja-

\footnotetext{
${ }^{29}$ Bullitt an Hull, 26.9., Murphy an Hull, 20.10.1939 (SD 893.0146/704, 751.93/65); Cosme an Daladier, L 331, 3.10., T 1107-8, 11.10., T 1141, 18.10., T 1180, 23.10., Léger an Cosme, T 491, 12.10., Saint-Quentin an Daladier, T 1813-15, 14.10., Chauvel an Saint-Quentin, T, 17.10.1939 (MAE Chine 739); Clark Kerr an Halifax, 21.10., Broadmead an Halifax, 22.10., Campbell an Halifax, 24.10., Note Scott, 26.10., Note Brenan, 30.10.1939 (FO 371/23461, F 11177, 11188, 11240/87/10).

${ }^{30}$ Cosme an Daladier, T 1176-79, 23.10., T 1181-85, 24.10; Note de la sous-direction d'AsieOcéanie, 19.10.1939 (MAE Chine 739, Japon 124); Léger an Cosme, T 526-28, 26.10.1939 (MAEN Pékin A 494); Clark Kerr an Halifax, 25.10., 23.10 .1939 (FO 371/23461, F 11299, 11196/87/10); Bullitt an Hull, 9.11., 1.12.; Reed an Hull, 12.11 .1939 (FRUS 1939, III, S. 313, S. 90f., SD 793.94/15532, 15533); Campbell an Howe, 16.11 .1939 (FO 371/23462, F 11986/87/10); Chauvel, Note, 20.7.1940 (MAE Vichy-Asie 124).
} 
$\operatorname{pan}^{31}$. Weitere Faktoren für die Rücksichtnahme auf China waren vermutlich der Wintereinbruch in Europa, der einen deutschen Angriff zunächst unwahrscheinlich und eine sofortige Hilfe durch Japan verzichtbar machte, und die ausbleibenden politischen und militärischen Erfolge Japans in China. Doch Japan entgegenzukommen, ohne China zu schaden, das sollte für Frankreichs Diplomaten der Versuch werden, die Quadratur des Kreises zu finden.

Wang Ching-wei diskreditierte sich weiter, als im Januar 1940 bekannt wurde, wie sehr er sich Tokio fügte. Auf seine Ankündigung am 24. Januar, im März 1940 unter Einbeziehung der (Marionetten-)Regierungen in Nanking und Peking ein neues Kabinett zu bilden, reagierten London, Washington und Paris mit der Erklärung, für sie bleibe Chiangs Regierung Chinas einzige legitime Vertretung. Der Quai d'Orsay hielt sich in den ersten Monaten des Jahres 1940 jedoch die Option der Zusammenarbeit mit Wang offen und blieb mit ihm in Kontakt. Im März oder April 1940 erhielt Cosme aus Paris die Erlaubnis, das 1937 geschlossene Konsulat an Wangs Regierungssitz Nanking wieder zu öffnen. Dies lehnte Cosme mit Rücksicht auf Chungking ab. Französische Akten über die Beziehungen zu Wang im Jahr 1940 existieren kaum. Amerikanische und italienische Dokumente ergeben das Bild, daß Paris den Aufbau offizieller Beziehungen zu Wang erwog, aber der Nichtanerkennungspolitik Washingtons und Londons folgte. Selbst Tokio verzögerte die Anerkennung der am 30. März in Nanking gebildeten Regierung bis November 1940, weil es parallel Geheimgespräche mit Chiang führte ${ }^{32}$.

Cosme gelang es am 4. Dezember 1939 in Chungking, Chiang Kai-shek zu beruhigen: Paris sei bereit, trotz der Last in Europa alles zu tun, um China zu unterstützen. Frankreich habe bereits die Yunnanbahn ausgebaut, es habe mit der Abschaffung der Transitsteuer China 50 Millionen Francs erlassen, und es erlaube einen umfangreichen Warenverkehr. Die Chinesen hingegen schafften es nicht einmal, ihren Teil der Yunnanbahn ausreichend zu bewachen und in China Anschlüsse für Straßen zu bauen, die in Indochina von der Küste bis zur chinesischen Grenze gebaut würden, sagte Cosme. Die US-Diplomaten in Chungking hielten Cosmes Versprechen, Frankreich wolle China mit großem

\footnotetext{
${ }^{31}$ Rede von René GiRAult, in: Français et Britanniques dans la drôle de guerre. Actes du collogue franco-britannique tenu à Paris du 8 au 12 décembre 1975, hg. vom Centre national de la recherche scientifique, Paris 1979, S. 153; DU RÉAU, Édouard Daladier, S. 378; Johnson an Hull, 8.12.1939 (FRUS 1939, III, S. 327f.).

32 Johnson an Hull, 20.1., 30.3.1940 (FRUS 1940, IV, S. 270f., S. 305f.); Peck an Hull, 29.1., Grew an Hull, 19.1., 8.2., Memorandum of Conversation, 22.3.1940 (SD 893.01/612, 637, 625, 694); GeorgesPicot an Daladier, T 116-17, 4.2., Reynaud an Saint-Quentin, T 609, Corbin, T 997, 27.3.; Note, Chauvel, 20.7.1940 (MAE Chine 761, Vichy-Asie 124); Halifax an Clark Kerr, 2.4.1940 (WO 208/241); Clifford, Retreat from China, S. 138; BUNKer, The Peace Conspiracy, S. 194f.; LANGER, Gleason, The Challenge, S. 583; Bianco, La Chine dans la guerte, S. 202; MONTGOMERY, Imperialist Japan, S. 413f.; QUIGLEY, Far Eastern War, S. 121; FEIS, Road to Pearl Harbor, S. 51.
} 
Aufwand und trotz enormer Risiken unterstützen, für glaubwürdig. Ob Chiang Kai-shek Cosmes Versicherungen glaubte, ist unklar. Aber angesichts der wirtschaftlichen und militärischen Abhängigkeit Chinas von den Transitwegen durch Indochina wollte Chiang den Konflikt mit Paris beilegen ${ }^{33}$.

\subsection{Diplomatische und militärische Pläne gegen die Sowjetunion}

Die Entwicklung in Europa sorgte dafür, daß sich Frankreichs Fernostpolitik immer stärker an dem Ziel orientierte, die Sowjetunion zu schwächen. Nach dem Waffenstillstand mit Japan begann am 17. September der Einmarsch sowjetischer Truppen in Polen, am 27. September gab die polnische Regierung auf. Die deutsche Wehrmacht beorderte die meisten Divisionen von der Ostan die Westfront. Täglich drohte nun ein Angriff auf Frankreich.

Die einzige Macht, die Frankreich sofort zumindest gegen Hitlers Partner Stalin mobilisieren konnte, war Japan. Mit dem sowjetischen Einmarsch in Polen wurden französische Überlegungen, Tokio gegen Moskau in Position zu bringen, erstmals aktenkundig. Cosme hatte zwar schon am 4 . September betont, daß Frankreich ein Interesse daran habe, mit Hilfe Japans zu verhindern, daß Moskau am Ende eines Krieges sein gesamtes Gewicht in Europa geltend mache, aber zu diesem Zeitpunkt hatten die Sowjets noch nicht in den Krieg eingegriffen. Légers Drohung vom 7. September gegenüber Bullitt, die Sowjetunion befinde sich mit Frankreich im Kriegszustand, falls sie Polen angreife, blieb folgenlos. Als die Rote Armee tatsächlich in Ostpolen einrückte, beschränkte sich Daladier auf einen diplomatischen Protest, weil er hoffte, daß sich Moskau und Berlin wieder entzweiten ${ }^{34}$.

$\mathrm{Ab}$ Mitte September wurde in Paris diskutiert, in Asien Militäroperationen auszulösen, um dort sowjetische Kräfte zu binden. Mitglieder des Auswärtigen Ausschusses des Senats forderten am 18. und 19. September ihre Regierung auf, Japan zu gewinnen, um Rußland zu lähmen. Eine Woche später erneuerte Ausschußvorsitzender Bérenger die Forderung. Um die Erwartungen zu erfüllen, berichtete Daladier vor den Auswärtigen Ausschüssen der Abgeordnetenkammer und des Senats von spürbar verbesserten Beziehungen zu Japan. Ende

\footnotetext{
${ }^{33}$ Peck an Hull, 3.12., Johnson an Hull, 8.12.1939 (FRUS 1939, III, S. 766f; S. 327f.); Cosme an Daladier, T 93-96, 4.12., Note de la sous-direction d'Asie-Océanie, 2.12.1939 (MAE Chine 677).

${ }^{34}$ Cosme an Bonnet, T 953-55, 4.9.1939 (MAEN Pékin A 494); Bullitt an Hull, 7.9., 17.9., Steinhardt an Hull, 21.9.1939 (SD 740.0011 European War 1939/204, 341, 361, 473); CARLEY, 1939, S. 222; BARDOUX, Journal, S. 95.
} 
September und Mitte Oktober äußerten Cosme und Corbin, nur Japan könne die Sowjetunion in Asien fesseln und ihren Druck auf Europa reduzieren. Noch deutlicher wurde Chauvel am 26. September gegenüber Bullitt. Der Krieg könne zu höchst unerwarteten Kombinationen führen:

For example, if Germany should begin to be defeated by France and England and admit the Red Army to German territory it might be in the interest of France and England to support Japan in an attack on the Soviet Union.

Es ist gut möglich, daß Antikommunist Bullitt selbst Vater des Gedankens war, denn der belgische Botschafter meldete zwei Tage später:

M. Bullitt est le plus 'jusqu'au boutiste< belliciste relativement rares que j'ai rencontrés jusqu'à présent. Il n'est pas loin d'une croisade où entrerait aussi bien le Japon que l'Amérique contre l'antéchrist à double tête: le bloc sovietico-nazi. M. Bullitt croit à la solidité de l'axe Moscou-Berlin jusqu'au jour où il se dissociera à la suite des coups récus par l'Allemagne sur le front de l'Ouest et aussi à la suite des nouveaux empiètements de la Russie à l'Est de l'Europe ${ }^{35}$.

Als die französische Regierung am 27. September hörte, daß die Sowjetunion sich mit 2000 Bombern an einem deutschen Angriff auf Frankreich beteiligen wolle, wurde die Suche nach einem Gegengewicht gegen die Sowjets noch dringender. Die Nachricht stellte sich als falsch heraus, aber am 28. September schlossen die deutsche und die sowjetische Regierung in Moskau einen Freundschaftsvertrag. Auch ein intensiver Wirtschaftsaustausch und eine enge Kooperation der Geheimdienste wurden beschlossen. Léger erklärte Bullitt und Cosme, er hoffe, Japan von der Kriegsteilnahme gegen die Sowjets zu überzeugen. Daß der Quai d'Orsay Mitte Oktober seine Militärmission aus China zurückrief, führte General Nolde ebenfalls auf den Versuch zurück, Japan als Gegner der Sowjetunion zu gewinnen. Chauvel sagte dem Ersten Sekretär der chinesischen Botschaft Wang, Frankreich und die Sowjetunion könnten sich schon bald im Krieg befinden ${ }^{36}$. Frankreichs Streben blieb nicht ohne Reaktion: Anfang Oktober regte Tokio offiziös Wirtschaftsgespräche an. London und Paris gingen auf die Offerte nicht ein, um die USA, die Ende Juli 1939 den Handelsvertrag mit Tokio gekündigt hatten, nicht zu verärgern. Die unklare Zukunft der US-japanischen Handelsbeziehungen mache Tokio zu

\footnotetext{
${ }^{35}$ Bardoux, Joumal, S. 78, S. 89, S. 91, S. 99; Phipps an Halifax, 7.10., 5.10.1939; Taliani an Ciano, T, 30.9.; Corbin an Daladier, L, 16.10; Bullitt an Hull, 26.9.; Le Tellier an Spaak, 28.9.1939 (FO 371/ 22913, C 15793, 15973/90/17; DDI Serie 9, I, 522; MAE Chine 783; SD 893.0146/704; DDB V, 169). ${ }^{36}$ Bullitt an Hull, 27.9., 29.9., 30.9.1939 (SD 740.0011 Eur. War 1939/584, 623, 635); David Wingate PIKE, Aide morale et matérielle et l'URSS à l'Allemagne nazie, in: Guerres mondiales et conflits contemporains 40.160 (I990), S. 113-122 (S. 116); Bullitt an Hull, 9.10., 20.10., 28.10.1939 (FRUS 1939, III, S, 282f., S. 295f., SD 760d.61/359); Léger an Cosme, T 526-28, 26.10.1939 (MAEN Pékin A 494); NoldE, Mission, S. 985; Note de la sous-direction d'Asie-Océanie, 21.10., Léger an Cosme, T 480-81, 9.10.1939 (MAE Chine 784, 679); Corbin an Daladier, L 736, 16.10., T 3693, 17.10.1939 (MAE Chine 783, MAEN Londres C 480).
} 
empfänglichen Gesprächspartnern für Paris und London, glaubten Henry und Militärattaché Thiébaut. Tatsächlich stiegen die US-Exporte nach Japan, vor allem von Flugbenzin, im Winter 1939/40 stark an ${ }^{37}$.

Anfang November 1939 wurden die Franzosen von Berichten aufgeschreckt, wonach Japan und die Sowjetunion ernsthaft verhandelten. Am 6. November besetzte Moskau den mehr als ein Jahr vakant gebliebenen Botschafterposten in Tokio. Kurz darauf kündigten beide Mächte Gespräche über Handelsfragen an. Naggiar nahm an, beide Mächte hätten sich bereits auf die Teilung Chinas geeinigt. Daladier hielt die Gefahr dieser Kooperation für so groß, daß er die Briten aufforderte, einen Handelsvertrag mit Japan abzuschließen. Washington warnte er, daß sich Tokio mit Moskau einige, falls sich Japans Beziehungen zu den westlichen Mächten nicht verbesserten. Chauvel sagte Bullitt, falls Amerika Frankreich jetzt nicht helfe, werde in Paris die Forderung stärker, sich mit Japan zu einigen - falls nötig auf Kosten Chinas. Doch Daladiers Initiative scheiterte: Das Foreign Office wartete erst ab und teilte Paris, als Welles London vor einer Annäherung an Japan warnte, seine Ablehnung mit $^{38}$.

Nach dem Hitler-Stalin-Pakt, vor allem nach Stalins Einmarsch in Polen, wurde der Antikommunismus zur dominierenden Stimmung in der französischen Öffentlichkeit. Die Regierung verbot die Parteizeitung "L'Humanité« am 26. August 1939 und löste am 26. September die KPF und die Kommunistische Partei Indochinas auf. Die Fahnenflucht des KPF-Generalsekretärs Maurice Thorez am 4. Oktober empörte Frankreich. Tausende Kommunisten, auch Abgeordnete, wurden festgenommen. Die Verfolgung der KP war ein innenpolitisches Manöver, weil es Daladier die Sympathien des Bürgertums sicherte. Aber die Regierung war auch überzeugt, daß Kommunisten Armee und Rüstungsbetriebe sabotierten und daß sowjetische und deutsche Geheimdienste in Frankreich kooperierten. Die pazifistische Propaganda der KP wollten weder Regierung noch Parlament in Paris dulden. Den Bruch mit Moskau hatte Paris bisher vermieden, weil die deutsch-russische Verbindung nicht dauerhaft schien. Dies änderte sich mit dem sowjetischen Überfall auf Finnland am 30. November. Nun erschienen Hitler und Stalin als vereinte

\footnotetext{
${ }^{37}$ Corbin an Daladier, T 3558, 5.10., Léger an Corbin, T, 9.10., Léger, Note, 10.10., Corbin an Daladier, T 3626, 11.10., Henry an Daladier, T 668-69, 30.10.1939 (MAEN Londres C 487); Note de la sous-direction d'Asie-Océanie, 12.10.1939 (MAE Japon 129); Thiébaut an EMA.2, 2.11.1939 (SHAT 7 N 3332); Hornbeck, Memorandum, 23.2.1940 (FRUS 1940, IV, S. 292f.).

${ }^{38}$ Welles, Note 7.12., Bullitt an Hull, 10.11.; 14.11., 28.11., Welles, Moffat, Memoranda, 21.12., 30.11.1939 (SD 761.94/1176, 1154; FRUS 1939, III, S. 318f., S. 86f., S. 99f.; SD 760d.61/658); Daladier an Corbin, T 2972-73, 16.11., Daladier an Saint-Quentin, T 1771-73, 17.11., Saint-Quentin an Daladier, T 2059-61, 18.11., T 2085, 21.11., T 2173-80, 3.12., Corbin an Daladier, T 4039, 20.11., T 4081, 24.11., T 4141, 30.11.; T 4165-67, 1.12.1939 (MAEN Londres C 487, MAE Japon 124); Lord Lothian an Halifax, 7.12.1939 (FO 371/23551, F 12525/4027/61); Campbell an Howe, 16.11.1939 (FO 371/23462, F 11986/87/10); VILLELUME, Journal, S. 32f., S. 107.
} 
Aggressoren. In Frankreich herrschte Kreuzzugsstimmung gegen die Sowjetunion, die in der Presse als Hauptgegner dargestellt wurde ${ }^{39}$.

US-Botschafter William Bullitt brachte in Paris die Idee auf, die Sowjetunion aus dem Völkerbund auszuschließen. Er begeisterte Völkerbund-Generalsekretär Joseph Avenol, Finnlands Gesandten Holma, Staatssekretär Champetier de Ribes und Daladier für den Vorschlag. Frankreichs Presse begrüßte den Ausschlußantrag, den Finnland, Uruguay und Argentinien gestellt hatten. Alexis Léger und das Foreign Office sahen die Entwicklung, die zum Abbruch der diplomatischen Beziehungen mit Moskau führen konnte, zunächst mit Sorge. Léger und die Briten nahmen aber an, daß die US-Regierung, nicht nur Bullitt, den Ausschluß der Sowjets unterstütze. Daladier forderte, die sowjetische Aggression nicht zu dulden. Der Ministerpräsident, der überlegte, selbst nach Genf zu reisen, wurde zur treibenden Kraft für den Ausschluß und überzeugte schließlich auch die Briten ${ }^{40}$.

Die entscheidende Rolle bei der Abstimmung in Genf spielte China, das im Rat den Ausschluß verhindern konnte. Die Sowjetunion war Chinas wichtigste militärische Stütze: Vom Herbst 1937 bis Ende 1939 hatte Moskau 1000 Flugzeuge, 1500 Fahrzeuge, große Mengen an Artillerie und Automatikwaffen geliefert sowie etwa 2000 bis 4000 Militärexperten, vor allem Piloten, abgestellt ${ }^{41}$. Chinas Regierung stand vor einem Dilemma. Einerseits wollte sie die USA, die hinter dem Ausschluß zu stehen schienen, und den Völkerbund, der China Entwicklungs- und humanitäre Hilfe gewährt hatte, nicht brüskieren. Andererseits durfte die Hilfe der Sowjetunion, ohne die der Krieg nicht fortgesetzt werden konnte, nicht gefährdet werden. Chinas Botschafter in London,

${ }^{39}$ Germaine WillaRd, 39/40: Les choix de la politique française, in: La Pensée 275 (1990), S. 71-79; J. Kim MUNHOLLAND, The Daladier Government and the »Red Scare« of 1938-40, in: Proceedings of the Annual Meeting of the Western Society for French History 1982, S. 495-506; CARLEY, 1939, S. 221; Henri MICHEL, Le problème communiste et l'évolution de la guerre, in: Français et Britanniques dans la drôle de guerre, S. 221-244 (S. 228f.); BERSTEIN, BECKER, Histoire de l'anticommunisme, Bd. I, S. 336, S. 366f;; Général Maurice GAMELIN, Servir. 3 Bde., Paris 1946-47, Bd. 3, S. 190; BÉDARIDA, Huit mois d'attente, S. 53; BARTEL, Frankreich und die Sowjetunion, S. $297 \mathrm{f}$.

${ }^{40}$ Bullitt an Hull, 30.11.; 1.12., Tittmann an Hull, 1.12., 3.12., 3.12., (SD 760d.61/544; 500.C001/ 1433, 1432, 1435, 1438); JeanNENEY, Journal, S. 23f;; Bova Scoppa an Ciano, 5.12., 7.12., 15.12.1939 (DDI Serie 9, II, 455, 505, 610); DURoselle, L'Abîme, S. 87f.; Butler an Halifax, 9.12., Avenol an Halifax, 3.12., Campbell an Halifax, 6.12., 7.12., 9.12., 10.12.1939 (FO 371/23695, N 7242, 6886, 7094, 7197, 7236, 7300/991/38); Sargent, Note, 3.12., Randall, Minute, 4.12., Campbell an Halifax, 5.12., 9.12., Halifax an Butler, 11.12., Halifax an Campbell, 11.12.1939 (FO 371/23694, N 7100, 7111, 7108, 7235, 7129, 7299, 7325/991/38); CADOGAN, Diaries, S. 235; War Cabinet Conclusions 112, 12.12.1939 (FO 371/23695, N 7365/991/38); Bullitt an Hull, 7.12., 14.12.1939 (SD 500.C001/1444, 760d.61/663, 740.0011 European War 1939/1162).

4! FISCHER, Kollektive Sicherheit, S. 430; James C. BowDEN, Soviet Military Aid to Nationalist China, 1923-41, in: GARTHOFF (Hg.), Sino-Soviet Military Relations, S. 44-56 (S. 54); HASLAM, The Soviet Union, S. 93f.; EASTMAN, Nationalist China, 1937-1945, S. 576. LiU nimmt geringere Zahlen an (A Military History, S. 168). 
Washington und Paris testeten, ob der Westen bereit war, sich Chinas Stimme in Genf etwas kosten zu lassen. In London und Washington stießen die Botschafter auf klare Ablehnung. In Paris erklärte Léger am 5. oder 6. Dezember Koo, Waffenhilfe an China könne Frankreich nicht leisten ${ }^{42}$.

Die Chinesen wandten sich nun an Daladier und sandten Li Yu Ying, der bereits in Paris die Verhandlungen über die Militärmission geführt hatte, zu ihm. Li schlug eine militärische Kooperation zwischen China und Indochina, die Entsendung einer neuen Militärmission und den Verkauf von Militärmaterial an China vor. Daladier lehnte dies ab, bot aber an, als Ersatz für die von den Japanern blockierte Straße nach Nanning eine Straße von Haiphong nach Laokai, parallel zur Yunnanbahn zu bauen - deren Bau Mandel schon im Frühjahr 1939 angeordnet hatte - und die Yunnanbahn für 80 Millionen Francs auszubauen. In einem persönlichen Brief an Chiang bat Daladier um Verständnis dafür, daß Frankreich nicht mehr helfen könne ${ }^{43}$.

Allerdings schloß am 11. Dezember auch das Bankenkonsortium Groupe uni mit Chinas Regierung völlig überraschend und nicht ohne Einflußnahme Daladiers einen Vertrag zur Finanzierung der 800 Kilometer langen Bahnlinie Yunnanfu-Suifu ab. Die französischen Banken gewährten einen Kredit über 480 Millionen Francs zum Kauf von französischem Material und erhielten das Recht, in einer Zone von 100 Kilometern Breite entlang der Bahnlinie 49 Prozent der Bodenschätze zu nutzen. Im Juni 1939 hatte die staatliche Assurance Crédit zwar grundsätzlich eine Garantie für das Bahnprojekt zugesagt, weitere Verhandlungen gab es danach aber nicht mehr. Das Finanzministerium in Paris hielt die Finanzierung der Strecke weiter für riskant. Offenbar wurde China der Kredit nur gewährt, um seine Stimme im Völkerbund zu gewinnen. Cosme sprach gegenüber US-Diplomaten von einem politischen Kredit. Die Assurance Crédit traf die definitive Entscheidung, 80 Prozent der Summe zu versichern, am 27. Februar 1940, so daß China das Geld erst im März erhielt, begleitet von der Kritik der Marionettenregierung in Nanking. Die Franzosen packten den Bau der neuen Bahnstrecke rasch an: Im April 1940 lagerten bereits 30000 Tonnen Eisenbahnmaterial in Haiphong, im Mai 1940 wurden 2000 Tonnen davon nach Yunnanfu gebracht. Der Kredit »half« China nicht nur bei der Entscheidung im Völkerbund, sondern er verbesserte auch das

42 Note on Conversation, 5.12.1939 (FO 371/23694, N 7109/991/38); Clark Kerr an Halifax, 11.12.1939 (FO 371/23695, N 7426/991/38); Hamilton, Note, 12.12., Hull, Memorandum of Conversation, 13.12.1939 (SD 760d.61/808, 757); Bullitt an Hull, 6.12.1939 (SD 500.C001/1443); Cosme an Daladier, T 106-9, 10.12.1939 (MAEN Londres C 487); SUN, China and the Origins, S. 127.

${ }^{43}$ Bullitt an Hull, 14.12., 13.12., 21.12., Peck an Hull, 3.12.1939 (SD 751.93/67; FRUS 1939, III, S. 769f., S. 329f., S. 766f.); Daladier an Chiang Kai-shek, L, 27.12.1939 (MAE Chine 677). 
Klima zwischen Chungking und Paris, wie der britische Botschafter feststellte. Die Sowjets spielten ihren Ausschluß herunter und halfen China weiter ${ }^{44}$.

Der Völkerbund kam China - wohl auf Hinweis der Franzosen - entgegen, indem der Haushaltsausschuß am 8. Dezember beschloß, die Schulden des Landes beim Völkerbund in Höhe von 371000 Goldfrancs zu streichen und Chinas Beiträge für 1939 und 1940 zunächst nicht einzufordern. Zudem wurde China als Mitglied des Rates wiedergewählt. Als die Vollversammlung und der Rat die Sowjetunion am 14. Dezember ausschlossen, enthielt sich Wellington Koo, bis zuletzt von den Franzosen bedrängt. Chinas Delegierter erklärte dies damit, daß er keine Anweisung aus Chungking erhalten habe.

Avenol bat die Mitgliedsstaaten per Telegramm, den Finnen, wie von der Vollversammlung empfohlen, materielle oder humanitäre Hilfe zu leisten etwas, was Avenol für China trotz ähnlicher Beschlußlage nie tat. Das Büro des Völkerbundes in Paris koordinierte heimlich die Militärhilfe der Mitglieder an Finnland. Daladier war zufrieden ${ }^{45}$. Der Ausschluß aus dem Völkerbund war die erste Maßnahme, mit denen Paris Moskau unter Druck setzte. Daladier regte am 11. Dezember den Abbruch der diplomatischen Beziehungen mit Moskau an. Rochat berichtete Bullitt drei Tage später von Plänen, Ölfelder im Kaukasus zu bombardieren. Reynaud hatte dies Mitte Oktober erstmals erwogen. Paris wollte 40000 Soldaten nach Skandinavien entsenden, die Finnland gegen die Sowjetunion unterstützen und gleichzeitig Schwedens Erzvorräte unter Kontrolle bringen sollten.

Ein Angriff auf die Sowjetunion bot einige Vorteile: Die Feldzüge reduzierten die sowjetischen Lieferungen an Deutschland: Ohne schwedisches Erz und russisches Öl würde Hitlers Kriegsmaschinerie bald erstarren. Der Angriff auf die Sowjets war in der Bevölkerung höchst populär, wobei auch nicht viele französische Opfer zu erwarten waren. Die Ausweitung des Krie-

\footnotetext{
${ }^{44}$ VALETTE, Indochine, S. 18; Perkins an Johnson, 21.12., Peck an Hull, 14.12.1939, 2.1.; Reed an Hull, 6.4., 12.6.1940 (SD 893.51/7038, 667, 7031, 851g.1561/14, 893.24/773); Groupe uni an Cosme, L, 28.2.; Reynaud an Bonnet, L 604, 12.1.1939, Cosme an Vichy, T 465-66, 21.8., Note, Droits et Intérêts Français dans les chemins de fer du sud et de l'ouest de la Chine, 6.2.1941 (MAEN Tchongking 7, Pékin A 132); Perkins an Hull, 30.1., Stanton an Hull, 29.5.1940 (SD 893.77/ 3269, 7081); Shigemitsu an Arita, 30.4., 15.5.1940 (JA. S 1.1.1.0-28, S. 496f., S. 498); LING, China's Epic Struggle, S. 254; YounG, China and the Helping Hand, S. 138; Clark Kerr an Halifax, 29.2.1940 (FO 371/24673, F 1590/57/10); BARTEL, Frankreich und die Sowjetunion, S. 300f.; Steinhardt an Hull, 4.1., Diplomatie an Colonies, L 50, 16.1.1940 (SD 761.93 15 Manchuria/205, MAE Chine 783).

${ }^{45}$ Quatrième commission, résumé des séances de la session de décembre 1939, Genf 1940; actes de la $20^{\mathrm{e}}$ session ordinaire de l'assemblée (11-14 décembre 1939), Genf 1940; GARVER, Chinese-Soviet Relations, S. 100; Bova Scoppa an Ciano, 15.12 .1939 (DDI Serie 9, II, 610); $106^{\mathrm{e}}$ session du conseil, procès-verbal, $1^{\text {re }}$ séance, 9.12., $107^{\mathrm{e}}$ session, $2^{\mathrm{e}}$ séance, 14.12 .1939 (JO-SDN 1939, S. 494, S. 501504); Avenol an Mitgliedsstaaten, T, 18.12.1939, VB-Ds. C.L.181.1939.VII., JO-SDN 1940, S. 11 ; Tittmann an Hull, 23.12.1939 (SD 760d.61/832); Campbell an Butler, 29.12.1939 (FO 371/23696, N 7904/991/38); Du RÉAU, Édouard Daladier, S. 402.
} 
ges in einen antikommunistischen Kreuzzug bot auch die Aussicht, Italien und Japan auf die Seite zu ziehen, wie General Gamelin Mitte Januar 1940 sagte $^{46}$. $\mathrm{Da} ß$ sich Frankreich und die Sowjetunion dann im Krieg befänden, nahmen Daladier, Léger, General Gamelin, Admiral Darlan und selbst Léon Blum bewußt in Kauf, zumal sie die Rote Armee für äußerst schwach hielten. Die Sowjetunion galt als Deutschlands Achillesferse. Doch durch extrem langsame Planung sabotierte Gamelin die Attacken auf die Sowjets, über die ganz Europa informiert war ${ }^{47}$. Mitte Februar schlug General Bergeret vor, mit Truppen aus Finnland und dem Kaukasus in einem Zangenangriff auf Moskau vorzustoßen. Bis Mitte April 1940 plante Paris weiter Attacken auf die Ölfelder von Baku und Batumi, doch die Briten blockierten die Ausführung ${ }^{48}$.

Die Angriffspläne erscheinen aus heutiger Sicht politisch und militärisch als Irrsinn. Allerdings mußte die französische Regierung darauf reagieren, daß die enge deutsch-sowjetische Verbindung Frankreichs gesamte Kriegskonzeption aushebelte. Paris ging seit den zwanziger Jahren davon aus, daß der nächste Krieg lang sein würde und daß es ihn dank seines Industriepotentials und der Ressourcen der Kolonien gewinnen würde. Da Hitler nun über die Rohstoffe der Sowjetunion verfügte, konnte Paris nicht weiter abwarten. Ende Dezember 1939 vereinbarten Moskau und Berlin, neun Eisenbahn-Umladestationen für den wachsenden Warenaustausch zu schaffen. Am 11. Februar 1940 schlossen das Reich und die Sowjetunion ein Handelsabkommen: Berlin sollte große Mengen Rohstoffe, darunter jährlich 900000 Tonnen Öl, erhalten, die über die Transsibirische Eisenbahn auch aus Ostasien herangebracht wurden ${ }^{49}$.

Im Pazifik gingen die Franzosen deshalb gegen die Sowjetunion vor. Die Briten brachten Anfang 1940 zwei sowjetische Frachter auf dem Weg nach Wladiwostok auf und schleppten sie nach Hongkong. Die Selenga hatte in

\footnotetext{
${ }^{46}$ Bullitt an Hull, 11.12., 14.12.1939 (SD 760d.61/711, 500.C001/1463); René GIRAULT, Les relations franco-soviétiques après septembre 1939, in: Cahiers du monde russe et soviétique, 17.1 (1976), S. 27-42 (S. 33f.); Eleanor GATES, End of the Affair. The Collapse of the Anglo-French Alliance, 19391940, Berkeley, Los Angeles 1981, S. 38; VILLELUME, Journal, S. 61.

${ }^{47}$ Bullitt an Hull, 30.12.1939, 15.1.1940 (SD 760d.61/892, FRUS 1940, I, S. 276f.); GiRAULT, Les relations, S. 35; HOOD, Royal Republicans, S. 174; BÉDARIDA, La stratégie secrète, S. 299; GAMELIN, Servir, Bd. 3, S. 194f.; Bova Scoppa an Ciano, 13.12.1939 (DDI Serie 9, II, 580); Naggiar an Daladier, T 37, 7.1.1940 (MAEN Londres C 487); RICHER, La drôle de guerre, S. 290; Steinhardt an Hull, 2.2.1940 (FRUS 1940, I, S. 590f.).

${ }^{48}$ HEIMSOETH, Der Zusammenbruch, S. 243f; Hans-Joachim LORBEER, Westmächte gegen die Sowjetunion, 1939-1941, Freiburg 1975, S. 59f.; BÉDARIDA, La stratégie secrète, S. 190f;; DE LA GORCE, L'Empire écartelé, S. 48f.; DUROSELLE, L'Abîme, S. 110f.; GATES, End of the Affair, S. 32f.; MAY, Strange Victory, S. 328f.; François LÉVÊQUE, Des diplomates dans l'impasse: Les relations franco-soviétiques de septembre 1939 à juin 1941, in: Guerres mondiales et conflits contemporains 172, Bd. 43 (1993), S. 111-123 (S. 114).

${ }_{49}$ Bardoux, Journal, S. 164f.; Ronald WhEATLEY, La guerre russo-finlandaise, les plans d'interventions alliés et les relations britanniques avec la Russie, in: Français et Britanniques dans la drôle de guerre, S. 245-261 (S. 258); PIRE, Aide morale et matérielle, S. $118 f$.
} 
Manila Wolfram von einem deutschen Schiff übernommen, die Maiakowski hatte Kupfer geladen. Auf Druck der Sowjets ließen die Briten die Schiffe fahren, doch nun brachte die französische Marine die Frachter auf und zog sie nach Saigon, wo sie bis Ende Juni 1940 blieben. Weitere sowjetische Schiffe mit angeblicher Ladung für Deutschland wurden in indochinesischen Häfen festgehalten. Eine besondere Operation plante Frankreichs Generalstab gegen die Transsibirische Eisenbahn. Militärattaché Thiébaut wurde angewiesen, einen Geheimdienst in Tokio aufzubauen und eine Sabotageoperation gegen die Eisenbahn zu unternehmen. Thiébaut lehnte den Plan als undurchführbar $a b^{50}$.

Um die Sowjets auch von Osten her zu bedrängen, wollte Paris Tokio unbedingt für eine antisowjetische Politik gewinnen. Daladier sagte am 28. Februar vor dem Auswärtigen Ausschuß der Kammer:

Je considère que nous avons le plus grand intérêt, si nous le pouvons, à avoir, avec le Japon, des relations cordiales, voire amicales. Si même nous pouvions le tourner vers ses voisins $\mathrm{du}$ Nord, je crois que ce serait une opération qui ne serait pas dépourvu d'intérêt. Dans les circonstances actuelles, ce serait une folie de ne pas profiter des intentions japonaises. Cela ne nous oblige pas à une politique ostensiblement tournée vers la Chine. Il s'agit seulement de faire une politique de rapprochement avec le Japon. Pour ma part, j'y suis bien déterminé.

Davon, erklärte Daladier, lasse er sich auch durch die USA nicht abbringen. Der US-Geschäftsträger habe ihn im Dezember 1939 aufgefordert, China stärker zu helfen, doch Paris dürfe bei einem Angriff Japans auf Indochina nicht mit Amerikas Hilfe rechnen. Der Regierungschef habe daraufhin dem US-Diplomaten erklärt, er werde nun die Japan-Politik verfolgen, die er für richtig halte. Auch London erwog kurz, Tokio gegen Moskau zu gewinnen ${ }^{51}$. Doch trotz deutlicher öffentlicher Erklärungen tat Daladier nicht viel, um Japan gegen die Sowjets in Stellung zu bringen. Vize-Außenminister Tani stellte Anfang Februar 1940 Paris eine Kooperation gegen Moskau vage in Aussicht; Mitte März fragte Léger Botschafter Sawada nach Tokios Beziehungen zu Moskau. Konkreter wurden die französisch-japanischen Gespräche über die Sowjetunion nicht, denn Daladier wollte den Krieg nicht weltweit führen ${ }^{52}$.

Drei weitere Gründe ließen Paris zögern, die Zusammenarbeit mit Tokio gegen Moskau weiter zu verfolgen: Tokio machte es zur Vorbedingung, daß Paris vor Gesprächen über die Sowjetunion den Transit durch Indochina unterbrach; ein Transitstop hätte jedoch die USA gegen Frankreich aufgebracht.

\footnotetext{
${ }^{50}$ ElPhICK, Far Eastern File, S. 245f.; BÉDARIDA, La stratégie secrète, S. 344f.; BaRTEL, Frankreich und die Sowjetunion, S. 346; GuILlaIN, Orient-Extrême, S. 7 If.

${ }^{51}$ Bulletin de commissions, tome IV, $2^{\mathrm{e}}$ partie, Paris 1946; BEST, Britain, Japan and Pearl Harbor, S. 100f.; SATO, Japan and Britain, S. 50f; HoRNBECK, Memorandum of Conversation, 19.6.1940 (SD 793.94/1601I).

${ }^{52}$ Note de la sous-direction d'Asie-Océanie, 16.3.1940 (MAE Chine 761); Redebeitrag W.B.R. NEAVE-HILL, in: Français et Britanniques dans la drôle de guerre, S. $379 f$.
} 
Paris bezweifelte, daß Tokio nach der Mißachtung französischer Rechte auf Hainan, den Paracels und den Spratlys eine gegen Moskau gerichtete Abmachung, die für Frankreich wegen der Reaktion Amerikas mit einem hohen Risiko verbunden war, wirklich einhalten würde. Der französischen Regierung erschien es zudem unwahrscheinlich, daß Japan, dem die Sowjets im Herbst 1939 mit der Schlacht von Nomonhan gerade eine militärische Lehrstunde erteilt hatten, einen neuen Konflikt mit den Sowjets ansteuern wollte.

\subsection{Die japanisch-französischen Gespräche unter Druck}

Das französische Außenministerium hatte geplant, die Gespräche mit Japan über eine Annäherung mit dem neuen Botschafter Sawada zu führen, der Mitte Dezember in Paris ankommen sollte. Außenminister Nomura eröffnete jedoch bereits am 17. November die politischen Gespräche - begleitet von einer militärischen Offensive in Südchina.

Wie von Paris erwartet, landete Japans Militär am 15. November 1939 in der Bucht von Pakhoi. Sein Ziel war nach westlicher Einschätzung, den Versorgungsweg von Indochina über Nanning nach Zentralchina zu zerstören und dem Volk einen neuen Sieg za präsentieren. Cosme nahm an, daß Japan vor allem Indochina einschüchtern und zum Unterbinden jeglichen Transits bewegen wollte. Pakhoi selbst sei für den Transit nicht mehr wichtig, da China die Handelsströme rechtzeitig umgelenkt habe. Militärattaché Thiébaut in Tokio fürchtete, daß die Truppen bis zur Grenze Indochinas vorrücken und dort Zwischenfälle provozieren könnten. Bereits am 24. November besetzte Japan Nanning. Der schwache chinesische Widerstand enttäuschte Paris. In Shanghai warnte Militärattaché Yvon, erstmals in Asiens Geschichte operiere eine japanische Armee an der indochinesischen Grenze. Frankreichs Herrschaft über Indochina sei in Gefahr. Der US-Konsul in Hanoi gewann allerdings den Eindruck, daß die Verantwortlichen in Indochina über die Entwicklung sogar froh waren, weil die Transitfrage, die ständig zu Reibereien mit Japan führte, mit dem Fall Nannings und der Zerstörung der Straße von Langson nach Nanning nun gelöst sei. Der Quai d'Orsay entschied, die japanische Operation im Herzen des französischen Interessengebietes in Südchina zu ignorieren, um die angelaufenen Gespräche nicht zu gefährden. Dem italienischen Botschafter in Paris zufolge wies die Regierung die Presse sogar an, die Landung nicht zu 
kommentieren. Erst am 8. Dezember bat Léger Henry, Auskunft über Ziel, Art und Dauer der Operation zu verlangen ${ }^{53}$.

Die japanisch-französischen Gespräche über eine Neuausrichtung der Beziehungen begann Nomura am 17. November freundlich im Ton, aber hart in der Sache. Den "versehentlichen Bombenabwurf" auf Indochina Ende August wolle er mit einer Zahlung von 625000 Francs wiedergutmachen. Es könne aber weitere Überflüge über indochinesisches Territorium geben, wenn sich der Waffentransit über die Yunnanbahn fortsetze. Wolle Paris neue Zwischenfälle ausschließen, müsse es diesen Transit unterbinden. Japans Presse schrieb nun von angeblichen Waffenkäufen Chinas in Frankreich. Daladier widersprach: Er versicherte den Japanern, daß kein Kriegsmaterial im Sinne der Genfer Konvention von 1925 die Grenze passiere. Andere Lieferungen, die militärisch genutzt werden könnten, wie Benzin und Lastwagen, seien kein Kriegsmaterial. Frankreich habe im Geist des Vertrages von 1907 freiwillig den Waffentransit unterbunden. Daß das Verbot befolgt werde, hätten mehrere Überprüfungen bestätigt, die auf Japans Wunsch durchgeführt worden seien ${ }^{54}$.

Am 30. November, als Tokio bereits Nanning besetzt und so seine Position verbessert hatte, erklärte Nomura Henry, Tokio begrüße Frankreichs Wunsch nach einer Verbesserung der Beziehungen. Doch zu dieser Verbesserung könne es nicht kommen, wenn Frankreich weiter Chiang Kai-shek unterstütze und Rohstoffexporte aus französischen Kolonien nach Japan behindere. China werde aus Indochina mit Waffen, Munition, Fahrzeugen, Benzin und Lebensmitteln versorgt. Falls Paris nicht den Warentransit nach China unterbinde, müsse Japan dies mit Gewalt tun. Um das Ende der Transporte in Indochina zu kontrollieren, wolle Tokio einen Diplomaten und einen Offizier entsenden. Daladier antwortete, die Wiederholung alter, entkräfteter Vorwürfe lasse ihn zweifeln, ob Tokio eine Einigung mit Paris wolle. Japaner könnten nach Indochina kommen, aber ohne dort besondere Rechte zu erhalten. Falls Japan Beschwerden habe, so habe auch Frankreich solche, etwa über die Besetzung Hainans, die Annexion der Spratlys oder die Einschränkungen französischer Interessen in China. Als Henry am 12. Dezember diese Botschaft Daladiers überbrachte, beharrte Nomura, es gebe einen Waffentransit durch Indochina.

\footnotetext{
${ }^{53}$ EMAA.2, Note, 9.11., EMA.2, compte rendu, 22.11 .1939 (SHAT 7 N 3301, 2516); Note de la sousdirection d'Asie-Océanie, 17.11.; Catroux an Mandel, T, 19.11.1939 (MAE Chine 564, Indfr 30); Cosme an Daladier, T 1279-82, 19.11., L 422, 14.12.1939 (MAE Chine 677, MAEN Londres C 479); Diplomatie an Guerre, L 5613, 20.11 .1939 (SHAT 7 N 3249); Reed an Hull, 24.11., 29.11., Murphy an Hull, 20.10.1939 (SD 793.94/15566, 15567, 751.93/65); Peck an Hull, 3.12., Bullitt an Hull, 30.11., 5.12.1939 (FRUS 1939, III, S. 766f., S. 716; SD 893.154/276); Thiébaut an EMA.2, L 59, 2.12., Yvon an EMA.2, L 261, 5.12.; EMA.2, Résumé, 30.1.1940 (SHAT 7 N 3292, 3319); Auriti an Ciano, 28.11.; Léger an Henry, T 655, 8.12.1939 (DDI Serie 9, II, 363, MAEN Londres C 487).

${ }^{54}$ Nomura an Henry, L 63, 17.11., Henry an Nomura, L 76, 27.11.1939 (MAEN Tchongking 3); Henry an Daladier, T 719, 21.11.; Daladier an Henry, T 612-14, 25.11.1939 (MAE Japon 129, Indf 30).
} 
Bei Japans Vormarsch auf Nanning habe China sogar Waffen in Indochina in Sicherheit gebracht. Trotz des heiklen Themas war die Atmosphäre zwischen Henry und Nomura herzlich und vertraulich. Beide hielten den Kompromiß, zwei Japaner als Kabinettskuriere nach Hanoi zu entsenden, für erwägenswert. In ihrem ersten Gespräch am 13. Dezember betonten auch der neue Botschafter Sawada und Léger ihren Wunsch, die bilateralen Beziehungen zu entspannen. Dafür sei jedoch, so Sawada, das Ende des Transits unabdingbare Voraussetzung. Léger versicherte, außer aus alten Bestellungen erhalte China keine Waffen über Indochina. Der Generalsekretär bat den Botschafter, sich für eine Beruhigung der Atmosphäre in Tokio einzusetzen. Gegenüber den Briten und vor allem den Amerikanern betonte Léger jedoch, wie sehr Japans und Frankreichs Positionen aufeinanderprallten ${ }^{55}$. Die Atmosphäre zwischen Tokio und dem Westen wurde durch Japans Erklärung entspannt, Teile des Jangtse für die internationale Schiffahrt zu öffnen ${ }^{56}$.

Informell fanden Henry und die japanische Regierung einen Weg, wie japanische Beobachter nach Indochina kommen konnten. Generalmajor Tsushihashi Yuitsu, der bis zum Sommer 1939 als Militärattaché in Paris residiert hatte, dann Stabschef der Armee in Kanton und schließlich Chef des Armee-Geheimdienstes in Tokio wurde, durfte als Privatmann nach Indochina reisen. Das Foreign Office und der britische Militär-Geheimdienst in Singapur fürchteten, die Franzosen und der General könnten sich einigen, den Transit zu unterbinden. Die Chinesen verbreiteten das Gerücht, Paris spreche über einen japanisch-französischen Nichtangriffspakt; die Italiener äußerten sich bereits voller Neid über die Annäherung zwischen Paris und Tokio.

Generalgouverneur Catroux empfing Tsushihashi und drei weitere japanische Offiziere am 20. Dezember in Hanoi. Der General sagte, er komme als Freund Frankreichs. Die Beziehungen seien durch die Transitvorwürfe belastet. Er würde gern die Vorwürfe entkräften und die Grenze zu China besichtigen. Catroux stritt jeden Transit ab, auch den von Lastwagen und Benzin. Die Grenze zu besichtigen, sei unmöglich. Der General tobte und brach das

\footnotetext{
${ }^{55}$ Henry an Daladier, T 747-54, 1.12., Daladier an Henry, T 659-62, 8.12.1939 (MAE Japon 129); Henry an Daladier, T 784-85, 12.12., Léger an Saint-Quentin, T 2008-10, 13.12.1939 (MAEN Londres C 487); Henry an Cosme, L 43, 13.12., T 401-3, 20.12.1939 (MAEN Tchonging 3, Pékin A 494); Nomura an Miyasaki (Paris), 13.12., Japanische Noten, 30.11 .1939 (JA, S 1.1.1.0-28, S. 7f.; S. 25f., S. 35f.); Henry an Nomura, L, [11.12.], Bericht über das Treffen Nomura-Henry, 12.12., Miyasaki an Nomura, 20.12.1939 (JA, S 1.1.1.0-28, S. 46f., S. 37f., S. 247f.); Japanese Communication, 30.11., French Communication 12.12.1939 (FO 371/24673, F 955, 1546/57/10); Craigie an Halifax, 9.12.1939 (FO 371/23462, F 12535/87/10); Craigie an Halifax, 1.1.1940 (FO 371/24743, F 2417/2417/23); Grew an Hull, 1.12., 11.12., 20.12.1939 (SD 893.24/651; FRUS 1939, III, S. 769; SD 751.94/93); Bullitt an Hull, 13.12.1939 (FRUS 1939, III, S. 769f.).

${ }^{56}$ Henry an Daldier, T 790, 18.12., Cosme an Daladier, T 138, 22.12.1939; Georges-Picot an Daladier, T 9499, 25.1., Cosme an Daldier, T 131, 20.2.1940 (MAEN Londres C 487, 481).
} 
Gespräch ab. Am folgenden Tag wiederholte Tsushihashi seine Bitte. Als Catroux erneut ablehnte, drohte der Japaner, man könne Indochina besetzen oder bombardieren, wenn der Transit weitergehe. Auch eine Pressekampagne drohte er an. Am 24. Dezember reiste Tsushihashi gedemütigt $\mathbf{a b}^{57}$.

In der japanischen Öffentlichkeit hatte sich der Ton gegenüber Frankreich deutlich verschärft. Der Sprecher der japanischen Armee in Shanghai drohte am 6. und 16. Dezember mit japanischen Bombenangriffen auf die Yunnanbahn, falls der Waffentransit weitergehe. Der Sprecher des Außenministeriums in Tokio sagte am 12. Dezember, via Indochina würden Waffen transportiert. Zudem zeigte die Ankündigung, daß das Gaimusho eine Abteilung für den südlichen Pazifik einrichte, daß sich Japan dem Süden zuwandte ${ }^{58}$.

Unspektakulär endete Japans Vorstoß an die indochinessische Grenze, den die Militärattachés Yvon und Thiébaut so gefürchtet hatten. Am 21. Dezember besetzte eine Abteilung mit 1000 Mann das 20 Kilometer von der Grenze entfernte Longtchéou und zerstörte dort Lager und Straßen. 200 Soldaten rückten bis an die Grenze vor, verhielten sich korrekt, tauschten Höflichkeiten mit dem Kommandeur der verstärkten französischen Verbände aus - und baten um Lebensmittel. Am 24. Dezember zogen sich die Japaner zurück, als Chiang am 16. Dezember letzte Reserven mobilisierte und eine Gegenoffensive begann. Die Franzosen hatten Chiang erklärt, ihre Haltung zu beiden Konfliktparteien hänge sehr davon $a b$, wer das Grenzgebiet zu Indochina kontrolliere. Mühsam drängte China Japans Truppen zurück ${ }^{59}$. Parallel vereinbarte Catroux im Januar 1940 mit dem japanischen Oberstleutnant Nishiura Susumu bei dessen Besuch in Hanoi, daß die abgeschnittene japanische 5. Armee in Nanning diskret aus Indochina Nachschub erhielt ${ }^{60}$. Die Hilfe sollte wohl Frankreichs Unnachgiebigkeit beim Transit die Spitze nehmen. Gleichzeitig stärkte Tokio

\footnotetext{
${ }^{57}$ Craigie an Halifax, 28.12., Note Hunniker-Major, 30.12 .1939 (FO 371/23462, F 13084/87/10); General Office Commanding Hongkong [GOC] an War Office, 18.12., 23.12., Note Hunniker-Major, 21.12., 30.12.1939 (FO 371/23419, F 12828, 13001/14/10); GSO.I Far East an War Office, 28.12.1939, GOC Hongkong an War Office, 8.1.1940 (FO 371/24653, F 263, 207/15/10); Grew an Hull, 28.12.1939 (SD 751.94/97); Georges-Picot an Daladier, T 1370-71, 23.12.1939 (MAEN Pékin A 312); Yvon an EMA.2, Note, 28.12.1939 (SHAT 7 N 3292); DECOUX, À la barre, S. 64; LEGRAND, L'Indochine, S. 15. Irttümlich legt CaTroux den Vorfall in den Februar 1940 (Deux actes, S. 51 f.).

${ }^{58}$ Georges-Picot an Daladier, T 1356-57, 16.12.1939 (MAE Chine 949); Henry an Daladier, L 238, 19.12.1939 (MAEN Pékin A 311); Henry an Daladier, T 798-800, 21.12.1939 (MAEN Pékin A 312).

${ }^{59}$ Diplomatie an Guerre, L 68, 6.1., T 1452-53, 13.3.1940 (SHAT 7 N 3249); Thiébaut an EMA.2, L 6, 13.1.1940 (SHAT 7 N 3332); GSO.1 (Intelligence) Far East an War Office, 28.12.1939 (FO 371/24653, F 207/15/10); Reed an Hull, 24.12., 26.12.1939, 6.1.1940 (SD 793.94/15601, 15602, 15650); Johnson an Hull, 27.12.1939 (FRUS 1939, III, S. 717f.); Lockhart an Hull, 23.1.1940 (SD 893.00 PR/165); Intelligence Shanghai an War Office, 22.2.1940 (FO 371/24654, F 1394/15/10); HÉDUY, La perle de l'empire, S. 408; DORN, The Sino-Japanese War, S. 287f.; CH'I, Nationalist China at War, S. 58; WILsoN, When Tigers Fight, S. 163.

${ }^{60}$ Hata, Army's Move, S. 158; VALETTE, Indochine, S. 22; MURAKAMI, Japan's Thrust, S. 57f.
} 
in der drôle de guerre in Indochina antifranzösische Kräfte. Japans Geheimdienst unterhielt Kontakte zu Nationalisten, finanzierte Kommunisten und baute die Spionage aus. Im November wurden sechs japanische Agenten ausgewiesen. Die Behörden vermuteten, viele Vietnamesen hofften, der Krieg in Europa werde ihnen die Unabhängigkeit bringen, notfalls mit Hilfe Japans ${ }^{61}$.

In Tokio entschied das Militär, dem Transit über die Yunnanbahn durch Luftangriffe ein Ende zu bereiten. Das Außenministerium in Tokio hatte schon im Dezember 1938 dem von der Marine gewünschten Bombenangriff grundsätzlich zugestimmt. Auslöser für die Angriffe im Dezember 1939 dürfte die Information gewesen sein, daß Frankreich mit Millionensummen die Transitwege nach China ausbaue und daß der Transit im November und Dezember deutlich zugenommen habe. Nachdem Japans Luftwaffe an den Vortagen Kwangchowan überflogen hatte, attackierten am 30. Dezember neun Bomber den chinesischen Teil der Yunnanbahn. Am 1. und 2. Januar 1940 wurde der Angriff mit je 27 Flugzeugen wiederholt. Ziel war stets die 83 Kilometer von der Grenze entfernte, 120 Meter lange Brücke über den Nam-Ti-Fluß, die Naggiar schon 1937 als einen der verwundbarsten Punkte der Linie bezeichnet hatte. Dabei wurde am 1. Januar ein Chinese getötet, aber kaum Sachschaden angerichtet. Die Bombenschäden vom 2. Januar wurden binnen drei Stunden beseitigt. Auch das vierte Bombardement am 4. Januar mit 27 Flugzeugen blieb erfolglos. Am 5. und 7. Januar erreichten die eingesetzten 38 und 36 Bomber ihr Ziel: Eine 50 Meter lange Brücke 235 Kilometer von der Grenze sowie die Nam-Ti-Brücke wurden schwer beschädigt. Mit monatelanger Sperrung wurde zuerst gerechnet, doch die Bahn war wieder rasch einsatzfähig.

Die Franzosen brachten Anfang Januar Luftabwehrgeschütze zur Brücke über den Nam-Ti; Catroux ordnete an, Flugzeuge, die Indochina überflogen, abzuschießen, doch die Geschütze wurden dann doch nicht eingesetzt. Stattdessen drängte Hanoi China, die Luftabwehr an der Bahn zu verstärken ${ }^{62}$.

Die Angriffe schreckten den Quai d'Orsay auf. Die französisch-japanischen Beziehungen verschlechterte sich aber nicht, wie dies John E. Dreifort annimmt. Paris ging nicht gegen Japan vor, sondern es nahm, im Gegenteil,

\footnotetext{
${ }^{61}$ JACQUIN, La guerre secrète, S. 35f.; Militär Tientsin an General Martin, T 97-98, ca. 10.9.1939 (SHAT 11 H 60); Walsh an Halifax, 10.12 .1939 (FO 371/22921, C 250/249/17); Reed an Hull, 5.10.1939, 2.6., 9.10.1940 (SD 851G.00/44, 793.94/15990, 851g.00P/2).

${ }^{62}$ Henry an Nomura, L, 27.12., 30.12 .1939 (JA, S 1.1.1.0-28, S. 164, S. 172, S. 179); Catroux an Mandel, T 20-22, 3.1.1940 (CAOM CM 551); Chauvel an Cosme, T 7-8, 7.1., Gandon an Daladier, T 19, 8.1., T 41, T 48, 17.1.1940 (MAE Chine 949); Reed an Hull, 31.12.1939, 10.1., 17.1., Peck an Hull, 10.1.1940 (SD 793.94/15605, 15652, 15653, 15588); Greenway an Halifax, 3.1., 5.1., 9.1., 19.1., Clark Kerr an Halifax, 18.1.1940 (FO 371/24772, F 106, 175, 310, 525, 526/51/10); Southard an Hull, 18.1.1940 (SD 893.24/683); Naggiar an Delbos, 27.10.1937 (MAE Chine 710); Business Report of 1939 by the Board of South Seas und Urteil (TWCT, III, S. 6801-6815 [S. 6802f.], XX, S. 48793); MURAKAMI, Japan's Thrust, S. 96f.; LEGRAND, L'Indochine, S. 15.
} 
das Bombardement zum Anlaß, Tokio ein neues Freundschaftsangebot zu machen. Als Daladier Henry am 3. Januar 1940 anwies, in Tokio gegen die Angriffe zu protestieren, bot er Japan gleich einen Ausweg, wie man ins Gespräch kommen könne: Er sei sicher, daß die Attacken örtlichen Initiativen entsprängen, während das Gaimusho eine Annäherung an Frankreich anstrebe. Der Quai d'Orsay wünsche einen breiten Meinungsaustausch.

In Paris versuchten Daladier und Léger, Elan in die Gespräche zu bekommen. Vermutlich nicht ohne Inspiration schrieb die französische Presse von einer Klimaverbesserung zwischen Japan und Frankreich. Dem italienischen Botschafter wurde zugeraunt, womöglich stünden Verhandlungen über einen japanisch-französischen Nichtangriffspakt bevor. Daladier bestellte Sawada am 2. Januar ein und sagte, Frankreich und Japan seien alte Freunde, die ihre Beziehungen verbessern müßten. Drei Tage später erklärte Léger Sawada, Frankreich sei bereit, Japan freundschaftlich entgegenzukommen, doch müsse Japan eine Gegenleistung anbieten. Sawada erwiderte, das Ende des Transits und die Anerkennung der japanischen Rolle in China seien Vorbedingung verbesserter Beziehungen. Offenbar dachte Sawada an eine Erklärung, wie sie Botschafter Craigie im Juli 1939 abgeben hatte. Sawada und Léger einigten sich, zunächst die bilaterale Atmosphäre zu verbessern. Die Gespräche in Paris sollten vertraulich sein. Die in Tokio überreichten Protestnoten übergaben die Franzosen dagegen an Briten und Amerikaner, so daß Stanley Hornbeck, Asienexperte im State Department, annahm, die Franzosen hätten seit 1937 Japans Drohungen resoluter widerstanden als die meisten anderen Länder ${ }^{63}$. Paris bemühte sich in Washington um den Eindruck, Frankreich halte strikt an Chinas Versorgung fest. Hornbeck lobte die französische Haltung. US-Außenminister Hull, der zuvor bekanntgegeben hatte, daß Japan aus den USA kein Flugzeugbenzin mehr erhalte, warnte Tokio am 19. Januar, daß Bombenangriffe auf die Yunnanbahn auch den US-Handel und amerikanische Bürger gefährdeten - diese Erklärung hatte sich der Quai d'Orsay gewünscht ${ }^{64}$.

${ }^{63}$ Dreifort, Myopic Grandeur, S. 182; Daladier an Henry, T 5-6, 3.1., Chauvel an Henry, T 20-21, 10.1., Henry an Daladier, T 21, 12.1.; Henry an Georges-Picot, T 413, 6.1.1940 (MAE Chine 949, MAEN Pékin A 312); Nomura an Sawada, 6.1., Sawada an Nomura, 8.1.1940 (JA, S 1.1.1.0-28, S. 269f., S. 253f., S. 273f.); Guariglia an Ciano, T 18, 18.1.1940 (DDI Serie 9, III, 163); Grew an Hull, 6.1., 9.1.; Note, Hombeck, 13.1.1940 (FRUS 1940, IV, S. 258, SD 793.94/15665, 15715).

${ }^{64}$ Saint-Quentin an Daladier, T 139, 30.1., Henry an Daladier, T 74, 2.2.1940 (MAEN Londres C 486, C 480); Grew an Arita, Memorandum, 31.1.1940 (FRUS Japan 1931-1941, I, S. 674); Chauvel an Saint-Quentin, T 120-31, 15.1.1940 (MAE Chine 949); Henry an Cosme, T 31-33, 17.1.1940 (MAEN Pékin A 311); Bullitt an Hull, 15.1., Hornbeck, Memorandum of Conversation, 20.1.1940 (FRUS 1940, IV, S. 262f., S. 268f.); Saint-Quentin an Daladier, T 115-16, 22.1.1940 (MAE SDN 366); Hull an Grew, 19.1., Saint-Quentin an Hornbeck, L, 22.1 ., Bullitt an Hull, 26.1., Hull an Bullitt, 2.2.1940 (SD 793.94/15621A, 15637, 15632, 15669B). 
Tokio blieb unnachgiebig: Nomura erklärte am 12. Januar Henry, Voraussetzung weiterer Gespräche sei die Einstellung des Transits. Falls dieser weitergehe, werde Japan die Yunnanbahn erneut bombardieren. Sämtliche Waren für China soliten in Indochina bleiben, vor allem Waffen, Fahrzeuge und Benzin. Nomura deutete an, Japan könne französische Schiffe vor der indochinesischen Küste aufbringen. General Tsushihashi drohte Militärattaché Thiébaut mit »unangenehmen Zwischenfällen«, falls der Transit nicht ende. Thiébaut fürchtete, daß Japan dem Bombardement der Yunnanbahn massivere Schritte folgen ließ. Es häuften sich die Hinweise, daß Tokio zehn Divisionen nach Südchina entsenden und eine Blockade über Indochina verhängen wolle. Um die Lage zu entspannen, luden die Franzosen General Nishiura zu einem Manöverbesuch nach Hanoi ein. Außenminister Nomura versicherte Henry, Japan wolle seine Beziehungen zu Frankreich verbessern ${ }^{65}$.

Als die Regierung Abe stürzte, wurde am 16. Januar Ex-Außenminister Arita Hachiro wieder Chef im Gaimusho. Er versicherte Henry, er wolle die Beziehungen zu Paris verbessern. Im Parlament erklärte Arita, Japan wolle die Mächte nicht aus China verdrängen, sondern gemeinsam mit ihnen eine neue Ordnung in China errichten - eine zweifelhafte Ehre für die Mächte. Arita und der neue Regierungschef Yonai Mitsamusa suchten das rapprochment an den Westen, sie wollten aber auch Japans Herrschaft in China festigen ${ }^{66}$. Léger sagte am 19. Januar Sawada, auch Japan müsse Zugeständnisse machen. Der Generalsekretär drohte, Paris werde japanischen Fluggesellschaften verbieten, beim Direktflug Tokio-Bangkok Indochina zu überfliegen, solange Tokio Bombardements androhe. Überraschend schlug Léger vor, Experten beider Länder sollten in Indochina untersuchen, ob ein Transit stattfinde. Er erwartete im Gegenzug Japans Verzicht auf weitere Angriffe bis zum Abschluß der Untersuchung. Dies müsse aber streng geheim bleiben. Da er fürchtete, daß Amerika von dem Vorschlag erfuhr, ließ er Bullitt zutragen, Georges Mandel habe die Untersuchungskommission angeregt, was der Quai d'Orsay jedoch ablehne. Während der Annäherungsbemühungen Légers wurde der Transit von Waffen und Munition durch Indochina stark reduziert. Chinas Verärgerung war erheblich. Die Franzosen erklärten dem US-Diplomaten Peck, gegen Japans militärische Drohungen gegen die Yunnanbahn seien sie machtlos.

\footnotetext{
${ }^{65}$ Henry an Daladier, T 24-28, 12.1.1940 (MAE Chine 949); Bericht über das Treffen NomuraHenry, 12.1., Nomura an Henry, L, 12.1.1940 (JA, S 1.1.1.0-28, S. 92f., S. 103f.); Grew an Hull, 16.1.1940 (SD 793.94/15667); Thiébaut an EMA.2, L 6, 13.1.1940; Diplomatie an Guerre, L 6195, 19.12.1939, L 68, 6.1., L 183, 12.1.1940 (SHAT 7 N 3332, 3249); GOC Hongkong an War Office, 17.1., 18.1., GOC Malaya an War Office, 20.1.1940 (FO 371/24653, F 427, 512, 529/15/10).

${ }^{66}$ Henry an Daladier, T 49, 18.1.1940 (MAEN Londres C 480); SATO, Japan and Britain, S. 42; UsUI Katsumi, The Role of the Foreign Ministry, in: BORG, OKOAMOTO (Hg.), Pearl Harbor, S. 127--148 (S. 147); IMAI, Cabinet, S. 73.
} 
Die Beamten im japanischen Außenministerium hielten es für denkbar, daß Frankreich den Forderungen nachgab. Sie überlegten Mitte Januar, ob Japan nach einer Unterbrechung des Transits in Indochina den Handel mit Deutschland einstellen müsse. Arita wies am 26. Januar Sawada an, erneut nach dem Transitverbot und der Überflugerlaubnis für die Verbindung Tokio-Bangkok zu fragen. Erstmals forderte Arita, daß Frankreich in Indochina den Transit von Lastwagen nach China stoppe. Das Entgegenkommen der Franzosen bei der Errichtung eines Konsulats in Nouméa und beim Nickelexport aus Neukaledonien sei selbstverständlich und müsse mit keiner Gegenleistung honoriert werden. Léger und Sawada kamen in ihrem Gespräch am 30. Januar nicht weiter. Sawada lehnte die Untersuchungskommission ab, weil es nicht Japans Sache sei zu beweisen, daß der Transit gestoppt sei. Léger beharrte, er verhandle nicht unter der Drohung weiterer Bombardements. Gleichzeitig zeigte der Fall der Asama Maru, daß es die japanische Regierung mit der Verbesserung der Beziehung zum Westen ernst meinte. Die britische Marine hatte am 21. Januar das Schiff Asama Maru 35 Meilen vor Tokio gestoppt und 21 deutsche Reservisten von Bord geholt. Den Zwischenfall regelten Arita und Craigie einträchtig: Die Briten gaben neun Deutsche heraus, Japan versprach, keine Deutschen im wehrfähigen Alter mehr nach Europa zu bringen ${ }^{67}$.

Parallel versuchte Léger, Tokio und Paris ökonomisch anzunähern, was den Japanern angesichts der Unsicherheit über die Wirtschaftsbeziehungen zu den USA sehr wichtig war, wie Botschaftsrat Fain in Tokio vermutete. Paris wollte in Japan Waffen kaufen: Das französische Militär ließ bereits zur Ansicht das Visier eines japanischen Flugabwehrgeschützes kommen. Zudem ordnete die französische Regierung am 25. Januar an, daß die Banque de l'Indochine die Gründung einer Filiale in Yokohama vorbereitete ${ }^{68}$.

Weil die Franzosen einen Transitstop ablehnten, griff die japanische Regierung wieder zur Gewalt. Am 1. Februar bombardierte die japanische Luftwaffe mit 27 Flugzeugen erneut die Brücke über den Nam-Ti. Bei dem seit Ende Dezember siebten Angriff auf die Yunnanbahn trafen die Bomben einen Passagierzug, der gerade einen Tunnel verließ. 105 Menschen wurden getötet, darunter 16 einheimische Bahnarbeiter und fünf Franzosen, alle Angestellte

\footnotetext{
${ }^{67}$ Sawada an Arita, 19.1., 22.1., 31.1.1940 (JA, S 1.1.1.0-28, S. 277f., S. 282f., S. 289f.); Bullitt an Hull, 15.1.1940 (FRUS 1940, IV, S. 262f.); Bidder an Ribbentrop, 6.1., 9.1., 12.1.1940 (AA Pol VIII 60, 2); Peck an Hull, 29.1.1940 (SD 893.01/612); Aufzeichnung über den Stop des Kriegsmaterials im Transit durch Indochina, 19.1., Arita an Sawada, 26.1.1940 (JA, S 1.1.1.0-28, S. 570f., S. 285f.); CLIFFORD, Retreat from China, S. 138; SATO, Japan and Britain, S. 44f.

${ }^{68}$ Grew an Hull, 28.1.1940 (FRUS 1940, IV, S. 280); Sawada an Arita, 31.1., 5.2.1940 (JA, S 1.1.1.028, S. 289f., S. 302f.); Bullitt an Hull, 27.1.1940 (SD 740.0011 Eur. War 1939/1564); Ministère des Finances an Mandel, 25.1., Colonies an Diplomatie, 27.3.1940 (CAEF, B 34.123). Schon Berthelot hatte 1931 gefordert, daß die Bank sich in Japan niederließ. Eröffnet wurde die Filiale am 2.11.1942 in Tokio (Berthelot, Note, 16.11.1931, MAE Chine 888; MeULEAU, Des pionniers, S. 408).
} 
der Bahn oder deren Angehörige. 124 Menschen wurden verletzt. Nach dem Angriff überflogen die Flugzeuge indochinesisches Territorium. Die Brücke wurde schwer beschädigt, der Bahnverkehr für wenige Tage unterbrochen ${ }^{69}$.

Trotz der Opfer setzte Japan die Angriffe fort. Am 3. Februar unternahmen 27 Bomber einen weiteren Angriff. Am 13. und 16. Februar attackierten 27 und 18 Bomber folgenlos eine Brücke. Am 17. Februar folgte ein weiterer erfolgloser Luftangriff durch 26 Flugzeuge. Das Bombardement am 18. Februar riß jedoch mehrere hundert Meter Schiene heraus und beschädigte das Gleisbett schwer. Der Bahnverkehr wurde für zwei Tage unterbrochen. Um eine Eskalation zu vermeiden, wies die Regierung in Paris das Militär in Indochina an, auf keinen Fall auf japanische Flugzeuge zu schießen ${ }^{70}$.

Die auffallend zurückhaltende Presseberichterstattung in Indochina und Frankreich sowie Äußerungen führender Militärs in Indochina und Daladiers in Paris ließen die Japaner den Eindruck gewinnen, daß die Franzosen die Angriffe, insbesondere die hohe Zahl an zivilen Opfern, zwar verurteilten und $\mathrm{da} ß$ eine völlige Beendigung des Warenverkehrs nach China ausgeschlossen war, daß es der französischen Regierung jedoch daran gelegen war, mit Tokio im Gespräch zu bleiben. Die französische Presse stellte die Bombardements als lokale Zwischenfälle dar, die vom Militär vor Ort ohne Wissen der Regierung ausgeführt wurden. »Le Temps« schrieb am 7. Februar sogar, man dürfe mit der Berichterstattung den Konflikt nicht noch verschärfen; Frankreich habe ein Interesse an der Zusammenarbeit mit Japan. Bis zum Beweis des Gegenteils gebe es keinen Grund, an der Aufrichtigkeit der japanischen Regierung zu zweifeln. Der japanische Konsul in Hanoi, Suzuki Rokuro, hatte General Martin, den Chef des französischen Heeres in Indochina, sogar so verstanden, daß man über Bombenangriffe auf die Bahnlinie hinwegsehen könne, wenn es nicht zu Toten komme. Suzuki schlug seiner Regierung deshalb vor, für zivile Opfer eine Entschädigung zu zahlen. Emeut wählte die französische Regierung bei ihrem diplomatischen Protest in Tokio sowie bei der Darstellung dieser Reaktion in Washington und London einen deutlich schärferen Ton, als ihn Daladier vertraulich gegenüber Sawada benutzte. Als kleiner Nadelstich wurden die Exporte von Reis aus Indochina nach Japan um

\footnotetext{
${ }^{69}$ Yvon an Daladier, T, 16.2.1940 (MAE Chine 949); Davidson an Halifax, 1.2., 3.2., Daily Herald, 6.2.: Firm Note by Paris; Daily Telegraph, 6.2.: France Protests Again to Japan; Cambon an Howe, 4.2., Prideux-Brune an Halifax, 12.2.1940 (FO 371/24772, F 753, F 813, F 847, F 1411/51/10); Murphy an Hull, 6.2., Southard an Hull, 8.2., Peck an Hull, 11.2.1940 (SD 793.94/15672, 15683, 15693); Miura (Shanghai) an Arita, 3.2.1940 (JA, S 1.1.1.0-28, S. 474f.). Von 86 Toten und 120 Verletzten ging Baudouin aus (Supreme Headquarters an State Dpt., 8.11.1944, SD 851g.00/11-844).

${ }^{70}$ Peck an Hull, 15.2., 18.2., 20.2., Meyers an Hull, 17.2.1940 (SD 793.94/15700, 15703-4, 15724); Crépin an Cosme, L 27, 22.2.1940 (MAEN Tchongking 7); Air Ministry an Foreign Office, 16.3.1940 (FO 371/24655, C 4263/166/17).
} 
eine Woche verzögert. Paris brachte die USA und Großbritannien dazu, gegen das Bombardement der Bahn, auf der ein Großteil ihres Handels abgewickelt wurde, in Tokio zu protestieren. Gerüchte über eine chinesisch-französische Geheimallianz, die wohl Chungking in Umlauf gebracht hatte, um die Annäherung zwischen Paris und Tokio zu behindern, dementierte Paris ${ }^{71}$.

Parallel zur zweiten Angriffswelle machte das Außenministerium in Tokio Angebote. Am 5. Februar übernahm Vize-Außenminister Tani gegenüber Henry die Verantwortung für die zivilen Opfer der Attacke und stellte eine Entschädigung in Aussicht, verlangte aber, daß Paris zumindest den Transport von Waffen, Munition, Flugzeugen, Ersatzteilen, Fahrzeugen, Maschinen, Metallen, Schienen, Lokomotiven und Medikamenten stoppe. Falls es für Paris schwierig sei, den Transit zu unterbinden, könne es erklären, daß die Zerstörung der Bahnlinie Transporte verhindere. Erfülle Frankreich die Bitte, biete Japan weitreichende Gespräche über die bilateralen Beziehungen an und räume Frankreich eine größere Rolle in Wang Ching-weis China ein. Chauvel nannte die Vorschläge intern eine Hilfe für Tokios Kriegführung. Tani fordere französisches Vertrauen, doch Japans Vorgehen gegen Hainan, die Spratlys, die Paracels und das Bombardement der Yunnanbahn gebe kaum Anlaß, Japan zu trauen. Unklar sei auch, ob die Regierung Yonai lange im Amt bleibe, ob sie das Militär kontrolliere und ob Wang Erfolg habe. Vor allem aber sei das Angebot des Beuteteilens und der Komplizenschaft in China mit Frankreichs Nähe zu Großbritannien und vor allem den USA kaum vereinbar. Léger wies Tanis Vorschlag zurück. Paris habe bereits die Waffentransporte gestoppt; den gesamten Transit könne man unmöglich unterbrechen. Der Generalsekretär verwies darauf, daß Frankreich Japan oft nachgegeben habe und dafür von Japan nur Schläge erhalten habe. Léger ließ dem Foreign Office und dem State Department Tanis Angebot und seine Antwort zuleiten, um zu zeigen, daß Frankreich an der festen Linie gegenüber Japan festhalte. Die französische Regierung wußte, daß Washington eine Sperrung der Bahn empört hätte ${ }^{72}$.

\footnotetext{
${ }^{71}$ Suzuki an Arita, 2.2., 3.2., 6.2.; Sawada an Arita, 3.2., 4.2., 5.2., 6.2., 7.2.1940 (JA, S 1.1.1.0-28, S. 459f., S. 461f., S. 466; S. 293f., S. 297f., S. 299f., S. 304f., S. 307f., S. 312f., S. 314f.); Daladier an Henry, T 79-80, 3.2., note de la sous-direction d'Asie-Océanie, 5.2., Corbin an Daladier, T 437, 5.2.1940 (MAE Chine 949, 761); Daladier an Corbin, T 285-86, 4.2., Daladier an Henry, T 81, 5.2.1940 (MAEN Londres C 480); Murphy an Hull, 6.2., Grew an Hull, 7.2., 23.2.; Grew an Arita, 11.3.1940 (SD 793.94/15672, 15675, 15710, FRUS Japan 1931-1941, I, S. 678); Campbell an Halifax, 7.2., Clarke, Note, 9.2.1940 (FO 371/24772, F 984, 1056/51/10).

${ }^{72}$ Bericht über Gespräch Tani-Henry, 6.2., Sawada an Arita, 8.2., 10.2.1940 (JA, S 1.1.1.0-28, S. 108f., S. 321f., S. 324f.); Note de la sous-direction d'Asie-Océanie 7.2., Diplomatie an Colonies, Briefentwurf, 20.2.1940 (MAE Chine 949); Campbell an Halifax, 9.2., Clarke, Note, 12.2., 21.2., Craigie an Halifax, 23.2.1940 (FO 371/24772, F 1050, 1151, 1300, 1355/51/10); Grew an Hull, 8.2., Reed an Hull, 8.2., Peck an Hull, 20.2.1940 (SD 793.94/15684, 16718, 15708); Hombeck, Memorandum of Conversation, 23.2.1940 (FRUS 1940, IV, S. 292f.).
} 
Trotz zahlreicher Bombardements war es Japan nicht gelungen, die Versorgung Chiang Kai-sheks zu unterbinden. Wohl deshalb ging Tokio erneut auf Paris zu. Arita forderte Sawada Mitte Februar auf, einen neuen Versuch zu unternehmen, um die Atmosphäre zwischen Japan und Frankreich zu verbessern. Sawada solle erreichen, daß Paris die Unterstützung Chinas beende, vor allem den Warentransit durch Indochina, und ein Abkommen unterzeichne, in dem es, wie Craigie im Juli 1939, Japans besondere Rechte bei der Kriegführung in China anerkenne. Stimme Frankreich zu, stelle Japan die Angriffe auf die Yunnanbahn ein und achte die französischen Rechte in China. Gespräche über Hainan, die Paracels und die Spratlys seien zu vermeiden. Entwickelten sich die Verhandlungen positiv, könne man Wirtschaftsfragen ansprechen. Arita war davon überzeugt, wie er Sawada am 26. Februar telegraphierte, daß Paris wirklich an freundschaftlichen Beziehungen zu Tokio interessiert war. Sawada hielt nichts von Aritas Aufforderung, denn wenn man auf den Quai d'Orsay zugehe, erwecke man den Eindruck, daß Tokio aus Schwäche die Verbindung suche. Frankreich sei in Europa noch lange gebunden. Warte Japan mit den Gesprächen und etabliere sich zudem das Wang-Regime in China, müsse sich Paris bewegen. Vize-Außenminister Tani wollte jedoch schnelle Fortschritte und rief am 22. Februar Henry zu sich. Tani bedauerte die Opfer des Angriffs vom 1. Februar und erklärte sich bereit, Entschädigungen zu zahlen, obwohl seine Beamten intern geurteilt hatten, daß Frankreich darauf keinen Anspruch habe. Tani schloß nicht aus, daß sich die Angriffe wiederholen könnten. Er wolle aber die Beziehungen verbessern, indem er zunächst eine Verständigung über Asien, dann über die Weltpolitik suche. Tani drückte die Hoffnung aus, daß Paris mit Moskau breche. Offenbar wollte Tani mit der Erwähnung der Sowjets den Franzosen die Annäherung schmackhaft machen, denn in China hatte Tani ja nichts anzubieten. Henry empfahl seiner Regierung, die Gelegenheit zu nutzen und weitreichende Gespräche mit Tokio aufzunehmen. Japan suche offensichtlich eine entente mit den Demokratien gegen die Sowjetunion. Daladier war sehr zufrieden über die Entwicklung ${ }^{73}$.

\footnotetext{
${ }^{73}$ Arita an Sawada, 12.2., 17.2., 21.2., 26.2., Aufzeichnung, 8.2., Aufzeichnungen, Grundprinzipien französisch-japanischer Verhandlungen, ohne Datum, Japanische Meinung über vorliegende Fragen, ohne Datum (JA, S 1.1.1.0-28, S. 328f., S. 331f., S. 342f., S. 354f., S. 579f., S. 546f., S. 548f.); Sawada an Arita, 20.2., 22.2., Bericht über Treffen Tani-Henry, 22.2., Die zwei Meinungen über die Zugbombardierung, Februar 1940, Memorandum, ohne Datum (JA, S 1.1.1.0-28, S. 338f., S. 351f.; S. 340f., S. 116f., S. 572f., S. 121f.); Henry an Daladier, T 127-36, 22.2.1940 (MAEN Londres C 480); BARDOUX, Journal, S. 225f. An Entschädigung verlangte Paris 1,2 Millionen Francs für die fünf französischen Opfer sowie für 19 getötete und 27 verletzte Vietnamesen 550000 Francs. Die übrigen Toten waren demnach Chinesen. Bis zum Juni 1940 zahlte Tokio nicht. Konsul Crépin regte an, die Reparaturen China in Rechnung zu stellen, das für den Schutz der Bahn verantwortlich war (Crépin an Cosme, L 50, 23.3., L 72, 23.5., Henry an Tani, L, 7.5.1940, MAEN Tchongking 7; Note, 6.6.1940, JA, S 1.1.1.0-28, S. 131f.).
} 
Chauvel und Léger waren sich einig, daß Tanis Offerte neue Angriffe nicht ausschloß, doch daß Japan seine Position verändert habe: Der Transitstop war keine Vorbedingung für Gespräche mehr, auch die Komplizenschaft in China wurde nicht mehr angeboten. Das Angebot, die Beziehungen zu entspannen, nahm Léger deshalb an. Amerikaner und Briten wurden über Tanis Offerte und Légers Einschätzung, daß die Demokratien von dem rapprochement an Japan nur profitieren könnten, informiert. London warnte, Tokio könne versuchen, Briten und Franzosen gegen die Amerikaner auszuspielen, und als Preis für seine Teilnahme an einer antisowjetischen Front die westliche Hinnahme seiner Herrschaft über China fordern. Grundsätzlich war aber auch London an der Zusammenarbeit mit Japan gegen die Sowjets sehr interessiert, weil dies Moskau und Tokio gleichermaßen schwächte ${ }^{74}$.

Das Gespräch zwischen Sawada und Léger am 29. Februar blieb jedoch ergebnislos, weil der Botschafter den Transitstop wieder zur Vorbedingung einer Einigung machte. Sawada sprach sogar davon, daß sich der Krieg auf Indochina ausdehnen könne. Am Folgetag suchte Sawada Daladiers Büroleiter Robert Coulondre auf und bat um eine rasche Antwort des Regierungschefs auf Japans Angebot. Sawada verlangte, vor allgemeinen Gesprächen müsse Paris Japans besondere Stellung in Ostasien anerkennen ${ }^{75}$. In Tokio sorgten Nachrichten für Unmut, wonach Cosme in Chungking China zum Widerstand auffordere, Frankreich den Bahnbau nach Suifu finanziere und Japans Truppen in Südchina aus Indochina kommende Waffen und große Mengen Benzin fänden. Arita verzichtete aber bewußt darauf, diese Themen anzusprechen ${ }^{76}$.

Vermutlich überlegte der Quai d'Orsay Ende Februar 1940, wie man Japan Wohlwollen zeigen könne, ohne Interessen in Asien zu opfern. Am 1. März erschienen sensationelle Äußerungen Daladiers in der »New York Times«. Der Regierungschef hatte japanischen Korrespondenten der Zeitungen »Osaka Mai-nichi« und »Nichi Nishi« ein großes Interview gegeben. Er erklärte, er sei

\footnotetext{
${ }^{74}$ Note de la sous-direction d'Asie-Océanie, 23.2.1940 (MAE Chine 761); Léger an Henry, T 124-26, 24.2., Daladier an Saint-Quentin, T 344-53, 26.2., Henry an Daladier, T 152, 27.2., Corbin an Daladier, T 790-93, 28.2., T 799-800, 29.2.1940 (MAEN Londres C 480); Hornbeck, Memorandum of a Conversation, 2.3., Japanese Note, 19.2.1940 (SD 793.94/15777); Arita an Sawada, 27.2., Sawada an Arita, 28.2.1940 (JA, S 1.1.1.0-28, S. 358f., S. 360); Campbell an Halifax, 27.2., Clarke, Note, 29.2.1940 (FO 371/24772, F 1442, 1459/51/10); Note Denning, 29.2., Note Clarke, Note Brenan, 1.3 .1940 (FO 371/24708, F 1462/193/61).

${ }^{75}$ Sawada an Arita, 29.2., 1.3., 2.3.1940 (JA, S 1.1.1.0-28, S. 361f., S. 368f., S. 365f., S. 370f.); Note de la sous-direction d'Asie-Océanie, 29.2., Daladier an Henry, T 143-44, 5.3.1940 (MAE Japon 129); Note de la sous-direction d'Asie-Océanie pour M. Léger, 29.2., Diplomatie an Colonies, L 207 , 29.2.1940 (MAE Chine 949); Clarke, Note, 8.3.1940 (FO 371/24673, F 1749/57/10).

${ }^{76}$ Miura (Shanghai) an Arita, 27.2., 28.2., 29.2., 3.3., 4.3., 13.3.1940 (JA, S 1.1.1.0-28, S. 484, S. 485, S. 486, S. 476f., S. 482f., S. 478f.); Arita an Sawada, Entwurf, ohne Datum, Unterlage von Ministersitzung über die Unterstützung Chiangs durch Frankreich, ohne Datum [Februar/März 1940]; Note, ohne Datum [März 1940] (JA, S 1.1.1.0-28, S. 509, S. 574f., S. 576f.).
} 
für herzliche Beziehungen zwischen Frankreich und Japan und wolle mit Tokio über die Anerkennung Mandchukuos sprechen. Daladier bestritt, daß Frankreich China unterstütze, und warnte vor Moskau, das die Ausdehnung des Krieges und des Bolschewismus wünsche. Am 2. März fragte Botschafter Saint-Quentin im State Department, ob es nicht vernünftig sei, Mandchukuo anzuerkennen. Paris habe die Nichtanerkennung der Herrschaft Italiens über Abessinien nur Nachteile gebracht. Widersprüchlich dementierte Paris Daladiers Interview: Chauvel erklärte dem US-Geschäftsträger Robert D. Murphy zunächst, die Japaner hätten kaum Französisch verstanden. Ein Stenograph sei nicht präsent gewesen. Hoppenot räumte dann ein, daß die Japaner Französisch gesprochen und stenographische Notizen gemacht hätten und daß der Text des Interviews im Quai d'Orsay und in Daladiers Büro genehmigt woren sei, allerdings von Beamten ohne Sachkenntnis. Daladier ließ das Interview in Washington und Chungking, aber nicht in Tokio dementieren. Paris beruhigte Chinas Regierung, jede Annäherung an Japan erfolge nur mit Zustimmung Washingtons und Chungkings. Am Tag nach der Veröffentlichung des Interviews gab das Gaimusho bekannt, daß Japan und Frankreich über die Verbesserung ihrer Beziehungen verhandelten ${ }^{77}$.

Sawada warnte Außenminister Arita erneut vor Eile, weil dies Japans Position schwäche. Tatsächlich ruhten die Gespräche zunächst. Die Franzosen in Indochina wunderten sich Mitte März, daß Japan die Yunnanbahn nicht mehr angriff. Am 13. März nahm Sawada das Gespräch mit einem Paukenschlag wieder auf. Er drohte Chauvel, wenn Paris nicht binnen zwei Tagen den Transit von Waffen, Munition, Benzin und Fahrzeugen unterbinde, werde Japans Militär dies »nicht ignorieren können«. Zumindest während der Verhandlungen solle Frankreich den Transit stoppen. Chauvel und Léger antworteten, daß man das Ultimatum nicht sofort befolgen könne, weil die meisten transportierten Güter aus den USA und Großbritannien stammten. Als Sawada am 15. März, als die Frist ablief, eine definitive Antwort verlangte, erklärte Léger, auf eigene Verantwortung werde er die Schließung anordnen ${ }^{78}$.

Chauvel übergab jedoch am folgenden Tag Sawada eine Note, die die vorübergehende Unterbrechung des Transports von Fahrzeugen und Benzin auf der Yunnanbahn daran knüpfte, daß Japan Frankreich in anderen Fragen entgegenkomme. Japan müsse die französischen Rechte in China respektieren

\footnotetext{
${ }^{77}$ Campbell an Halifax, 2.3.1940 (FO 371/24772, F 1538/51/10); Hombeck, Memorandum of Conversation, 2.3.1940 (SD 793.94/15777); Bullitt an Murphy, 2.3., Murphy an Bullitt, 4.3., 9.3., Murphy an Hull, 27.3, 3.4.1940 (SD 751.94/100A, 101, 102, 109, 112); Henry an Daladier, L 70, 6.3; Daladier an Cosme, T 100-1, 12.3.1940 (MAEN Tokyo B 79, Tchongking 7); Changed Temper of Japan. Offers to Britain and France, Japan Times, 5.3.1940 (AA Pol II Po 3 England Bez GB-Japan 3).

${ }^{78}$ Sawada an Arita, 7.3., 13.3., 15.3., Arita an Sawada, 12.3., 13.3., 15.3.1940 (JA, S 1.1.1.0-28, S. 385, S. 388f., S. 393f., S. 386f., S. 391f.); Reed an Hull, 15.3.1940 (SD 793.94/15791).
} 
und sich verpflichten, nicht in Südchina einzugreifen. Auch über die Paracels und Spratlys wolle man sprechen, die Unabhängigkeit und Integrität Chinas seien zu garantieren. Paris führe keine Gespräche ohne Wissen Amerikas und Englands. Auf Nachfrage sagte Chauvel, die Unterbrechung des Transits durch Indochina sei noch nicht befohlen worden, denn Gespräche über den Transit und allgemeine Verhandlungen gehörten zusammen. Sawada könne mit Léger am 18. März sprechen - dem Tag, auf den Arita das erste Ultimatum bereits verlängert hatte. Léger trieb den Preis für eine Einigung hoch. Briten und Amerikaner wurden über die neue Runde der Gespräche nicht informiert. Der US-Marine-Geheimdienst erhielt allerdings Anfang April Kenntnis von den französischen Forderungen, die ja auf der US-Linie lagen ${ }^{79}$.

Am 18. März einigten sich nach Rücksprache mit Daladier Léger und Chauvel mit Sawada und dessen Mitarbeiter Harada auf eine Lösung: Die Franzosen würden den Transport von Fahrzeugen und Benzin auf der Yunnanbahn bis 31. März untersagen, was aber streng geheim bleibe. Sie seien bereit, der Craigie-Arita-Formel vom 24. Juli 1939 zu folgen und das Ergebnis der japanisch-britischen Verhandlungen über die Konzessionen in Tientsin und das dort gelagerte Silber zu übernehmen. Parallel werde in einem weiten Rahmen über die japanisch-französischen Beziehungen gesprochen. Frankreichs Forderungen waren deutlich bescheidener als am 15. März: Paris verlangte nur noch japanischen Respekt für die französischen Rechte in China und seine Einflußsphäre in Südchina. Hinweise auf die Integrität Chinas, die Paracels und Spratlys sowie die Rolle der USA und Großbritanniens fehlten.

Brachte dieses Entgegenkommen des Quai d'Orsay den Durchbruch? Japans Regierung, die ebenso wie der japanische Konsul in Hanoi glaubte, daß Paris die Versorgung Chinas bis Ende März tatsächlich gestoppt hatte, lehnte eine nur vorübergehende Unterbrechung des Transits ab. Der Transitstop sei zwingende Vorbedingung weiterer Gespräche. Mit der Zwischenlösung wolle Paris Zeit bis zum Beginn der Regenzeit gewinnen. Der 18. März war Höhepunkt und gleichzeitig Ende der japanisch-französischen Verhandlungen. Weitere Gespräche lehnte Tokio ab. Damit waren die gegenseitigen Bemühungen um Annäherung gescheitert, auch wenn Henry weiter hoffte, Frankreich könne sich über die Feindschaft zur Sowjetunion Japan annähem ${ }^{80}$.

\footnotetext{
${ }^{79}$ Note de la sous-direction d'Asie-Océanie, 16.3.1940 (MAE Chine 761, auch in JA, S 1.1.1.0-28, S. 402f.); Arita an Sawada, 16.3., Sawada an Arita, 17.3., 18.3.1940 (JA, S 1.1.1.0-28, S. 397f., S. 410, S. 41 If., S. 413); Office of Naval Intelligence, Memorandum, 5.4.1940 (SD 751.94/113).

${ }^{80}$ Sawada an Arita, 18.3., 19.3., 20.3., Französisches Memorandum, 18.3., Arita an Sawada, 19.3., Suzuki an Arita, 13.3.; Streng geheime Aufzeichnung des Gaimusho, Die Verhandlungen über das Waffen-Transportverbot in Indochina [ohne Datum], (JA, S 1.1.1.0-28, S. 414f., S. 417f., S. 419f., S. 431, S. 433, S. 421 f., S. 434f., S. 468; S 1.1.1.0-45, S. 8f.); Henry an Reynaud, T 226-32, 25.3., Grew an Hull, 5.4.1940 (MAEN Londres C 487, SD 793.94/15855).
} 
Selten zuvor in den jahrhundertelangen französisch-japanischen Beziehungen gab es so viele Treffen hochkarätiger Diplomaten beider Länder in so kurzer Zeit wie zwischen Mitte November 1939 und Mitte März 1940. Beide Regierungen wünschten eine Einigung. Die Gespräche scheiterten dennoch, weil Japan nur das Ziel verfolgte, Chiang Kai-shek von der Versorgung über Indochina abzuschneiden und selbst für den Fall, daß Frankreich den Transit unterbrach, keine konkrete Gegenleistung anbot, außer, die bisher respektierten französischen Rechte weiter zu achten. An einem Krieg mit Moskau hatte Tokio kein Interesse. Für die französische Regierung war es unmöglich, die Yunnanbahn für die Exporte nach China zu sperren, weil dies Amerikas Regierung und Öffentlichkeit gegen Frankreich aufgebracht hätte. Daß die Gespräche bei dem guten Willen beider Außenministerien so rasch scheiterten, lag auch an Botschafter Sawada, der in Paris mit Freude empfangen worden war, aber unnachgiebiger auftrat als seine Regierung.

Am 30. März drohte Sawada erneut mit dem Bombardement der Bahn, obwohl Tokio wußte, daß die früheren Angriffe die Kapazität der Bahn stark reduziert hatten. Vergeblich wies Paris auf das gemeinsame Interesse an Gesprächen hin. Ab Anfang April überflog Japans Luftwaffe mehrfach das chinesisch-indochinesische Grenzgebiet, Mitte April warf sie in China Bomben ab. Am 26. und am 30. April wurde die Bahn erneut bombardiert. Der Schaden blieb begrenzt. Paris ließ es bei platonischen Protesten bewenden ${ }^{81}$.

Die Deputiertenkammer hatte unterdessen am 19. März Daladier ihr Mißtrauen erklärt. Paul Reynaud, der Daladier am 21. März als Regierungschef und Außenminister ablöste, ließ nach Beginn des alliierten Norwegenfeldzugs Sawada seinen Wunsch zutragen, die Beziehungen zu Japan zu verbessern und verwies auf die Abhängigkeit beider Länder von den USA. Doch Reynauds isolierter Versuch scheiterte ebenso wie die Bemühungen des Quai d'Orsay, Japan über Handelsgespräche zu Konzessionen zu bewegen. Mit dem jeweils nur um einen Monat verlängerten Handelsvertrag sowie dem stark reduzierten Verkauf von Nickelerz aus Neukaledonien wollte Paris Tokio dazu bringen, keine Waren an die Sowjetunion zu verkaufen, die den Weg nach Deutschland finden könnten ${ }^{82}$. Tokio wartete $a b-$ es hatte die Zeit auf seiner Seite.

\footnotetext{
${ }^{81}$ Reynaud an Henry, T 191-94, 30.3.; Chauvel an Henry, T 304, 1.5.; Fain an Cosme, T 131-35, 7.4.1940 (MAE Japon 129, Chine 949; MAEN Pékin A 312); Grew an Hull, 10.4.1940 (FRUS 1940, IV, S. 314f.); Grew an Hull, 26.4., 2.5., 14.5., Johnson an Hull, 27.4., Reed an Hull, 2.5.1940 (SD 793.94/15877, 15901, 15902, 15842, 15876); Wakassegi an Arita, 20.3., Kita an Suzuki, 17.4., Suzuki an Arita, 19.4., Sawada an Arita, 30.4.1940 (JA, S 1.1.1.0-28, S. 494f, S. 469f., S. 471f., S. 444f.).

${ }_{82}$ Duroselle, L'Abîme, S. 125f.; Bullitt an Hull, 12.4., 3.5.1940 (SD 740.0011 European War 1939/2167, FRUS 1940, IV, S. 320f.); Chauvel an Henry, T 449, 5.5.; Note, visite de M. Sawada, 3.5.1940 (MAE Chine 949, 1069); Sawada an Arita, 27.4., Aufzeichnungen über die Treffen TaniHenry 28.5., 4.6.1940 (JA, S 1.1.1.0-28, S. 438f., S. 125f.; S. 127f.).
} 


\subsection{Indochina und die Konzessionen im europäischen Krieg}

Der Krieg, den Frankreich in Asien gegen Deutschland führte, war ein Wirtschaftskrieg: Paris wollte einerseits den deutschen Handel mit dem asiatischpazifischen Raum kappen, andererseits die Rohstoffe, Arbeitskräfte und Soldaten Indochinas für sich mobilisieren. Vor einer japanischen Bedrohung hatte ja der Hitler-Stalin-Pakt Indochina schlagartig in Sicherheit gebracht.

Gemeinsam patrollierten britische und französische Kriegsschiffe vor den Häfen Japans und Niederländisch-Indiens, in die deutsche Frachter geflüchtet waren. In Japan bauten französische und britische Konsuln ein Informantennetz auf, das deutsche Schiffe beobachtete. Die Forces navales d'ExtrêmeOrient versuchten, deutsche Frachter zwischen Hongkong und Singapur aufzubringen, und eskortierten französische Handelsschiffe bis Djibouti, nachdem das deutsche Taschenschlachtschiff Graf Spee am 15. November 1939 im Indischen Ozean zwei britische Frachter versenkt hatte. Fünf Schiffe gaben die F.N.E.O. nach Europa ab, in Indochina wurden acht Frachter zu Hilfskreuzern aufgerüstet. Indochina blieb ungefährdet. Den Versuch indochinesischer Kommunisten, das Land durch Streiks zu lähmen, hatten die Behörden im Griff ${ }^{83}$.

Wichtiges französisches Ziel war, Berlin und Moskau von Chinas Wolframexporten abzuschneiden. Der Quai d'Orsay und der Groupe uni wollten sich schon 1937 Chinas Wolfram sichern. 50 Prozent der Weltproduktion des kriegswichtigen Erzes entfielen auf China. Im Februar 1938 vereinbarten Minister T.V. Soong und Gustave Moutet für den Groupe uni die Gründung einer gemeinsamen Wolfram-Exportgesellschaft. Das Projekt scheiterte aber ${ }^{84}$. Als Briten und Sowjets im Oktober und November 1939 große Mengen Wolfram kaufen wollten, entsandte der Quai d'Orsay Henri Cosme nach Chungking, um mit Chiang über Wolframkäufe zu sprechen. Vom Erfolg der Gespräche, telegraphierte Paris, hänge Frankreichs Frühjahrsoffensive ab. Daß Finanzminister Kung Berlin, das 70 Prozent seines Wolframs aus China bezog, alle Wolframund Zinnvorräte Chinas gegen Waffenlieferungen angeboten hatte, wußte Paris nicht. In seinen Memoiren schreibt Cosme, daß Chiang den Franzosen entgegenkam und anbot, sie dürften das in Indochina lagernde chinesische Wolfram sofort nutzen. Über den Preis rede man später. Der Quai d'Orsay verlangte jetzt aber, zunächst einen Preis festzulegen. Gleichzeitig konfiszierte

${ }^{83}$ Decoux, À la barre, S. 28; MORDal, Marine Indochine, S. $11 \mathrm{f}$; ELPHICK, Far Eastern File, S. 243f.; WEINBERG, A World at Arms, S. 83; HeSSE D'Alzon, L'armée française d'Indochine, S. 81; Pierre BROCHEUX, "L'occasion favorable 1 1940-1945. Les forces politiques vietnamiennes pendant la Seconde Guerre mondiale, in: BROCHEUX u.a. (Hg.), L'Indochine française, S. 131-175 (S. 134).

${ }^{84}$ Note de la sous-direction d'Asie-Océanie, 22.9.1937 (MAE Chine 707); Hoppenot an Naggiar, L 149, 24.9.1937, Naggiar an Delbos, T 109, 4.2.1938 (MAE Bureau d'études Jean Chauvel 135). 
Generalgouverneur Catroux in Indochina 4000 Tonnen Wolfram und 3000 Tonnen Antimon, um deren Export in die Sowjetunion zu verhindern ${ }^{85}$.

Der Quai d'Orsay strebte einen raschen Abschluß der Kaufgespräche an. Die Ministerien für Rüstung und Blockade wollten jedoch nur den Verkauf des Wolframs an die Sowjetunion verhindern. Das Blockadeministerium zog die Gespräche in die Länge und entsandte im Dezember 1939 zwei Experten nach Chungking. Im Frühjahr 1940 regte Paris an, der Westen solle die gesamte Wolframproduktion aufkaufen, während Chungking die Vorräte an Moskau abgeben wollte. Paris zog die Gespräche in die Länge und nutzte dabei aus, daß China das Erz nur über Indochina exportieren konnte ${ }^{86}$.

Wo große Beträge im Spiel waren, war der Waffenhändler Jean Audinet nicht weit. Im November 1939 hatte Audinet den Chinesen angeboten, gegen die Lieferung von Rohstoffen für 410 Millionen Francs Artilleriematerial und für 190 Millionen Francs Industrieanlagen zu liefern. Schon im August 1939 hatten Audinet und Finanzminister Kung eine entsprechende Absichtserklärung unterzeichnet. Ein Drittel der Summe sollte in Rohstoffen bezahlt werden. Die Chinesen verlangten, daß Audinet zunächst 17 der schon 1937 bestellten Flugzeuge liefere. Der Quai d'Orsay unterstützte Audinets Geschäft, das Frankreich wichtige Rohstoffe verschaffen sowie sowjetische Waffenlieferungen und Einflußnahme begrenzen konnte. Im März 1940 wurde Audinet von Anatole de Monzie, Minister für Travaux publics, beauftragt, mit China über die Lieferung von Wolfram zu verhandeln. Damit sprach nach Cosme und den Gesandten des Rüstungsministeriums der dritte französische Unterhändler mit offiziellem Auftrag mit der chinesischen Regierung. Im Mai erklärte sich Chungking bereit, Frankreich sämtliches Wolfram in Haiphong sowie die Produktion des Metalls der folgenden 42 Monate zu verkaufen, falls Paris den Gesamtwert sofort bezahle - knapp zwei Milliarden Francs! China wolle zudem für 230 Millionen Francs 108 Geschütze mit Munition in Frankreich erwerben ${ }^{87}$. An diesen Forderungen scheiterten die Gespräche.

\footnotetext{
${ }^{85}$ FreYEISEN, Shanghai, S. 40, S. 329; Cosme, Chine 1939-1944, S. 9f; Pernot an Finances, L 2488, 30.11., Catroux an Mandel, T 1843, 10.10 .1939 (CAEF 32.817, CAOM FM Tel 82); Catroux an Mandel, T 2340-41, 28.11., Mandel an Catroux, T 1658, ohne Datum (MAE Indfr 45); Wai Kiao Pu, Note, 12.12., Note Cosme, 30.12.1939 (MAEN Pékin A 291); CHAUVEL, Commentaire, S. 67f.

${ }^{86}$ Diplomatie an Finances, L 276, 31.12.1939, L 91, 11.1., L 268, 28.1.1940; Note, réunion du 5/1 [1940] aux Affaires étrangères (CAEF 32.817); Peck an Hull, 29.1., 5.2.1940 (FRUS 1940, IV, S. 638f.); Corbin an Daladier, T 442, 5.2.1940 (MAEN Londres C 487); Cosme an Daladier, T 99-102, 6.2.; Chauvel an Saint-Quentin, T 277-78, 12.2., Chauvel an Cosme, T 61, 13.2., Crépin an Cosme, L 36, 9.3., Cosme an Daladier, T 205, 12.3.1940 (MAE Chine 783, 853); Conseil supérieur de la défense nationale, résumé, Ref. L 570 SPDN du 8.4.[1940] (SHAT 2 N 63).

${ }^{87}$ Yvon an EMA.2, L 202, 7.11, note de la sous-direction d'Asie-Océanie pour les relations commerciales, 8.12.1939 (MAE Chine 555); Diplomatie an Finances, L 2638, 16.12., Audinet, note, 22.11.1939 (CAEF 32.817); Monzie an Audinet, L 1894, 13.3., Audinet an Bussy, T 289, 9.5.1940 (MAE bureau d'études Chauvel 135); Gandon an Cosme, T 166, 5.5.1940 (MAEN Pékin A 395).
} 
Frankreichs Oberkommando erwartete einen langen Krieg, über den die Mobilisierung der Kolonien entschied. Im Ersten Weltkrieg hatte eine halbe Million Kolonialsoldaten für Frankreich gekämpft. Von ihnen starben 71000 , darunter 1100 Indochinesen. Weitere 200000 Bewohner der Kolonien waren Arbeiter in Europa. 43000 Soldaten und 49000 Arbeiter kamen aus Indochina ${ }^{88}$.

$\mathrm{Da}$ die Regierung in Paris den mythe impérial pflegte, wäre zu erwarten gewesen, daß sie die Unterstützung durch das rohstoff- und bevölkerungsreiche Indochina eingeplant hätte. Allerdings war die Kolonie vor September 1939 in nicht eine Mobilierungsübung einbezogen. Geplant war seit 1936 nur, im Krieg 60000 Arbeiter aus Indochina anzufordern. Noch nach Kriegsausbruch wehrte sich General Gamelin dagegen, Truppen aus den Kolonien einzusetzen, weil er ihre Kampfkraft für gering hielt. Um die Moral in Frankreich zu heben, versprach Mandel Ende September öffentlich, Frankreichs Kolonien könnten zwei Millionen Soldaten und 500000 Arbeiter mobilisieren ${ }^{89}$.

Weil Mandel schon im Sommer 1939 angenommen hatte, daß Indochina in einen möglichen Krieg verwickelt werden würde, entweder direkt oder als Rohstoff- und Rekrutenlieferant für die Metropole, ersetzte er den bisherigen Generalgouverneur Brévié, dem er Formalismus und fehlendes Engagement für die Verteidigung Indochinas vorwarf, durch einen hohen Offizier. Mitte Juli berief Mandel General Georges Catroux. Weil Mandel auch ihm nicht restlos vertraute, wurde Catroux zunächst nur kommissarisch eingesetzt und erst am 20. Mai 1940 von der Regierung zum Generalgouverneur ernannt ${ }^{90}$.

In einer Rundfunkansprache stellte Mandel am 8. November die Stärke der Kolonien heraus, nannte aber kaum konkrete Zahlen. Mandel sagte lediglich, die Kolonien hätten 100 Bataillone gebildet. Er habe angeordnet, $70000 \mathrm{Ar}$ beiter aus Indochina nach Frankreich zu bringen. Ende November reduzierte Mandel vor dem Kolonialausschuß der Kammer die Zahl auf 50000 Arbeiter.

\footnotetext{
${ }^{88}$ AGERON, Les colonies, S. 24; BouCHE, Histoire de la colonisation française, Bd. 2, S. 289f.; DE LA GORCE, L'Empire écartelé, S. 20; MARTIN, L'Empire triomphant, Bd. 2, S. 256f;; MCALISTER, Viet Nam, S. 67; TOINET, Une guerre de trente-cinq ans, S. 17f.; RÉMOND, Frankreich im 20. Jahrhundert, S. 112; Jean DE BAUMONT in: L'Illustration, 27.8.1938, zit. nach Wilson an Hull, 2.9.1938 (SD 851.01/45); HESSE D'Alzon, La présence militaire, S. 15, Fußnote 11; BOUVIER, GIRAULT, THOBIE, L'impérialisme, S. 225; SARRAUT, La mise en valeur, S. 44f.

${ }^{89}$ Marine, note $\mathrm{n}^{\circ} 1179,12.7 .1933$; Circulaire ministerielle, exercise de mobilisation nationale en 1938, 15.12.1937; Circulaire, aménagement des dispositifs de tension extérieure, 25.1.1939 (SHM 1BB2 63); État-major des colonies, $1^{\text {er }}$ bureau, rapport annuel sur l'état d'avancement de la préparation de la défense nationale 1938, 1.2.1939 (CAOM CabMil 2616); Pomaret vor dem Kolonialausschuß, 14.2.1940, Bulletin de commissions, tome IV, $2^{\mathrm{c}}$ partie, Paris 1946; BüHRER, Aux heures tragiques, S. 113f.; PertinaX, Les fossoyeurs, Bd. 1, S. 29; ANDREW, KanYa-Forstner, France Overseas, S. 250; BOUCHE, Histoire de la colonisation française, Bd. 2, S. 350.

${ }^{90}$ Catroux, Deux actes, S. 5, S. 13; Decoux, À la barre, S. 12; MarTn Du Gard, La carte impériale, S. 413; Henri LeRner, Catroux, Paris 1990, S. 132f.; Walsh an Halifax, 28.8.1939 (FO 371/22921, C 13613/249/17); Campbell an Halifax, 21.5.1940 (FO 371/24319, C 2423/166/17).
} 
Mangels Winterkleidung und Schiffsraum sowie wegen Krankheiten sank die Zahl weiter: Am 1. März, so Philippe Richer, waren erst 6000 Arbeiter aus Indochina in Frankreich angekommen. Anfang Mai 1940 erklärte Arbeitsminister Pomaret den Briten, 18000 Arbeiter aus Indochina seien eingetroffen ${ }^{91}$.

Die Mobilisierung von Soldaten scheiterte ebenfalls. Gamelin plante auf Druck Mandels und Bührers ab Herbst 1939 Verbände der Kolonien ein. Die Armee in Indochina bereitete zwei Divisionen für die Entsendung nach Syrien und in die Metropole vor. Ende November 1939 sagte Mandel dem Kolonialausschuß der Kammer, in den Kolonien stünden 470000 Mann bereit. Bis Juli 1940 würden 300000 Mann, davon 85000 aus Indochina, in die Metropole verlegt und 500000 weitere Mann ausgehoben. Ende Dezember berichtete Mandel dem Ausschuß, bis Juni 1940 kämen aus den Kolonien 130000 Soldaten. Im April 1940 erklärte Mandel wieder, 600000 Soldaten stünden in den Kolonien bereit, die Aufstockung auf zwei Millionen sei möglich. Einer Aufstellung des Kolonialministeriums zufolge warteten in Übersee 249000 Mann, davon 45000 europäische Reservisten. Nach Frankreich entsandt wurde noch weniger: Marc Michel schreibt, bis März 1940 seien 89000 oder 110000 Soldaten aus den Kolonien nach Europa verlegt worden, darunter 10000 Mann aus Indochina. Philippe Franchini zufolge kamen 8000 Kämpfer aus Indochina. Nach Zahlen, die die USA in Indochina erhielten, waren 7000 Reservisten nach Europa verschifft worden. In seinen Memoiren beklagt Catroux, indochinesische Kräfte seien nicht an der französischen Front eingesetzt worden. Paul-Marie de la Gorce errechnet, daß sich am 1. Mai 1940 in Frankreich 46000 Mann Kolonialtruppen aufhielten. Das Kolonialministerium nahm im April 1940 an, daß 40000 Mann aus Übersee nach Frankreich verlegt worden waren - wo bereits 4,9 Millionen Franzosen unter Waffen standen! Noch im April klagte General Georges vom Generalstab über die geringe Kampfkraft der Truppen aus den Kolonien. Diese Soldaten in reguläre Verbände aufzunehmen, solle nur Mandels und Bührers réclame personelle dienen ${ }^{92}$.

\footnotetext{
${ }^{91}$ Georges MANDEL, The French Colonial Contribution since the Beginning of the War, in: Asiatic Review [London], Januar 1940, S. 94-97; Mandel im Kolonialausschuß der Kammer, 28.11.1939, Pomaret im Kolonialausschuß der Kammer, 15.2.1940, bulletin de commissions, tome IV, $2^{e}$ partie, Paris 1946; Catroux an Mandel, T 1690, 26.9., T 16.10.1939 (CAOM FM Tel 82); RichER, La drôle de guerre, S. 194; Dossier by the French Minister of Labour, 7.5.1940 (FO 371/24295, C 6590/8/17).

${ }_{92}$ Mandel im Kolonialausschuß der Kammer, 28.11.1939, bulletin de commissions, tome IV, $2^{\mathrm{e}}$ partie, Paris 1946; THOMAS, The French Empire, S. 45; AGERON, La perception de la puissance française, S. 19; BARdoux, Journal, S. 162; BüHRER, Aux heures tragiques, S. 109; RoQUES, DONNA-DIEU, L'Empire, S. 157; MiCHEL, La puissance par l'empire, S. 38; FRANCHINI, Les guerres d'Indochine, Bd. 1, S. 151; General Bond, notes on a liaison visit to French Indochina, 5.-20.12.1939 (WO 106/5455); CATROUX, Deux actes, S. 24; DE LA GoRCE, L'Empire écartelé, S. 494; Défense nationale, résumé, réf. L 570 SPDN du 8.4.1940 (SHAT 2 N 63); VILlelume, Journal, S. 283; Pierre MONTAGNON, La grande histoire de la Seconde Guerre mondiale, Paris 1992, Bd. 1, S. 124.
} 
Auch Indochinas Wirtschaftsressourcen wurden kaum genutzt: Bei Kriegsausbruch wurde Catroux beauftragt, große Mengen Reis, Mais, Kautschuk, Kaffee und Tee zu liefern. Catroux befolgte die Anweisung. Doch weil Frankreichs Regierung nicht über genug Schiffsraum verfügte und den von Catroux mit Reedern ausgehandelten Transportpreis nicht zahlte, verkaufte der Generalgouverneur die 200000 Tonnen Lebensmittel an chinesische Händler. Paris kaufte den Reis nun in Äpypten. Im Dezember 1939 lieferte Indochina 350 Tonnen Reis an Frankreich - ein Jahr zuvor waren es noch 13200 Tonnen gewesen. Der Anteil der Exporte, den Indochina nach Frankreich absetzte, sank von 60 Prozent auf 15 Prozent im Januar/Februar 1940. Dafür nahm Japan ein Drittel der Exporte Indochinas ab, darunter viel Reis ${ }^{93}$. Die Vernachlässigung der Kolonie bei der Führung des Wirtschaftskrieges führte dazu, daß sich Indochina Anfang 1940 in Japans wirtschaftlichen Orbit hineinbewegte.

So wenig Paris Indochina nutzte, um seine Position in Europa zu verbessern, so wenig nutzte es seine Konzessionen, um den Deutschen in Asien zu schaden. Daß Deutschland gegen Frankreich und Großbritannien Krieg führte, in den am 11. Juni 1940 Italien eintrat, spürte man in Shanghai kaum. Schon vor dem Kriegsausbruch waren die Beziehungen zwischen Bürgern, Militärs und Diplomaten der europäischen Mächte und der USA in China von einer auf der gleichen Rassenzugehörigkeit beruhenden Solidarität getragen. Das Denken, daß die »weißen Mächte« in China gemeinsam Japan gegenüberständen, verbreitete im Sommer 1938 selbst ein Aufsatz in »Politique étrangère ${ }^{94}$.

Die Verbundenheit der "Weißen « schloß bis in die dreißiger Jahre Japan ein. Als Tokio China angriff, richtete sich das Gemeinschaftsgefühl der Europäer auch gegen die Japaner. Die Deutschen blieben 1939 und 1940 in die Solidarität einbezogen, denn Japan ging gegen den deutschen Handel genauso vor wie gegen den anderer Nationen. Deutschlands Verkäufe in Nordchina sanken von 1937 bis 1939 um zwei Drittel. In Tientsin erzählte man sich 1938 von dem betrunkenen japanischen Soldaten, der einem deutschen Geschäfts-mann sagte, Deutschland und Japan seien Freunde - deshalb würden die Deut-schen als Letzte aus China hinausgeworfen. Im Februar 1940 warnte der deut-sche Generalkonsul in Shanghai vor Japans Dominanz in China: Durch eine Allianz mit Japan liefere Berlin »selbst den Strick [...], der unseren Handel hier ebenso wie den der anderen Ausländer [...] erdrosselt«. Der deutsche China-

\footnotetext{
${ }^{93}$ Catroux, Deux actes, S. 24f.; BardouX, Joumal, S. 160f.; Queuille, Journal, S. 107f., S. 256; Lerner, Catroux, S. 134; NGUYEN, Histoire, S. 176; ButTINGER, Vietnam, Bd. 1, S. 232f.; Roth, Japan Strikes South, S. 40f.

${ }_{94}^{94}$ René LA BRUYĖRE, Bases navales et bases d'hydravions dans le Pacifique, in: Politique étrangère 3 (Juni 1938), S. 250-265 (S. 250, S. 263); Wie wichtig diese Gemeinsamkeit war, zeigte sich auch 1939 in einer Kontroverse zwischen "Le Temps« und der NS-Presse über die Frage, wer die Solidarität des Weißen Mannes in Asien zerstört habe (SOMMER, Deutschland und Japan, S. 263).
} 
Handel ließ Frankreichs Geschäftsträger in Berlin noch am 1. August 1939 vermuten, Deutschland habe kein Interesse an einem dominierenden Japan ${ }^{95}$.

Die deutsche und die italienische Regierung unterstützen die Regierung in Tokio. Doch die deutschen und italienischen Konsularbeamten und Militärs in China schlugen sich nicht auf die Seite des japanischen Militärs, sondern heimlich auf die ihrer europäischen Kollegen. Der französische Oberkommandierende Casseville lobte während der Blockade Tientsins die stets korrekte Haltung des deutschen Generalkonsuls Stoller. Dieser helfe englischen, amerikanischen und französischen Kollegen, so oft er könne. Ihrerseits behandelten die französischen Behörden die Deutschen und Italiener mit Respekt.

Einige für die Asienpolitik verantwortliche Franzosen waren überzeugt, daß erst die Aufstachelung durch Berlin Tokio dazu brachte, französischen Interessen zu schaden: Der Marine-Geheimdienst in Shanghai äußerte, Deutschland habe Japan zu einer antifranzösischen Kampagne geraten. Naggiar glaubte, Berlin wolle Japan gegen den Westen aufbringen. Frankreichs Luftwaffenattaché nahm an, daß Berlin hinter einer japanischen Pressekampagne gegen Paris stand. Henry meldete, die Deutschen stachelten Japan zum Vorgehen gegen Indochina auf. Das Gerücht, daß Japan die Tientsin-Krise auf deutsche Veranlassung provoziert habe, verbreitete Corbin. Léger hielt eine Information Cosmes, Japan wolle auf deutschen Druck alle Konzessionen einer Blockade unterwerfen, für glaubhaft. Corbin, der französische Armee-Geheimdienst, wie auch Kreise in London, waren sicher, daß Japan die Demokratien auf deutsche Veranlassung herausfordere. Daladier, die Diplomaten René Massigli und Ernest Lagarde sowie Teile der Presse gingen zeitweise von einem abgesprochenen Vorgehen Deutschlands, Italiens und Japans aus, um den Westen unter Druck zu setzen. Delbos und Bonnet, so ihre Aussagen vor dem Auswärtigen Ausschuß der Kammer, glaubten nicht an gemeinsame Pläne der deutschen und der japanischen Regierung. Allerdings sähen Berlin und Tokio Aggressionen des Partners als Gelegenheit zu eigener Expansion ${ }^{96}$.

\footnotetext{
${ }^{95}$ KIRBY, Germany and Republican China, S. 243, S. 241; JONES, Japan's New Order, S. 92f.; Boissezon an Cosme, L 211, 25.5.1939 (MAE Chine 887); Henry an Bonnet, T 493-99, 11.9 .1938 (DDF XI, 85); Bracklo an Ribbentrop, 29.10.1938, Fischer an Ribbentrop, 21.2.1940 (AA Pol VIII 58 A 2, A 3); Saint-Hardouin an Bonnet, D 663, 1.8.1939 (DDF XVII, 383).

${ }_{96}$ Casseville an Bührer, L 82, 21.6., EMA.2, Note, 31.7.1939 (SHAT 11 H 63, 7 N 2524); STS-Bulletin, 1.6., 1.7.; Naggiar an Bonnet, T 1119-22, 8.8.; La Ferté Sénectère, rapport, 4.8.1938 (MAE Chine 533, 726, 565); Corbin an Bonnet, T 1870-71, 16.6., T 2119, 6.7.1939 (DDF XVI, 448; MAE Chine 1067); Henry an Bonnet, T 136-39, 6.3.; T 450-53, 4.8.; Léger an Corbin, T 1355, 3.7.1939 (DDF XIV, 265; MAE Chine 1068, 755); Maisky an Molotow, 26.6.1939 (SPE II, 347); Compte rendu de la liason hebdomaire, 2.7.1938 (DDF X, 135); Bullitt an Hull, 11.2., 11.4., 10.3.1939 (FRUS 1939, III, S. 104, SD 740.00/772, 614); Ausschußsitzungen 18.11.1937 und 21.6.1939, in: Archives de l'Assemblée nationale. $16^{\mathrm{e}}$ législature. Annexes des procès-verbaux et autres documents officiels. Procès-verbaux de la Commission des affaires étrangères, $n^{\circ} 6$ (1937), $n^{\circ} 8$ (1939/49).
} 
Der Generalstab nahm zur Jahreswende 1938/39 an, daß Tokio und Berlin ihre Aktionen so präzise abstimmten, daß man eine bevorstehende deutsche Aggression in Europa am Verhalten der Truppen Japans in der Mandschurei erkennen könne. Im Juli $1939 \mathrm{kam}$ die Armee zu dem wohl zutreffenderen Schluß, Japan nehme sich Aggressoren in Europa lediglich zum Vorbild ${ }^{97}$.

Womöglich, so fürchteten einige Franzosen in Asien, würden die Deutschen sogar selbst aktiv, um Frankreich zu schaden. Der französische Generalkonsul in Kalkutta und der französische Luftwaffenattaché in Shanghai trauten im Sommer 1939 den Deutschen zu, französische Kriegsschiffe in Asien zu sabotieren und mit Wasserflugzeugen Indochina anzugreifen. Der Jurist René Cassin hatte ähnliche Befürchtungen. Die Sorge, daß sich Berlin mit vietnamesischen Nationalisten verbünden könnte, taucht hingegen in französischen Akten nicht auf, obwohl die Deutschen im Ersten Weltkrieg Unruhen in Laos geschürt hatten. Tatsächlich baten annamitische Nationalisten 1938 und 1939 mehrfach deutsche Diplomaten in China, das Auswärtige Amt und die Gestapo um Hilfe gegen Paris. »Aus allgemein politischen, wie aus [...] besonderen Gründen«, wie das Auswärtige Amt im Dezember 1938 seinem Generalkonsul in Hongkong schrieb, erhielten die vietnamesischen Revolutionäre jedoch keine Unterstützung ${ }^{98}$. Berlin traute den Studenten offenbar nicht.

Obwohl der deutschen Regierung also zugetraut wurde, die französische Position im Fernen Osten mit Rat und Tat zu unterminieren, verhielten sich Frankreichs Vertreter in China gegenüber den Repräsentanten des Deutschen Reiches dort nicht feindselig. Diese wohlwollende Haltung behielten die Franzosen nach dem 3. September 1939 bei.

Schon während der Sudetenkrise 1938 hatte Naggiar dem deutschen Konsularbeamten Bracklo versichert, bei einem Kriegsausbruch dürften die Deutschen in der französischen Konzession wohnen bleiben. Im September 1939 erklärten die französischen Behörden deutschen Diplomaten, sie wollten Zwischenfälle vermeiden. Die Deutschen würden behandelt wie bisher, wenn sie keine antifranzösischen Aktivitäten unternähmen. Die Europäer hielten einen Burgfrieden. In Tientsin duldeten die französischen Behörden das Aufziehen deutscher Flaggen ebenso wie die Briten in Shanghai. Die Anweisung aus Paris, den Handel mit dem Feind zu stoppen, unterband zwar fast sämtliche Exporte aus Shanghai nach Deutschland, blieb in der Stadt aber folgenlos.

\footnotetext{
${ }^{97}$ EMG.2 an Diplomatie, L 3415, 30.12.1938 (MAE Japon 148); EMG.2, bulletin de renseignement $\mathrm{n}^{\circ} 47,6.7 .1939$ (SHM 1BB2 92).

${ }^{98}$ Generalkonsul Kalkutta an Bonnet, L 64, 28.6.; La Ferté Senectère an EMAA.2, L 215, 8.2.1939 (MAE Ac 74, Chine 104); René Cassin, Note, 13.7.1939 (DDF XVII, 197); TONNET, Une guerre de trente-cinq ans, S. 17; HÉDUY, La perle de l'empire, S. 403; Generalkonsul Hongkong an Berlin, 3.10., Strachwitz (Berlin) an Hongkong, 2.12.1938; Geheime Staatspolizei an Auswärtiges Amt, 9.2.1939 (AA Pol VIII 60, 2).
} 
Natürlich gab es Gerüchte, etwa die, die Deutschen hätten in Shanghai ein Spionagezentrum eingerichtet oder sie planten einen Handstreich gegen die Konzessionen in Kanton und Shanghai. Die unklare Loyalität der deutschen jüdischen Flüchtlinge bereitete der französischen Polizei Sorgen, obwohl sich bei Kriegsausbruch 260 von ihnen zu den französischen Waffen meldeten.

Die Deutschen wurden nicht behelligt. Bis Mitte Juni 1940 waren lediglich fünf Reichsangehörige der Konzession verwiesen worden. Die Franzosen hatten nicht einmal verhindert, daß 30 deutsche Reservisten über die Transsibirische Eisenbahn nach Europa reisten. Aus Hanoi und Hongkong kamen sogar einige Dutzend Deutsche neu nach Shanghai - um unter Frankreichs Flagge Schutz zu finden. Der Quai d'Orsay erwog im April 1940, gegen die Deutschen in den Konzessionen vorzugehen, verwarf dies dann aber ${ }^{99}$. Großzügig zeigte sich Paris auch bei der Behandlung deutscher Lieferungen an China: Nach Kriegsausbruch konnten 5000 Tonnen Waren, die zumeist für Chinas Militär bestimmt waren, über Indochina nach China gelangen, als China bescheinigte, daß es die Waren vor dem 3. September bezahlt hatte ${ }^{100}$.

Ähnlich widersprüchlich wie zu den Deutschen war das Verhältnis der französischen Behörden zu den Italienern in China: Das französische Militär befürchtete schon 1937 und 1938, Italien kooperiere in der Spionage mit Japan und erkunde für Tokio Indochinas Küste. Italienische Schiffe wurden deshalb genau beobachtet. Der französische Gesandte in Bangkok war überzeugt, Rom leite die antifranzösische Propaganda in Japan. Henry nahm an, daß Italien in Japan eine Kampagne zur Besetzung Hainans geführt habe. In Shanghai waren Prügeleien zwischen italienischen Matrosen und französischen Polizisten fast an der Tagesordnung. Französische und italienische Offiziere unterhielten dagegen korrekte Beziehungen: An französischen und internationalen Truppenschauen in Tient-sin und Shanghai nahmen die Italiener bis in den April 1940 teil. Nur zu eige-nen Paraden luden die Italiener seit 1938 nicht mehr ein, um gegenüber der japanischen Armee nicht als allzu solidarisch mit den Briten, Amerikanern und Franzosen zu erscheinen. 1938 begannen sie auch, statt mit dem Westen des Endes des Ersten Weltkriegs zu gedenken, allein den Marsch auf Rom zu feiern. Mindestens bis Ende 1938 tauschten die Offiziere der französischen, britischen, amerikanischen und italienischen

99 Bracklo an Ribbentrop, 4.10.1938, Fischer an Ribbentrop, 26.9.1939; Stoller an Ribbentrop, 6.10.1940 (AA Pol VIII 58 A 2, A 3, Botsch Peking Pol 5-12); WASSERSTEIN, Secret War, S. 49f; FREYEISEN, Shanghai, S. 479; Colin, note, 4.9., EMA.2, compte rendu, 23.9.1939 (SHAT 11 H 79, 7 N 2516); Baudez an Bonnet, T 67, 7.9., Beauvais an Baudez, T I L, 16.9.1939; Marine an Diplomatie, L, 25.5., Augé an Reynaud, L 35, 21.3.; Note de la sous-direction d'Asie-Océanie, 12.4.1940 (MAE Chine 806, 1069, 1064, 949); Butrick an Hull, 11.6., 12.6.1940 (FRUS 1940, IV, S. 742f.).

${ }^{100}$ Conseiller commercial en Chine, note, 6.11.1939, Cosme an Shanghai, T 31-34, 18.1.1940 (MAEN Pékin A 395); Diplomatie an Colonies, L 1218, 2.12., L 69, 22.1.1940 (MAE Indfr 45). 
Kontingente in Tientsin aber einmal wöchentlich Informationen über den Kriegsverlauf aus ${ }^{101}$. Auch auf konsularischer Ebene waren die französischitalienischen Beziehungen widersprüchlich: Italiens Botschafter Taliani pflegte Beziehungen zu den Marionettenregimes. Generalkonsul Steffanelli in Tientsin offenbarte aber seinem französischen Kollegen Italiens Pläne in der Stadt und versuchte, sie zu vereiteln ${ }^{102}$. Im September 1939 änderte sich die Lage kaum. Die französische Marine ordnete an, italienische Soldaten höflich zu behandeln. Mitte Mai und Anfang Juni 1940 erklärten die italienischen Kommandeure in Shanghai und Tientsin ihren französischen und britischen Kollegen, sie wollten selbst bei einer Kriegserklärung Italiens Spannungen unterbinden. Im Frühsommer 1940 waren die Beziehungen zwischen den europäischen Verbänden sehr gelöst ${ }^{103}$.

$\mathrm{Da} ß$ die französische Regierung den Krieg gegen Deutschland in Ostasien nur begrenzt führte, hat zwei Ursachen: Sie wollte das auch für Frankreichs Prestige schädliche Bild, wie Weiße sich vor der Augen der Kolonisierten bekriegten, vermeiden. Das zweite Motivbündel belegt, wie sehr Frankreich eben doch eine nur europäische Macht war: Die französische Militärführung war vor und während des Krieges viel zu sehr mit Europa beschäftigt, und Frankreichs Kräfte in Ostasien waren zu schwach, als daß Paris dort ernsthaft aktiv werden konnte. $\mathrm{Da} \beta$ in Indochina die Mobilisierung der Ressourcen Nahrungsmittel, Rohstoffe und Menschen scheiterte, lag daran, daß sie weder vor noch während des Krieges ernsthaft betrieben wurde, offenbar, weil Paris daran zweifelte, daß es die Verbindung nach Ostasien würde aufrechterhalten können. Hilfe aus Indochina einzuplanen, wäre leichtsinnig gewesen. General Gamelin dachte nicht nur nicht in imperialen Dimensionen, sondern er schätzte Frankreichs Kräfte auch realistisch ein. Indochina nicht in die französische Kriegswirtschaft einzubinden, riskierte allerdings, daß sich die Kolonie wirtschaftlich an einer anderen Großmacht orientierte: Japan.

${ }^{101}$ Martin an EMA.2, L 237, 25.3.1938 (SHAT 10 H 75); FNEO, compte rendu, 29.3.1939; Militär Shanghai an Marine Saigon, T 748, 7.12 .1938 (SHM 1 BB4 74, BB9 141); Lépissier (Bangkok) an Bonnet, T 97, 10.8.; Lépissier (Tientsin) an Bonnet, L 74, 5.11., STS-bulletin, 1.4.1938 (MAE Japon 127, Chine 830, 533); Henry an Bonnet, T 136-39, 6.3.1939 (DDF XIV, 265); Garnsion de Tientsin Ville, Note, 21.10.1938; Note du détachement français de Changhai, $\mathrm{n}^{\circ}$ 77, [März/April] 1939; Kommandant Battaglione Italiano en Cina an Casseville, 10.5., 17.6.1939; FTFC, État-major note, $\mathrm{n}^{\circ}$ 746, 9.4.1940 (SHAT 11 H 61, 63). Protokolle der wöchentlichen Treffen in SHAT 11 H 61.

${ }^{102}$ Lépissier an Bonnet, L 76, 14.11., Naggiar an Bonnet, T 1797-98, 23.11.1938; STS-bulletin, 22.1., Knobel an Bonnet, T 233-34, 20.2., Clark Kerr an Halifax, 24.2.1939 (MAE Chine 771, 830, 772; DBFP, $3^{\text {th }}$ series, VIII, 503); Taliani an Ciano, 28.6., Appunto, 3.7.1939 (DDI Ser. 8, XII, 381-82, 339).

${ }^{103}$ EMG.3 an alle Schiffe, T 6041, 26.8.1939 (SHM 1 BB9 271); Fletcher (Tientsin) an Hull, 17.5.1940 (SD 893.0146/773); Corbin an Bonnet, T 2439, 8.6.1940 (MAEN Londres C 482); Commander Shanghai an War Office, 16.5.1940 (FO 371/24654, F 3025/15/10). 


\subsection{Beruhigung der Krisen um Thailand, Tientsin und Shanghai}

Mit Abschluß des Hitler-Stalins-Paktes und der Isolierung Japans entspannte sich die Lage an der Grenze zu Thailand. Die Regierung in Bangkok bemühte sich auffallend um Frankreichs Wohlwollen.

Am 1. September erklärte Thailands Vize-Kriegsminister, ihn beunruhigten die Militäraktivitäten in Indochina. Er deutete dem Gesandten Paul Lépissier an, seine Regierung strebe einen Nichtangriffspakt mit Paris an. Mit der Kriegserklärung an Berlin hätten London und Paris Entschlossenheit gezeigt; dies verbessere ihre Position in Thailand. Bangkok fürchte Frankreichs Macht, meldeten Lépissier und Militärattaché Pichon. Zwar gab es erneut Gerüchte über die Präsenz japanischer Soldaten an der indochinesisch-thailändischen Grenze, doch daß Bangkok Japans Militärattaché wegen »revolutionärer Aktivitäten« auswies, zeigte, daß Regierungschef Pibul den Westen nun im Vorteil sah. London und Paris erklärten, sie respektierten die thailändische Neutralität. Von einem Nichtangriffspakt war zunächst nicht mehr die Rede ${ }^{104}$.

Am 26. oder 27. September schlug Premierminister Luang Pibul dem britischen Gesandten Crosby öffiziös vor, mit London und Paris einen Nichtangriffspakt abzuschließen. Darin sah Lépissier eine wirksame Bestätigung der Grenzen, Léger blieb aber skeptisch, denn ihm war nicht klar, was die Thais bezweckten. Werde der Vorschlag aber offiziell unterbreitet, so Léger, stimme man zu. Pibul sagte Crosby am 14. Oktober, da Sowjets und Deutsche den Begriff des Nichtangriffspakts diskreditiert hätten, verfolge er die Idee nicht länger. Großbritanniens und Frankreichs Neutralitätserklärung seien für Thailands Sicherheit ausreichend. Dann änderte Pibul seine Meinung: Er bat Lépissier am 19. Oktober, Vorschläge für einen Pakt vorzulegen, acht Tage später regte Pibul Gespräche darüber an. Auch über eine Verlegung der Grenze im Mekong solle gesprochen werden. Statt wie bisher in dem Flußarm, der Thailand am nächsten lag, solle die Grenze stets durch die tiefste Stelle des Flusses (»Thalweg-Prinzip«) gehen, wie dies international üblich war. Einige Inseln im Mekong würden dann an Thailand fallen. Dies sei die einzige territoriale Forderung, die Bangkok habe. Daß Pibul beide Fragen verband, machte Lépisssier Paris nicht deutlich. Schon beim ersten Vorschlag eines Paktes Ende September hatte Pibul die Grenzverschiebung angesprochen, doch

${ }^{104}$ Lépissier an Bonnet, T 149, 1.9., T 159-60, 12.9., Léger an Lépissier, T 118, 9.9., Corbin an Daladier, T 3224-25, 18.9., Chauvel an Lépissier, T 128, 19.9., T 137, 24.9., Lépissier an Daladier, $T$ 164, 18.9., T 168-69, 23.9.; L 414, 14.9., Lépissier an Bonnet, T 154, 7.9., Lépissier an Catroux, L 640, 8.9., L 655, 21.9., Léger an Lépissier, T 123, 16.9 .1939 (MAE Siam 84, 80); Pichon an EMG.2, compte rendu, 2.9., 8.9., 16.9.1939 (SHM 1 BB2 257); REYNOLDS, Anomaly or Model, S. $245 f$. 
Lépissier, der den Pakt unterstützte, verschwieg dies dem Quai d'Orsay. Der Gesandte vertraute seinem britischen Kollegen an, daß er die Grenzkorrektur für richtig hielt. Lépissier bat um britische diplomatische Hilfe, weil die Verwaltung in Indochina Widerstand leisten werde. Um in Paris das Klima für Bangkoks Wünsche zu verbessern, spielte Lépissier auch den Umfang der japanisch-thailändischen Kooperation herunter. Pibus Bemühungen um Frankreichs Freundschaft belegte Lépissier mit dem Hinweis, der Regierungschef habe angewiesen, von einem Messestand der Armee eine Karte zu entfernen, die die alten Grenzen zeigte. Gleichzeitig berichtete Militärattaché Pichon aber von territorialen Forderungen der Öffentlichkeit. Das Kolonialministerium in Paris nannte Thailand eine Gefahr, die man scharf beobachten müsse ${ }^{105}$.

Mandel und Léger waren sich einig: Schon die kleinste Konzession an Thailand könne territoriale Forderungen wiederbeleben, zumal Bangkok schon früher Ansprüche auf die Mekong-Inseln erhoben habe. Es gebe keinen Grund, sich eine territoriale Garantie durch Gebietsabtretungen zu erkaufen. Auch von London, das Ende Oktober 1939 vorsichtig auf Zugeständnisse drängte, ließ sich Paris nicht überzeugen ${ }^{106}$. Um Siam zu schwächen, kam Paris ein Konflikt zwischen China und Siam um das Vorgehen thailändischer Behörden gegen die chinesische Minderheit gerade recht. Von Oktober bis Dezember 1939 wurden hunderte Chinesen festgenommen, einzelne wurden ermordet. Bangkok ging gegen chinesische Schulen, Zeitungen und Banken vor und beschlagnahmte Geld, das Chinesen für Chiang Kai-shek gesammelt hatten. Während sich die Briten dem Streit fernhielten, forderte Lépissier auf Anweisung aus Paris die Regierung mehrfach zur Zurückhaltung auf ${ }^{107}$.

Léger und Mandel erklärten London Anfang November 1939, daß die Briten der Verlauf der thailändisch-indochinesischen Grenze nichts angehe. Grenzveränderungen seien ausgeschlossen. Lépissier warnte jedoch, Thailand könne sich Japan zuwenden, mit dem es ebenfalls über einen Nichtangriffspakt sprach. Nicht Gebietsgewinne, sondern nur die Gleichberechtigung strebe

${ }^{105}$ Crosby an Halifax, 27.9., 20.10.1939 (FO 371/23596, F 11648, 11460/1860/40); Campbell an Charvériat, L, 27.9., Léger an Lépissier, T 141, 28.9., T 162-63, 22.10., Léger an Campbell, L, 2.10., Lépissier an Daladier, T 179, 3.10., T 184-85, 14.10., T 187-88, 18.10., T 193-94, 19.10., T 204-5, 27.10.; T 214-15, 4.11., T 225, 13.11., L 550, 11.11., L 612, 15.12., Catroux an Mandel, T 2157-58, 13.11.1939 (MAE Siam 84, 81); Pichon an EMG.2, Note No. 41/D, 14.12.; État-major des Colonies, $5^{\mathrm{e}}$ bureau, synthèse de renseignements, 31.12.1939 (SHM 1 BB2 257, MAE Indfr 52).

${ }^{106}$ Léger an Corbin, T 2741, 26.10., T 2776, T 2788-89, 29.10., note du ministère des Colonies, 27.10., Corbin an Daladier, T 3807, 28.10., T 3846, 1.11., notes de la sous-direction d'Asie-Océanie, Déclaration Salisbury-Courcel, 1.11., La revendication siamois, 1.11., l'idée d'un pacte de non-agression, 2.11.1939 (MAE Siam 84); Corbin an Halifax, L, 1.11.1939 (FO 371/23596, F 11483/1860/40).

${ }^{107}$ Lépissier an Daladier, L 445, 27.9., T 199-200, 25.10., Cosme an Daladier, T 4823, 20.10., Léger an Lépissier, T 161, 22.10., Corbin an Daladier, L 766, 30.10.; Cambon an Daladier, L 817, 18.11., Lépissier an Daladier, T 242, 29.11., T 257-57, 14.12., L 612, 15.12.1939 (MAE Siam 80, 81). 
Bangkok an. Als Thailands Regierung auf eine Anfrage Légers erklärte, die Fragen des Paktes und der Grenzkorrektur seien nicht miteinander verbunden, doch der Pakt werde ohne veränderte Grenzen nicht vom Parlament ratifiziert werden, fror Léger Mitte November die Verhandlungen ein $^{108}$. Vorsichtig wies London Paris auf die Nachteile hin, die der Westen durch den Gesprächsabbruch habe. Intern klagte Sir Josiah Crosby am 15. November, sthe continuance of the old French attitude of harshness and unappeasement towards the Thais is nothing short of suicidal«. Drei Tage später nannte Henniker-Major im Foreign Office die französische Politik in der Grenzfrage wvery near to being ridiculous«. Lépissier, der wegen der Härte seiner Regierung schon um seine Abberufung bitten wollte, versuchte, mit persönlichen Briefen Daladier, Léger, Mandel und Hoppenot zu überzeugen. Unterstützung bei dem Wunsch nach Grenzrevision erhielt Lépissier von Catroux, der ihn aber warnte, daß Bührer und die Banque de l'Indochine Lépissier für zu nachgiebig hielten und in Paris Widerstand leisteten. Lépissier hatte nicht nur in Paris Gegner. VizeAdmiral Decoux warf ihm vor, er habe nur aus Eitelkeit die Verhandlungen vorangetrieben. Der Militär-Geheimdienst in Hanoi hielt Lépissier Unkenntnis des Fernen Ostens vor:

Depuis quelque temps notre Légation à Bangkok s'est engagé dans une politique de faiblesse et des concessions. Cette politique nuit réellement à notre prestige et il faut vraiment ne pas connaître les Asiatiques pour croire qu'elle puisse jamais nous procurer un avantage quelconque. [...] Il faut se méfier de notre Légation à Bangkok qui sans doute ne présente pas la Thailande sous son vrai jour ${ }^{109}$.

Ende Januar 1940 kam der Quai d'Orsay zu dem Schluß, daß Frankreich die Verhandlungen mit Siam über den Nichtangriffspakt wiederaufnehmen müsse. Die Briten hatten schon Ende Dezember 1939 auf Druck aus Birma, Malaysia und Australien der thailändischen Regierung einen Entwurf vorgelegt. Mandel war mit der Wiederaufnahme der Gespräche einverstanden, wenn es keine offizielle Verbindung zwischen dem Nichtangriffspakt und der Grenzkorrektur gebe. Die Neuziehung der Grenze müsse zudem auf protokollarisch niedrigem Niveau durch die örtlichen Verwaltungen erfolgen. Als Lépissier und London Paris zur Eile drängten, weil man Thailand nicht in Japans Arme treiben wollte, forderte Anfang März auch Mandel eine rasche Lösung. Experten aus Paris sollten die neue Grenze mit thailändischen Fachleuten klären. Bangkok war

${ }^{108}$ Mandel an Diplomatie, L 1714, 8.11., Léger an Lépissier, 15.11., T 186-87, 17.11., Lépissier an Daladier, T 219-21, 10.11., T 229-31, 15.11., T 240, 25.11., T 249-50, 5.12.1939; T 6-7, 11.1.1940 (MAE Siam 84, 85); Campbell an Halifax, 16.11.1939 (FO 371/23596, F 12001/1860/40).

${ }^{109}$ Campbell an Halifax, 12.11., Crosby an Halifax, 3.11., 15.11., 18.11., Note Henniker-Major, 4.12., Halifax an Crosby, 10.11., 24.11.1939 (FO 371/23596, F 11808, 11516, 11808, 12204, 12321, 12641, 11516, 12001/1860/40); DECoUX, À la barre, S. 130; Ministère des Colonies, note, 1.4., SEH, note, 21.3.1940 (MAE Siam 81); DECOUX zufolge lehnte Catroux den Vertrag ab (À la barre, S. 131). 
mit der Verwaltungslösung einverstanden. Ende März waren Bangkok, Paris und London grundsätzlich einig. Der Nichtangriffspakt enthielt die Verpflichtung zum Gewaltverzicht, zum Respekt der bestehenden Grenzen und zur Neutralität, falls ein Unterzeichner von einem Dritten angegriffen wurde. In einem zweiten Vertrag verpflichteten sich Bangkok und Paris, die Grenze im Mekong nach dem Thalweg-Prinzip zu ziehen. Am 10. April einigten sich England und Thailand auf einen Text, der Anfang Mai unterzeichnet werden sollte. Bis dahin sollten sich auch Paris und Bangkok über letzte Details einigen, damit die Verträge gleichzeitig unterzeichnet werden konnten ${ }^{110}$.

Nach Deutschlands Einmarsch in Dänemark und Norwegen akzeptierte der Quai d'Orsay, daß Bangkok die Verträge erst ratifizierte, wenn die Mekonggrenze neu gezogen war. Paris und Bangkok einigten sich am 9. Mai über alle Details, für den 10. Mai war die Unterzeichnung vorgesehen. Die thailändische Regierung stand aber unter starkem Druck Japans, das parallel mit Thailand über einen Nichtangriffspakt verhandelte. Um seine Unabhängigkeit zu demonstrieren, entschied Bangkok, die Verträge mit Paris, London und Tokio zeitgleich zu unterzeichnen und deshalb die Zeremonien mit den Briten und Franzosen zu verlegen. Paris gab die Hoffnung auf, mit dem Vertrag Thailand in sein Lager ziehen zu können. Anfang Juni, als der Krieg in Europa für Frankreich bereits verloren schien, war der neue Generalsekretär François Charles-Roux froh, daß Bangkok die westlichen Mächte und Japan mit der parallelen Unterzeichnung ihrer Verträge am 12. Juni gleich behandelte, wobei die Vereinbarung mit Japan in Tokio signiert wurde. Der Text der Verträge mit Frankreich und England blieb, wie Ende März vereinbart. Daß Bangkok trotz der Lage in Europa und zwei Tage, nachdem Frankreichs Regierung Paris geräumt hatte, den Pakt mit London und Paris unterzeichnete, nannte der US-Geschäftsträger in Bangkok sehr mutig. Tatsächlich ging es Bangkok nur darum, mit Hilfe der westlichen Mächte nicht zu tief in Japans Orbit gezogen zu werden. Sechs Wochen später, am 31. August, erklärte Thailands Regierung, sie werde die Verträge mit den Westmächten nicht ratifizieren. Ab November 1940 attackierte Bangkok Indochina militärisch ${ }^{111}$.

${ }^{110}$ Lépissier an Daladier, T 266, 22.12.1939; Campbell an Charvériat, 12.1., Diplomatie an Colonies, L 112, 31.1., L 203, 28.2., L 329, 2.4., Mandel an Diplomatie, T 216, 5.2., T 440, 2.3., T 624, 4.4., Lépissier an Daladier, T 13-14, 7.2., Chauvel an Campbell, Note, 15.2., Léger an Lépissier, T 27-30, 6.3., T 48-54, 8.4., Lépissier an Reynaud, $\mathrm{T}$ 39-41, 26.3., T 43, 30.3., T 49, 10.4., Campbell an Charvériat, Note, 12.4.; Note, 9.2., Lépissier an Daladier, T 19, 17.2.1940 (MAE Siam 84, 85, 81).

${ }^{111}$ Lépissier an Reynaud, T 51-52, 14.4., T 75, 9.5., L 153, 10.5.; Note de la sous-direction d'AsieOcéanie, 27.4., Diplomatie an Colonies, L 430, 30.4., Lépissier an Reynaud, T 73, T 77, 9.5., T 8283, 10.5., T 87-89, 14.5., T 106, 29.5., Léger an Lépissier, T 94-96, 11.5., Charles-Roux an Corbin, T 2339-40, 3.6.1940 (MAE Siam 81, 85); Chapman an Hull, 13.6.1940 (FRUS 1940, IV, S. 24f.). 
Paris hatte in den Gesprächen nichts gewonnen; es konnte in Bangkok aber auch nichts gewinnen, weil sich der ebenso vorsichtige wie listige Luang Pibul den stärksten Bataillonen anschloß. Eine Weile konnte Indochinas Militär Thailand beeindrucken, aber dieser Bluff mußte früher oder später auffliegen.

So wie London und Paris bis in den Sommer 1940 ihre Beziehungen zu Thailand stabil hielten, brachten sie auch Ruhe in den Konflikt um Tientsin. Dieser Streit dominierte zwar nicht mehr, wie im Sommer 1939, die Beziehungen zwischen Japan und dem Westen, aber die Kontroverse um das Silber in den Konzessionen stand der Annäherung zwischen dem Westen und Japan im Weg. Mitte Oktober 1939 einigten sich Craigie und Tani im Grundsatz auf eine Lösung: Ein Teil des Silbers werde den Marionettenbehörden übergeben und verkauft, um Hochwasseropfern zu helfen. Der größere Teil verbleibe in den Konzessionen und werde von Japanern und Briten versiegelt. Die Nutzung der Marionetten-Währung sei denkbar, erklärte Craigie. Am 1. November wies Léger Henry an, die Lösung zu unterstützen, weil sie dem Konflikt die Brisanz nehme und zu einer raschen Lösung führen könne. Doch Craigie ließ sich Zeit, weil er glaubte, Moskaus wachsende Stärke mache Tokio nachgiebiger ${ }^{112}$.

Die Lage in Tientsin blieb gespannt: Als das Hochwasser schwand, nahm Japans Armee die Blockade wieder auf und verschärfte sie im November. Die Franzosen durften ihre Konzession nur mit Hilfe von Armee-Lastwagen mit Lebensmitteln versorgen. Ab November verließen 500 bis 1000 chinesische Geschäftsleute am Tag die Konzession, während 15000 mittellose Flüchtlinge neu in das französische Gebiet kamen. Colin warnte, die Konzession stehe vor dem Ruin. Ende Januar 1940 wurden die Kontrollen weiter verschärft. Die chinesische Regierung zahlte zwar für die Versorgung der Flüchtlinge, doch angesichts des Auszugs der chinesischen Steuerzahler aus der Konzession sei Japan dabei, so warnte Colin, die Konzessionen risikolos auszulöschen ${ }^{113}$.

Léger forderte die Briten auf, sie sollten rasch eine Lösung finden. Immerhin hätten sie durch Fehler die Tientsin-Krise verschuldet. Die Zukunft der britischen und der französischen Konzession sei gefährdet. Das Foreign Office antwortete, die Gespräche in Tokio machten Fortschritte, doch ihr Erfolg hänge letztlich von Chinas Regierung ab. Die Franzosen ließen in London und in Tokio ihre Bereitschaft erkennen, aus ihrer Konzession den gleichen Anteil

${ }^{112}$ Corbin an Bonnet, T 2844-45, 30.8.1939 (DDF XIX, 219); Corbin an Daladier, T 3501, 3.10., T 3742, 23.10., T 3991, 17.11.1939 (MAE Chine 739; MAEN Londres C 487, 482); Henry an Daladier, T 633, 10.10., T 644 45, 20.10.1939 (MAE Chine 885); SATO, Japan and Britain, S. 32f.; Havas, reprise des négociations, 28.10., Léger an Corbin, L 3103, 29.11.1939 (MAE Chine 1068, 1069).

${ }^{113}$ Colin an Daladier, L 407, 30.11.1939, T 14, 20.2.1940 (MAE Chine 773, MAEN Londres C 482); Colin an Cosme, L 74, 7.12.1939, Chauvel an Cosme, T 79, 29.2., Cosme an Daladier, T 161, 1.3., Colin an Daladier, T 48, 7.11., T 49, 22.11.1939, T 2, 4.1., T 4, 20.1., L 2, 30.1., T 11, 12.2.1940; T 5, 26.1., T 7, 29.1., T 12, 13.2., T 17-18, 2.3., L 4, 7.2.1940 (MAE Chine 1069, 832). 
Silber herauszugeben wie die Briten. Doch Chungking schaltete trotz aller französischen und britischen Bemühungen auf stur: Von Anfang Dezember 1939 bis Ende Januar 1940 lehnte China jede Einigung ab. Mit Rücksicht auf Washington wollte London die Chinesen nicht übergehen. Paris aber drängte auf eine schnelle Einigung: Wegen des chinesischen Exodus' halte die französische Konzession die Blockade nicht mehr durch. Chiangs Nein solle man ignorieren ${ }^{114}$. Frankreichs Konzession zeigte sich bereit, die Marionettenwährung anzunehmen, ging aber dann wieder davon ab, weil sich die alte Währung Fapi gegenüber dem Federal-Reserve-Dollar behauptete. Der Stadtrat der britischen Konzession drohte Botschafter Clark Kerr, man einige sich allein mit Japan, wenn die Diplomatie dies nicht tue. Ende Januar wurde ein Japaner Mitarbeiter des britischen Konsulats. Zur Belohnung für die »erfolgreiche gemeinsame Bekämpfung des chinesischen Terrorismus« in der Konzession erlaubte die japanische Armee den Briten, Lebensmittel in ihr Gebiet zu bringen. Cosme hielt die britische Nachgiebigkeit für verheerend ${ }^{115}$.

Von Anfang März bis Mitte April sprachen Briten und Japaner in Tokio und London 14 Mal über die Silberfrage. Craigie und Tani blieben schließlich bei der Formel vom Oktober 1939. 100000 Pfund aus Silberverkäufen sollten die Marionettenregime als humanitäre Hilfe erhalten, 200000 Pfund wurden aus den Beständen der französischen Konzession erwartet. Der Rest werde versiegelt. Die Nutzung des Geldes überwache eine Kommision aus Briten, Franzosen, Japanern und Chinesen. Vereinbarungen über die Marionettenwährung und die Kooperation zwischen britischer und japanischer Polizei sollten folgen. Die französische Regierung glaubte, sie sei in einer starken Position, weil Japan auch mit ihr ein Abkommen abschließen wolle, aber bereits nach der Einigung mit den Briten die Blockade der Konzessionen aufhebe. Paris könne dann in Ruhe ein besseres Abkommen aushandeln. Allerdings kam es gar nicht zu Gesprächen mit Paris, weil Chiang Kai-shek und das japanische Militär in Tientsin der britisch-japanischen Übereinkunft nicht zustimmten ${ }^{116}$.

\footnotetext{
${ }^{114}$ Léger an Corbin, L 3103, 29.11.1939, L 285, 19.2.1940, Corbin an Daladier, T 4147-48, 30.11., T 4389, 14.12., Chauvel an Cosme, T 50, 11.12.1939, T 84-85, 4.3.1940, Léger an Cosme, T 51, 14.12., T 70-72, 22.12.; Cosme an Daladier, T 104, 7.2., T 188, 8.3.1940, Henry an Daladier, T 782-83, 12.12.1939 (MAE Chine 1069, 885); Léger an Corbin, T 763, 9.3.1940 (MAEN Londres C 482).

${ }^{115}$ Cosme an Daladier, T 10, 4.1., T 30-34, 13.1., T 52-53, 22.1., T 95, 5.2., Chauvel an Cosme, T 42, 29.1., Charvériat an Cosme, T 2, 7.1., Colin an Reynaud, T 49, 30.3., T 23-24, 9.4.1940 (MAE Chine 1069); Colin an Daladier, T 10, 2.2.; Cosme an Daladier, T 117, 13.2., Colin an Daladier, T 19, 2.3.1940 (MAE Chine 832, 885); Cosme an Daladier, T 182-83, 5.3., Boissezon an Cosme, L 51, 30.1.1940 (MAE Chine 838, 1072); TAYLOR, The Struggle for North China, S. 125.

${ }^{116}$ Fain an Reynaud, T 291-99, 7.4., Campbell an Charvériat, aide-mémoire, 12.4.1940; Léger an Henry, T 215-7, 9.4., Henry an Reynaud, T 307, 12.4., T 330, 23.4., Corbin an Reynaud, T 1372, 15.4., Cosme an Reynaud, T 273, 17.4.; Colin an Reynaud, T 26, 20.4.; T 27, 27.4.1940 (MAE Chine 885, 1069, 832, MAEN Londres C 482); Campbell an Halifax, 14.4., 24.4.1940 (FO 371/24651, F 2730, 2932/5/10); SATO, Japan and Britain, S. 52.
} 
Obwohl Japans Luftwaffe am 26. und 30. April erneut die Yunnanbahn bombardierte, wollte der Quai d'Orsay einen raschen Vertragsabschluß. Henry erklärte Tani am 2. Mai, Paris sei bereit, für das in Tientsin lagernde Silber Abkommen wie London abzuschließen. Mit schikanösen Kontrollen der Franzosen und Briten zeigte die japanische Armee in Tientsin, daß sie nach wie vor Herr des Verfahrens war. Zum Vertragschluß zwischen London und Tokio kam es aber nicht, weil Chungking weiter Widerstand leistete. Zudem konzentrierten sich London und Paris jetzt auf den Krieg in Skandinavien ${ }^{117}$.

In Shanghai blieb die Lage während der drôle de guerre ruhig. Japan und China verfolgten die Entwicklung in Europa. Chinas Terror in Shanghai versiegte völlig. Die Behörden bekamen zur Jahreswende 1939/40 Plünderungen und Streiks gegen drastisch gestiegene Reispreise unter Kontrolle. Japan begnügte sich damit, ein Gebiet nahe der Internationalen Konzession, das vom Settlement kontrolliert worden war, zu besetzen. Gefährlich für den Westen war Japans Versuch, im April 1940 bei der Kommunalwahl die britischamerikanische Vorherrschaft im Settlement friedlich zu brechen. Ohne einen Schuß abzufeuern hätten sie bei einem Sieg ihrer Kandidaten die Konzession übernehmen können. Briten und Amerikaner stimmten aber diszipliniert für ihre Bewerber. Auch Deutsche und Italiener besannen sich, so Generalkonsul Baudez, ihrer weißen Rasse, wählten die angloamerikanischen Kandidaten und verschafften den Briten so einen beachtlichen Prestigeerfolg ${ }^{118}$.

Japans Marine nutzte die Konzentration Frankreichs auf Europa, um ihre Präsenz auf den Spratlys auszubauen. Ab Oktober 1939 legte sie Gebäude aus Beton an, darunter eine Eisfabrik und ein Kühlhaus, ein Öldepot, Läden und Wohnungen. An Militäranlagen entstanden eine Kaianlage aus Stahlbeton und ein Bootshaus; eine 14000 Quadratmeter große Halle wurde für Flugzeuge errichtet. Beamte aus Formosa erkundeten die Topographie und schlugen Wege durch den Busch. Im Dezember brachten sie 40 Pferde auf die Insel. Der Schiffsverkehr nach Formosa intensivierte sich. Als Ablösung kamen im Januar 72 japanische Arbeiter und elf Frauen auf die Insel, die Gesamtstärke der Japaner betrug 100 Personen. Auch die Präsenz japanischer Kriegsschiffe erhöhte sich. Die Franzosen entsandten im September 1939 die Savorgnan de Brazza und im März 1940 die Marne zu den Spratlys, als keine japanischen Schiffe vor Ort waren. Beide Male protestierte das Gaimusho gegen »die Nutzung japanischer Hoheitsgewässer«, aber in Tokio und in Paris wurden die

${ }^{117}$ Colin an Reynaud, T 28, 1.5., T 29, 8.5., Cosme an Reynaud, T 299, 4.5.1940 (MAE Chine 1069); Bullitt an Hull, 3.5.1940 (FRUS 1940, IV, S. 320f.); Hayter an Halifax, 5.5.1940 (FO 371/24652, F 3232, 3229/5/10); Corbin an Daladier, L 404, 28.5., T 270-71, 5.6.1940 (MAEN Londres C 482).

${ }^{118}$ Havas, dépêche interdite pour tous, 16.12.1939; Baudez an Daladier, L 6, 26.1., L 18, 4.3.1940; Cosme an Bonnet, T 988, 10.9.1939; Cosme an Daladier, L 317, 18.9.1939; Havas, le Japon envisage la rétrocession de ses concessions, 21.3., Baudez an Reynaud, L 42, 15.4.1940 (MAE Chine 1064). 
Proteste ohne Energie betrieben, weil die Annäherung durch eine Nebensächlichkeit nicht weiter erschwert werden sollte. Im Oktober 1940 brachte Japan die letzten 25 Vietnamesen zurück an Land und begann, einen Flugplatz zu bauen. Im Pazifischen Krieg dienten die Spratlys als Stützpunkt für U-Boote. Auf den Paracels blieb die französische Mission bis zum März $1942^{119}$.

\subsection{Französische Waffenlieferungen durch Indochina}

Die französische Regierung gewährte Chungking von 1937 bis 1940 - außer für den Eisenbahnbau - keine Kredite, sie übte für China keinen diplomatischen Druck in Tokio aus. Frankreichs wichtigstes Mittel, um den Krieg zu beeinflussen, war der Grad an Versorgung, den es in Indochina zuließ. Gleichzeitig sorgte der angebliche Transit von Waffen für Chiang Kai-shek über Jahre für heftige Konflikte zwischen Japan und Frankreich, und er war Auslöser für die Entsendung der japanischen Beobachtungsmission, mit deren Ankunft am 29. Juni 1940 das Ende der französischen Souveränität über Indochina begann. Zu Recht bezeichnete ein zeitgenössischer Beobachter die Haltung zum Nachschub über die Yunnanbahn als "Schlüssel zur französischen Diplomatie im Fernen Osten ${ }^{120}$. Waren Japans Anschuldigungen, Indochina sei Chinas wichtigste Nachschublinie, berechtigt? Oder war der französischen Versicherung, es gebe keinen Waffentransit über Indochina, zu glauben? Wie viel Material erhielt China über die französische Kolonie wirklich?

Die Forschung gelangte zu keiner schlüssigen Antwort. In ihren Memoiren behaupten Jules Bührer und Georges Catroux, es habe keinen Transit militärischen Materials gegeben. Jean Decoux schreibt, die Verpflichtung, keine Waffen passieren zu lassen, sei "mehr oder weniger« eingehalten worden. General André Nolde zufolge war der Transit komplizierten, wechselnden Regeln unterworfen. Geheimdienstoffizier Raoul Salan gibt an, China sei über die Yunnanbahn versorgt worden, erwähnt aber kein Kriegsgerät; sein Kollege Henri Jacquin berichtet von massiven Waffentransporten über Indochina.

Auch die Historiker fällen gegensätzliche Urteile: Donald Lancaster, Ellen Hammer, Joseph Buttinger, Chen King, King Wunsz, Abderahmane Benabi

\footnotetext{
${ }^{119}$ Henry an Daladier, L 189, 3.10., Catroux an Mandel, T, 21.10., 21.12.1939; L 406, 27.2., L 423, 29.2.; Henry an Daladier, T 613, 30.9.1939, T 156-57, 2.3., T 169-73, 8.3.; Note de la sous-direction d'Asie-Océanie, 8.1.; Daladier an Henry, T 95-96, 12.2., T 145-47, 5.3.1940 (MAE Chine 752); Tschiba an Arita, 5.3., Marine an Europa-Asienabteilung, 8.3.1940 (JA, S 1.1.1.0-28, S. 492f., S. 603); Flood an Hull, 22.10.1940 (SD 851g.014/34); CATLEY, KeLlaT, Spratlys, S. 25; SAMUELS, Contest, S. 65.

${ }^{120}$ RoTH, Japan Strikes South, S. 24.
} 
und Pierre Montagnon schreiben, nur Lastwagen und Benzin, keine Waffen seien über Indochina nach China gelangt. Hata Ikuhiko nimmt an, geringe Waffenmengen seien geschmuggelt worden. Gottfried Haas und Philippe Franchini zufolge bestand Mandel darauf, Waffen und Munition vom Transit auszuschließen. Hingegen nimmt Gilbert David an, daß die Behörden in Indochina dieses Verbot ignorierten. William L. Langer und S. Everett Gleason, Ling Hung-Hsun, Murakami Sachiko, John E. Dreifort und John Keay gehen davon aus, daß beträchtliches Kriegsmaterial Indochina passierte. Francis Paul Walters glaubt, daß die Franzosen zunächst den Waffentransit untersagten, Unregelmäßigkeiten duldeten und dann das Verbot aufhoben. Von einer sich häufig ändernden Transitpolitik für Lastwagen und Flugmaterial geht Andrew Roth aus. Nach Arthur N. Young konnten Waffen, die mit zivilen Gütern getarnt oder vermischt waren, die Grenze passieren. Christoph Babinet zufolge sorgte die Komplizenschaft der örtlichen Verwaltung dafür, daß verbotenes Kriegsmaterial falsch deklariert nach China gelangte. Maurice Martin du Gard schreibt, tausende Kanonen und Lastwagen, hunderte Panzer und Maschinengewehre seien dank Schmiergeldern heimlich und falsch deklariert über die Grenze gelangt. Jacques Valette urteilt, es sei unmöglich, genau festzustellen, wieviele Waffen über die Yunnanbahn transportiert wurden ${ }^{121}$.

Eine fundierte Antwort auf die Fragen wird durch die Aktenlage erschwert. Der Regierungsbeschluß vom Oktober 1937, den Transit nur für Militärgüter zu erlauben, die vor dem 13. Oktober 1937 verschifft oder vor dem 15. Juli in Frankreich bestellt worden waren, blieb offiziell bis zum Sommer 1940 in Kraft. Tatsächlich änderten die Minister in Paris und der Generalgouverneur in Hanoi oft die Transitpolitik, meist, ohne dies schriftlich festzuhalten. Die Erklärungen, die Paris den Regierungen in London und Washington gab, waren widersprüchlich, auch die ausländischen Beobachter in Ostasien gewannen gegensätzliche Erkenntnisse. Paris mußte das Kunststück gelingen, einerseits den Chinesen, Briten, Amerikanern und den eigenen Waffenproduzenten zu widerstehen, die auf unbegrenzte Transporte drängten, andererseits gegenüber

121 Catroux, Deux actes, S. 9, S. 50; BüHrer, Aux heures, S. 82f.; DecouX, À la barre de l'Indochine, S. 63f.; NoldE, La Chine, S. 185; SALAN, Mémoires, S. 58; JACQUIN, La guerre secrète, S. 33; LANCASTER, The Emancipation, S. 91; HaMmER, The Struggle, S. 14; Buttinger, Vietnam, Bd. 1, S. 228; CHEN, Vietnam and China, S. 42; KING, China, S. 94; BENABI, Les Français, les Japonais et le mouvement national, S. 75; MonTAGNON, Grande Histoire, Bd. 2, S. 108; HATA, Continental expansion, S. 308f.; HAAS, Französisch-Indochina, S. 38; FranchINI, Les guerres d'Indochine, Bd. 1, S. 152; Gilbert DAVID, Chroniques secrètes d'Indochine (1928-1946), Bd. 1: Le Gabaon, Paris 1994, S. 90; Langer, Gleason, The Challenge, S. 597; Ling, China's Epic Struggle, S. 253; MURAKami, Japan's Thrust, S. 93f;; DreiforT, Myopic Grandeur, S. 177; KeAY, Last Post, S. 163; F[rancis] P[aul] WALTERS, A History of the League of Nations, London 1952, S. 738; ROTH, Japan Strikes South, S. 25; YounG, China and the Helping Hand, S. 50f.; BABINET, L'Indochine, S. 104f;; MARTIN DU GARD, Carte impériale, S. 416f.; VAlETTE, Indochine, S. 15. 
den Japanern standhaft zu bleiben, die verlangten, daß China überhaupt nicht über Indochina versorgt wurde.

In der ersten Kriegsphase sah Japan wegen des geringen Umfangs über den Nachschub via Hanoi hinweg. Französische Firmen lieferten bis zum Frühjahr 1938 vier Mörser, 107 Geschütze, 28000 Granaten, 20 MGs, 11000 Fliegerbomben und 1,2 Millionen Patronen über Indochina nach China. Zudem wurden große Mengen amerikanisches Flugbenzin transportiert. Deutschem, italienischem und belgischem Material blieb der Transit versagt. Brévié und Moutet gestatteten auf chinesischen Druck, daß einmalig 600 Tonnen deutsche Waffen nach China gelangten. China erhielt keine großen Mengen über die Kolonie, doch C.T. Wang, Chiangs Botschafter in Washington, äußerte sich zufrieden über den über Indochina kommenden Nachschub ${ }^{122}$.

Nach der "Lord Cochrane-Affaire" änderte Paris die Transitpolitik. Der britische Frachter Lord Cochrane kam am 3. Januar 1938 mit 3000 Tonnen sowjetischen Waffen und Munition, darunter 32 Panzern und fünf Flugzeugen, in Haiphong an. Als China den Hafenbehörden Dokumente vorlegte, wonach die Ladung seit Mitte Oktober auf See war, erlaubte Brévié das Entladen. Obwohl Kolonialminister Moutet wußte, daß Japaner das Schiff beobachteten, und ihm klar wurde, daß die Chinesen gefälschte Papiere vorgelegt hatten, um die Transitgenehmigung zu erhalten, griff er nicht ein.

Hoppenot und Léger wollten das Ausladen unterbinden, doch Delbos und Moutet einigten sich, die Fracht rasch löschen und nach Yunnanfu bringen zu lassen. Mindestens zwei, womöglich sogar vier, weitere britische Dampfer mit sowjetischen Waffen steuerten Haiphong an. Tokio reagierte: Es bombardierte am 11. Januar Nanning, wobei ein französischer Pater starb, protestierte am 12. und 14. Januar in Paris und ließ am 19./20. Januar 200 Mann kurzzeitig auf Hainan landen. Hoppenot und Léger warnten, Japan werde bei einer Fortsetzung des Transits die Wege von Indochina nach China bombardieren und auf Hainan, den Paracels und den Spratlys französische Interessen mißachten. Dennoch ließen Brévié und Moutet bis zum 28. Januar 1700 Tonnen Waffen entladen und nach China bringen. Als Léger Gamelin und Daladier von der Gefährlichkeit des Transits überzeugt hatte, untersagten Daladier, Delbos und Moutet am 1. Februar 1938 sämtliche Waffentransite durch Indochina. Mitte

\footnotetext{
122 Brévié an Moutet, lettre personnelle, L 4807, beide 29.10.1937 (MAE Indfr 33, CAOM NF 106); Moutet an Brévié, T 618, 29.9., T 637, 7.10., T 694, 27.10., T 706, 30.10., T 724, 8.11., T 794, 2.12., T 811, 8.12.,T 829, 11.12., T 863, 19.12.; Brévié an Moutet, T 795, 5.10., T 814, 9.10., T 877-78, 26.10., T 920, 31.10., T 923, 2.11., T 953-55, 11.11., T 958, 11.11., T 966, 13.11., T 1014, 25.11., T 1046, 1.12., T 1048, 1.12., T 1070, 8.12.1937 (CAOM FM 661, 666); Brévié an Steeg, T 115, 3.2., Brévié an Mandel, T 446, 15.4.; Steeg an Brévié, T 89, 5.2., Mandel an Brévié, T 311., 16.4.1938 (CAOM FM 677, 672); Hull, Memoranda, 7.12.1937, 3.1., Roberts an Hull, 18.2., Meyer an Welles, 30.3.1938 (FRUS 1937, III, S. 773f., 1938, III, S. 519f., SD 851g00/PR 6, 893.24/395).
} 
Februar erfuhr Domei - womöglich in Paris diskret informiert - von dem Verbot. Die Minister entschieden, bereits verkauftes französisches Kriegsmaterial dürfe nur über Hongkong und Birma nach China gelangen. Nur die von Audinet verkauften Flugzeuge durften Indochina passieren, weil die Exportversicherung des Staates sonst hätte zahlen müsssen. Etwas später durften dann doch wieder alle vor Juli 1937 erteilten Bestellungen über Indochina abgewickelt werden. Mitte März, als mit Ministerpräsident Blum, Außenminister Paul-Boncour und Kolonialminister Moutet drei ausgesprochene ChinaFreunde an die Regierung gekommen waren, gab der Quai d'Orsay Chiangs Drängen nach und erlaubte, daß die noch in Haiphong lagernden 1300 Tonnen sowjetischen Waffen auf Dschunken nach China geschmuggelt wurden. Nur die 32 Panzer, die in Yunnanfu blockiert waren, durften nicht mehr an die Front gebracht werden - denn dies hätte sich kaum verheimlichen lassen ${ }^{123}$.

Berichte in Japans Presse, wonach vor allem Deutschland, Italien und Großbritannien China Waffen lieferten, und Lob von Domei für die französische Transitpolitik zeigten, daß Paris wieder Spielraum gewonnen hatte. Moutet wollte deshalb kurz vor dem Ausscheiden aus dem Amt am 6. April zwei weiteren britischen Frachtern, die mit 60 sowjetischen Panzern und weiteren 5000 Tonnen Kriegsmaterial Haiphong anfuhren, das Ausladen gestatten. Beide Schiffe entluden aber in Hongkong ${ }^{124}$.

${ }^{123}$ Bullitt an Hull, 22.11.1937 (SD 893.24/323); Campagnie Universelle du Canal Maritime de Suez an Sir Ian Malcalm, 20.12.1937, 11.1., Coultas an Eden 11.1.1938 (FO 371/22071, F 488, 451/34/10); Moutet an Brévié, T 806, 7.12.; Brévié an Moutet, T 1182, 31.12.1937; Brévié an Moutet, T 7, 3.1., T 312, 23.3., Brévié an Steeg, T 105, 28.1., T 155-56, 17.2.1938 (CAOM FM 661, 666, 677); Moutet an Brévié, T 18, 3.1., T 233, 21.3., T 245, 25.3., Steeg an Brévié, T 49, 22.1., T 56, 25.1., Steeg an Brévié, T 111, 11.2., Mandel an Brévié, T 365, 11.5.; Brévié an Mandel, T 560, 11.5.1938 (CAOM FM 672, 678); Notes de la sous-direction d'Asie-Océanie pour le ministre, 8.1., 2.2., note pour M. Léger, 8.1., Colonies an Diplomatie, L 285, 19.2., Delbos an Steeg, L 284, 22.2., Naggiar an Delbos, T 281-83, 24.2., T 343, 10.3., Léger an Naggiar, T 149, 13.3., Varenne an Paul-Boncour, L, 16.3., Léger an Défense nationale, L 815, 21.3.1938 (MAE Ac 136); Wright an Halifax, 4.5.1938 (FO 371/22072, F 4796/34/10); Meyer an Hull, 29.1., Berichte US-Marineattaché (Peking) No. 51, 6.6., Vize-Heeresattaché, 15.4.1938 (SD 893.24/367, 445, 425); Henry an Delbos, T 22, 12.1., Note, Japanische Botschaft, 14.1.; Corbin an Delbos, T 130-31, 21.1., Delbos an Steeg, L 111, 22.1.1938 (MAE Ac 136); Crépin an Naggiar, L 16, 10.2., Diplomatie an Colonies, L 239, 14.2., Brévié an Naggiar, T 186, 19.5.; Colin an Naggiar, T 268, 9.3.1938 (MAEN Pékin A 394, A 55 bis); EMA.2, note pour le chef du cabinet du ministre, 22.1., mit handschriftlichen Anmerkungen, 24.1., 4.2.; EMA.2, Note, 21.2., Delbos an Daladier, L 461, 15.2., EMA.2, Résumé, 25.2., Sabattier, note pour l'EMA.2, 21.5.; Ministre de la Défense nationale, cabinet du ministre, analyse, 28.3.1938 (SHAT 7 N 3311, 3313, 5 N 579); Note de la sous-direction d'Asie-Océanie, 27.8.; Défense nationale an Audinet, L 1948 5.3.; Varenne an Paul-Boncour, L, 8.4.1938 (MAE Chine 783, 560, 721); MAUX-ROBERT, Le dragon de l'est, S. 82; Southard an Hull, 25.3.1938 (SD 893.113/1678); Memorandum, Hamilton, 20.4., Wilson an Hull, 2.4., 5.4.1938 (FRUS 1938, III, S. 595f,, S. 594f., S. 135f.).

${ }^{124}$ Craigie an Halifax, 3.2.1938 (FO 371/22071, F 1429/34/10); Dupuy an Delbos, T 3, 7.2.; Knobel an Delbos, T 478-79, 4.4., Henry an Delbos, L 3, 19.1.1938 (MAE Ac 136, Chine 553); Moutet an Brévié, T 281, 6.4., T 291, 28.4.; Brévié an Mandel, T 502, 28.4.1938 (CAOM FM 677, 672, 678). 
Eine Chance für eine neue Transitpolitik sahen Naggiar und Brévié, die sich im April in Haiphong trafen, als sich in Paris Daladiers neue Regierung bildete. Sie regten an, angesichts Chinas verbesserter militärischer Lage den Transit zu liberalisieren. Über Ausnahmen vom Transitverbot solle der Generalgouverneur nach Rücksprache mit dem Botschafter allein entscheiden. Mandel unterstützte dies. Doch die Asienabteilung im Quai d'Orsay bremste: Die Gründe für die bisherige Transitpolitik blieben gültig, Japans Drohung gegen die Yunnanbahn gelte fort, wobei Tokio den Transit noch schärfer beobachten werde. Hoppenot und Léger setzten sich durch. Mandel teilte Brévié mit, die alte Regierungsentscheidung solle wie bisher angewandt werden ${ }^{125}$.

Auf den Wegen, auf denen Waffen von Haiphong nach China gelangen konnten, wurde im Frühjahr 1938 unterschiedlich verfahren. Berühmt war die Yunnanbahn in die Provinz Yunnan. Kaum bekannt waren die zwei Strecken in Kwangsi. Auf den 300 Kilometern von Haiphong bis zur Grenze in Dongdang konnten die Waren über die Bahn oder eine schmale, asphaltierte Straße gebracht werden. Weitere 250 Kilometer waren es auf der Straße bis Nanning. Vorteil dieser Wege war, daß sie schlecht zu beobachten waren. Brévié und Naggiar vereinbarten offenbar, den Transit auf Kwangsi zu konzentrieren.

Zunächst hörten die US-Beobachter in Kanton, Hongkong, Shanghai und Saigon nur Gerüchte, wonach trotz der offiziellen Schließung der Grenze beträchtliche Mengen an Waffen heimlich über Haiphong nach China gelangten. Ab Mitte April 1938 zeigte sich deutlicher, daß auf der für ZehnTonner geeigneten Straße große Mengen an Nachschub, auch Waffen, nach China kamen. Militärattaché Sabattier bestätigte dies dem US-Marineattaché. Kriegsmaterial kam auch mit Dschunken von Haiphong nach China, erfuhren die Beobachter aus Amerika. Die Yunnanbahn schien, außer französischem Material, das bis Juli 1937 bestellt worden war, keine Waffen zu transportieren. Im September 1938 erklärte der für Waffenimporte zuständige General Gaston Huang US-Diplomaten, die Bahn werde seit Frühjahr nicht mehr für Nachschub genutzt, während die Verbindung über Langson beliebig genutzt werden könne. Mit den französischen Beamten vor Ort könne man sich stets einigen, während es mit den Behörden in Paris oft zu Differenzen komme.

Auf der Yunnanbahn begannen heimliche Transporte. Kisten mit Waffen und Munition trugen falsche Etiketten. Brévié vereinbarte mit Naggiar und

\footnotetext{
${ }^{125}$ Brévié an Mandel, T 438-39, 14.4., T 570, 14.5., Brévié an Moutet, T 423, 8.4.; Mandel an Brévié, T 314, 17.4., T 365, 11.5., T 374, 14.5.; Note de la sous-direction d'Asie-Océanie, 21.4.1938 (CAOM FM 677, 672; DDF IX, 216); Naggiar an Bonnet, T 12-20, 23.4., T 556-60, 1.5.1938 (MAEN Pékin A 394, MAE Ac 136); Wilson an Hull, 14.5.1938 (SD 793.94/13078). Von dem Gebot, keine Waffen aus staatlichen Depots an China abzugeben, wich Léger ab, um Material aus dem Ersten Weltkrieg zu verkaufen: Anfang 1938 wurden 300 Mörser aus dem Jahr 1918 mit 100000 Granaten von 1922 und 1924 nach China geliefert, der Verkauf von 700000 alten Gewehren an China scheiterte jedoch.
} 
Knobel von April 1938 bis Februar 1939 in mindestens zehn Fällen, daß »Bücher«, »Elektrochemie-Material« oder »Labormaterial« ohne Kontrolle transportiert wurden ${ }^{126}$. Chinesische Stellen klagten zwar weiter über den schwierigen Transit, doch T.V. Soong dankte Brévié für die Erleichterungen, die er Chinas Nachschub eingeräume ${ }^{127}$. Jacques Baeyens aus der Asienabteilung im Quai d'Orsay bestätigte US-Diplomaten die Existenz von Waffentransporten über die Straße via Langson, Hoppenot erklärte Léger, in Einzelfällen und geheim könne man Transitregeln umgehen. Ob Bonnet über die Lage in Indochina informiert war, ist unklar. Daß das Außenministerium von der Transitpraxis nichts wußte, wie Cosme später klagte, wird man nicht sagen können. Er hatte aber recht, daß in Indochina für französische Exporteure schärfere Regeln galten als für deutsche oder amerikanische Firmen ${ }^{128}$.

Die mit dem Waffentransit befaßten französischen und chinesischen Beamten gingen diskret mit dem Kriegsmaterial-Schmuggel um: Ende März, Ende April, Ende Juni, Anfang Juli und Ende August 1938 legte die japanische Regierung Listen von Kriegsmaterial vor, das über Indochina nach China gelangt sei. Mitte Mai, Mitte Juni sowie Mitte und Ende Oktober beschwerte sich Tokio allgemein über den Waffentransit. Doch Belege dafür konnte die japanische Regierung nie vorlegen. Japans Geschäftsträger glaubte den ihm aus Tokio übermittelten Listen bald selbst nicht mehr. Im Dezember 1938 legte er diese nur noch als Hinweis und ohne Protest vor. Auch ein Besuch des früheren japanischen Gesandten in der Schweiz Yada in Haiphong gab Tokio keine Hinweise. Anfang Oktober gab Vicomte Inouye, der Präsident des Panpazifischen Clubs, in Tokio sogar eine öffentliche Ehrenerklärung für Indochina $a b$. Intern war sich Japans Außenministerium nicht sicher, ob wirklich Waffen über Indochina transportiert wurden. Tokio wußte nur, daß

${ }^{126}$ Jarvis an Hull, 13.1.1939; US-Militärattaché, Intelligence Report, 24.9., 27.9.; Note, Office of Arms and Munitions Control, 2.3., Palmer an Hull, 25.3., 8.4., 22.3., 6.5., Salisbury an Hull, 9.6.1938 (SD 793.94/14722, 14268, SD $893.113 / 1675,1682,1684,1693,1696,1701$ ); Hamilton, Memorandum, 12.3., Palmer an Hull, 19.8.1938 (FRUS 1938, III, S. 591f., S. 605f.); Bericht USMarineattaché Peking, No. 51, 6.6., Meyer an Hull, 14.4., 30.4., 14.5., 31.5., 13.10., Southard an Hull, 28.5., Palmer an Hull, 17.6., Flood an Hull, 28.10.1938 (SD 893.24/445, 397, 401, 406, 415, 488, 485, 421, 419, 484); Higgins an Hull, 20.6.1938 (SD 895.51/6637); Brévié an Naggiar, T 193, 25.5., T 205, 8.6., T 209, 24.6., T 216, 2.7., T 268, 31.8., T 275, 8.9., T 336, 9.10.1938; T 85, 7.2.1939; Colin an Naggiar, T 440, 25.4., T 624, 21.6.1938 (MAEN Pékin A 395); HASLAM, The Soviet Union, S. 123.

${ }^{127}$ Koo, Note, 21.4.1938 (MAE Chine 553); TUNG, V.K. Wellington Koo, S. 44; Gandon, Note, 5.5., General Georges, Note, 5.5.1938 (MAE Chine 558, 676); Phipps an Halifax, 23.5.1938 (FO 371/ 22073, F 5531/34/10); Soong an Naggiar, 15.6., 21.7.; Crépin an Naggiar, L 145, 10.11.1938 (MAEN Pékin A 394, Tchongking 9); Brévié an Mandel, T 873-79, T 884-88, 31.7.1938 (CAOM FM 678). In Paris arbeiteten auch professionelle Waffenschieber für China (MILLER, Shanghai, S. 111).

${ }^{128}$ Wilson an Hull, 14.5., 19.10.1938 (SD 793.94/13078; FRUS 1938, III, S. 326f.); Hoppenot an Léger, Note [Mai 1938], Léger an Naggiar, T 8, 16.4.1938 (MAE Chine 661, Ac 136); Bullitt an Hull, 30.1.1939 (SD 740.00/561); Cosme an Chauvel, L 159, 6.8.1940, L 35, 31.3.1941 (MAEN Tokyo B 78, MAE Vichy-Asie 124). 
fast 50 Prozent der Importe Chinas, insbesondere Benzin und Fahrzeuge, über die Yunnanbahn ins Land kamen ${ }^{129}$. Die geschickte Geheimhaltung sorgte dafür, daß sich entfernte Beobachter der Existenz eines Waffentransits viel sicherer waren als die Vertreter der Mächte vor Ort. Die französische, deutsche und die britische Botschaft in Tokio sowie die Asienabteilungen des State Department und des Foreign Office - nicht aber Staatssekretär Cadogan, der Légers und Hoppenots Beteuerungen glaubte, es gebe keinen Transit - gingen davon aus, daß erhebliche Mengen an Kriegsmaterial über Indochina nach China gelangten, während der deutsche Konsul in Hanoi, der US-Konsul sowie der französische Konsul in Yunnanfu, der US-Botschafter in Tokio, Frankreichs Luftwaffenattaché und der Marine-Geheimdienst in Shanghai überzeugt waren, es gebe keinen Waffentransit. Großbritanniens Botschafter und Militärattaché in China sowie der britische Vize-Konsul in Haiphong glaubten, unbedeutende Mengen an Waffen würden von Haiphong nach China geschmuggelt. Dazu neigte auch der britische Konsul in Saigon, der zwischen dem Bericht eines Majors aus Malaysia, der Waffentransit sei erheblich, und den Versicherungen der Franzosen, dieser existiere nicht, schwankte ${ }^{130}$.

Die japanische Besetzung Kantons am 21. Oktober 1938 veränderte Frankreichs Transitpolitik erneut. Bis dahin kamen monatlich 60000 Tonnen über Hongkong nach China. Nun drohten Haiphong und Kwangchowan zu Haupt-

${ }^{129}$ Diplomatie an Colonies, L 432, 28.3., Brévié an Mandel, L 199, 7.7.1938 (CAOM Indo-NF 107); Note du Service des cessions de matériel à l'étranger, 30.3 .1938 (SHAT 7 N 3313); Note d'audience du secrétaire général, 20.5.; Diplomatie an Colonies, L 572, 25.4.; Diplomatie an Colonies, T 827, 23.6., note de la sous-direction d'Asie-Océanie, 26.8.1938 (DDF IX, MAE Ac 136, Japon 127); Craigie an Halifax, 3.11., 3.7., 28.10., 29.10., Phipps an Halifax, 3.11.1938 (DBFP, $3^{\text {rd }}$ series, VIII, 202, FO 371/22074, F 7130, 11426, 11429, $11655 / 34 / 10)$; Mandel an Brévié, T 333, 26.4., T 469, 24.6., T 505, 7.7., T 620, 31.8., T 949, 20.12.; Brévié an Mandel, T 502, 28.4., T 743, 28.6., T 811, 10.7., T 978, 2.9., T 1480, 23.12.1938 (CAOM FM 672, 678); Léger an Henry, T 230-33, 13.7.1938 (DDF X, 201); Wilson an Hull, 13.10., 29.10.1938 (FRUS 1938, III, S. 318f., S. 351f.); Naggiar an Bonnet, T 1319, 16.9.1938 (MAEN Pékin A 55 bis); Walsh an Halifax, 18.11.1938 (FO 371/22075, F 12589/34/10); Geheime Aufzeichnung des Gaimusho, Die Verhandlungen über das WaffenTransportverbot [ohne Datum], (JA, S 1.1.1.0-45, S. 8f.); HATA, The Army's Move, S. 157.

${ }^{130}$ Kolb an Ribbentrop, 5.7.1938 (AA Botsch Paris 444 b Japan 4); Grew an Hull, 28.6., Hamilton, Memorandum, 5.7.; Meyer an Hull, 15.6., 29.6., 11.7., 26.7., 9.8.1938 (FRUS 1938, III, S. 207, S. 213f., SD 893.24/433, 434, 437, 448, 461); Neumann an von Neurath, Ribbentrop, 25.11.1937, 6.1., 2.5., 15.7., 25.11., 25.12.1938 (AA Pol VIII 59,1; 60,2); Crépin an Naggiar, T 62, 2.11.; Henry an Paul-Boncour, T 187-89, 8.4.1938; Crépin an Cosme, L 31, 20.3.1939 (MAEN Pékin A 394, MAE Japon 126, Chine 949); Grew an Hull, 15.2.1939 (SD 793.94/14761); La Ferté Senectère, rapport, 4.8.1938; STS-bulletin, 1.3.1939 (MAE Chine 565, 534); FO-Memorandum, 16.11.1938 (FO 371/ 22176, F 12923/4727/61); Major Vinden, Report, 26.3.1938 (WO 106/5455); Phipps an Halifax, 5.4., Coultas an Halifax, 5.4., 8.4., 14.4., Minutes, Ronald, 26.4., Cadogan, 30.4., Sharman an Halifax, 5.5., Clark Kerr an Halifax, 17.5., Militärattaché an War Office, 17.5.1938 (FO 371/22072-73, F 3686, $3762,4116,4113,4711,5455,5337,5338,5407 / 34 / 10)$; Sharman an Halifax, 22.6., Walsh an Halifax, 22.11.; Corbin an Bonnet, T 1609-11, 3.7.1938 (FO 371/22074-75, F 7060, 12918/34/10; MAEN Londres C 479); Clark Kerr, Annual Report, 28.2.1939 (FO 371/23443, F 3662/53/10). 
umschlagsplätzen für China zu werden. Anfang November verlegte Chinas Post ihr Verteilzentrum von Hongkong nach Kwangchowan. Am 29. Oktober und 5. November klagte Japans Marineattaché in Paris, Indochina werde zu Chinas Nachschubzentrum. Schiffe mit deutschem und sowjetischem Kriegsmaterial führen bereits nach Haiphong und Saigon. Japans Regierung glaube, daß das Kolonialministerium in Paris die Hilfe unabhängig vom Außen- und Kriegsministerium organisiere. Ob Mandel bis dahin von Bréviés Transitpraxis wusste, ist unklar. Im Außenministerium erfuhr Mandel jetzt,

grâce [à] certaines connivences administratives [du] matériel [de] guerre non autorisé transiterait clandestinement et sur [une] large échelle par [l']Indochine sous [de] fausses indications de chargement.

Mandel forderte Brévié telegraphisch und telefonisch zur strikten Beachtung des offiziellen Transitverbots auf. Brévié versicherte Mandel, es gebe keinen geheimen Waffentransit. Der Quai d'Orsay erklärte Mandels Vorsicht damit, daß er Japan keinen Anlaß geben wolle, gegen Indochina vorzugehen ${ }^{131}$.

Japan setzte Paris unter Druck: Am 14. Oktober sagte ein japanischer Botschaftssekretär, Frankreich müsse einen Angriff auf die Yunnanbahn erwarten, sobald Kanton besetzt sei. Am 24. und 29. Oktober warnte Militärattaché General Tsushihashi den Chef des Deuxième Bureau, Oberstleutnant Gauché, vor einem Angriff auf die Bahnlinie, wenn der Transit nicht sofort aufhöre. Das Verteidigungs- und das Außenministerium nahmen die Drohung sehr ernst: Ende Oktober schloß der Hafen in Haiphong für eine Woche. Sämtliche Transite, auch von Lastwagen und Benzin, waren untersagt. Paris wußte nicht, daß Tokio tatsächlich einen Luftangriff auf die Bahn plante. Gegen die Sperrung protestierten französische Waffenhersteller und Chinas Regierung. Chungking klagte, die Transitregeln änderten sich oft und seien unpräzise ${ }^{132}$.

In Absprache mit dem Quai d'Orsay lockerte Mandel im November 1938 schrittweise seine Anweisungen. Er wies Brévié an, in Haiphong zivile Lastwagen und Benzin unbegrenzt passieren zu lassen. Nur Lastwagen, deren Aufbauten oder Ausrüstung klar militärischer Natur seien, müsse er zurückhalten. Weil der Quai d'Orsay befürchtete, daß sich die Kämpfe auf Kwangchowan

${ }^{131}$ LIU, A Military History, S. 156; Note de la sous-direction d'Asie-Océanie pour le ministre, 21.11.1938 (MAE Chine 713); Mandel an Brévié, T 766, 24.10., T 786, 29.10., T 795-96, 1.11., T 798, 2.11., T 803, 3.11., T 812, 7.11., T 831, 12.11.; Brévié an Mandel, T 1222, 28.10., T 1245, 1.11., T 1249, 2.11., T 1252-54, T 1256, T 1258, 3.11., T 1269, 7.11.; Marine an Colonies, T 7457, 1.11., T 7754, 5.11.1938 (CAOM FM 672, 678, 677); Wilson an Hull, 15.11.1938 (SD 893.24/501).

${ }^{132}$ Colonies, renseignement, 14.10.; EMA.2, note, 24.10.; EMA.2, compte rendus, 24.10., 29.10.1938 (SHAT 7 N 3313, 2524, 3311); Compte rendu de la réunion hebdomadaire, 26.10.; SEH, renseignements 28.10., 16.12.1938 (DDF XII, 224, CAOM CM 81-82); Georges-Picot an Naggiar, T 1100-1, 7.11.1938 (MAEN Pékin A 394); Crépin an Bonnet, T 13, 16.12.1938; STS-bulletin, 1.2.1939 (MAE SDN 365, Chine 534); Brandt an Daladier, 9.12.1938, 23.1.1939 (SHAT 7 N 3313). 
ausdehnten, durften keine Lastwagen das französische Pachtgebiet passieren. Mandel ordnete an, den Lastwagenverkehr durch Haiphong so zu gestalten, daß nicht der Eindruck eines massiven Nachschubs entstehe. Pro Monat sollten höchstens 100 Laster abgefertigt werden. Dabei war Mandel klar, daß mehrere tausend Fahrzeuge, vor allem aus den USA, auf den Transit warteten. Im Hafen von Haiphong lagerten bereits 1000 Lastwagen. Zur Ablenkung verbreiteten französische Beamte in Hanoi, Peking und Shanghai, für Autos sei der Transit untersagt. Unverändert blieb dagegen die im Oktober 1938 eingeführte Praxis der französischen Regierung, Waffenherstellern nur dann eine Exporterlaubnis für China zu erteilen, wenn sich diese verpflichteten, ihre Waren nicht über Indochina, sondern über Rangun nach China zu bringen ${ }^{133}$.

Die chinesische Regierung beklagte sich über die französische Haltung. Chinas prekäre Versorgung und die Interessen von US-Herstellern ließen auch Washington in Frankreich intervenieren. Mitte Dezember gab Paris nach: Mandel erlaubte den zivilen Lastwagenverkehr von Haiphong über Langson nach Nanning ohne Einschränkung. Der Verkehr durch Kwangchowan blieb untersagt. In der »New York Times« versuchte Brévié Verständnis in Amerika für seine Haltung zu wecken: Der Generalgouverneur setze den weitgehenden Transitbann nur ungern durch, schrieb die NYT, doch von der Unterdrückung des Nachschubs für China hänge ab, daß Japan nicht Hainan besetze ${ }^{134}$.

Der heimliche Waffentransit wurde fortgesetzt, auch wenn Hoppenot Bullitt im Februar 1939 versicherte, es gebe so gut wie keine solcher Transporte. Chinas Botschafter in Berlin erklärte hingegen, deutsche Waffen gelangten über Indochina nach China. Der Geheimdienst der US-Marines meldete, große Mengen Waren, auch Waffen, kämen über Indochina nach China. Die Franzosen nutzten dafür weniger die Yunnanbahn als (vor allem nachts) die Straßen

${ }^{133}$ Mandel an Brévié, T 790, 29.10., T 808, 5.11., T 819-20, 9.11., T 832, 12.11., T 865, T 867, 21.11., T 878, 24.11., T 909, 1.12., T 913, 2.12.; Brévié an Mandel, T 1249, 2.11., T 1261, 5.11., T 1280, 9.11., T 1290, 11.11., T 1323, 18.11., T 1332, 20.11., T 1374, 30.11.1938 (CAOM FM 672, 678); Naggiar an Bonnet, T 1675-81, 6.11., T 1700-2, 11.11.; Brévié an Naggiar, T 391, 7.11., T 1396, 24.11., Naggiar an Bonnet, T, 8.11., Naggiar an Chungking, T 537-38, 17.11.1938 (MAE Japon 127, MAEN Pékin A 395); Southard an Hull, 8.11.; 26.11.; Lockhart an Hull, 7.11.; G-2 Digest, 18.11.1938 (FRUS 1938, III, S. 608, SD 65lg.11251/7, 893.24/482, 793.94/14419); Neumann an Ribbentrop, 12.12.; John J. Taylor an Smets, 1.11.1938 (AA Botsch Peking Pol 5-12, VB R 5777).

${ }^{134}$ Johnson an Hull, 15.11., 25.11., Peck an Hull, 22.12.1938 (SD 893.24/491, 500, 517); Wilson an Hull, 16.11., 5.12., Johnson an Hull, 17.11., 5.12., Welles an Wilson, 1.12., Southard an Hull, 22.12, 19.11., Palmer an Hull, 23.11.1938 (FRUS 1938, III, S. 609, S. 612, S. 383f., S. 611, S. 610, S. 613; SD 65lg.116/10, 651g.11251/6); Naggiar an Bonnet, T 1769-72, T 1773, 20.11.; Saint-Quentin an Bonnet, T 1294-99, 23.11.1938 (MAE Chine 731, SDN 365, DDF XII, 363); Mandel an Brévié, T 948, 19.12., T 960, 22.12., T 986, 29.12; Brévié an Mandel, T 1471, 22.12., T 1500, 29.12.1938; Brévié an Mandel, T 1, 3.1.1939 (CAOM FM 672, 678, Tel 80); Knobel an Bonnet, T 1993-98, 18.12., Hoppenot an Knobel, $\mathrm{T} 730,22.12$; Note de la Direction des affaires politiques et commerciales, 3.12., Außenministerium an chinesische Botschaft, L, 24.12.; Paris-Tokyo Pact Halts Arms Flow, New York Times, 25.12.1938 (MAE Chine 835, DDF XIII, 22, 219; MAEN Pékin A 394). 
in Kwangsi, erfuhren US-Diplomaten. In Haiphong warteten Anfang 1939 fast 25000 Tonnen Material auf den Weitertransport. Von Mitte Dezember 1938 bis Mitte Februar 1939 fuhren 800 Lastwagen nach Nanning ${ }^{135}$.

Während Léger und Hoppenot stets betonten, es gebe keinen Waffentransit durch Indochina, schlug Daladier bei Bullitt andere Töne an: Im Mai 1938 brüstete sich der Regierungschef, er habe nach Amtsantritt als Regierungschef die Behörden in Indochina angewiesen, die Yunnanbahn für alle Flugzeugund Waffentransporte nach China zu öffnen - was aber offiziell nie geschah. Auch andere Indizien passen nicht zum Bild des China-Freundes Daladier: Anfang April 1938 notierte Hoppenot, Daladier wolle jeden Waffentransit durch Indochina stoppen und nicht einmal die Auslieferung alter Bestellungen dulden. Im Juni klagte ein chinesischer Diplomat, Daladier blockiere Waffenexporte nach China. Im Juli 1938 bat Daladier das Außenministerium mit Verweis auf die Gefahren für Indochina, möglichst wenige Transit zu erlauben. Allerdings setzte sich Daladier im März 1938 dafür ein, daß der von ihm protegierte Waffenhändler Audinet Flugzeuge über Indochina ausliefern konnte. Kurz nachdem er am 10. April 1938 Regierungschef geworden war, erlaubte das Außenministerium einigen Rüstungsproduzenten, Bestellungen aus China anzunehmen. Daladier lehnte allerdings im Frühjahr 1939 die Bitte des Kriegsministeriums ab, den Transit zu begrenzen, und befürwortete im Januar 1940 - erneut in Sachen Audinet - die rasche Lieferung von Waffen an China, die jedoch nicht über Indochina erfolgen solle. Wellington Koos Biograph William L. Tung lobt, im Gegensatz zum übervorsichtigen Bonnet habe Daladier Chinas Bitten erfüllt und die Passage von Kriegsmaterial und Flugzeugen erlaubt. Daladier verfolgte aber, wenn es nicht um Audinet ging, eine vorsichtige Transitpolitik. Seine Aussagen im Februar und Juni 1939 gegenüber Bullitt, täglich unterzeichne er Exportgenehmigungen, China erhalte alle Waffen, die Frankreich erübrigen könne, sollten für Sympathie in den USA sorgen. Bullitt glaubte Daladiers Äußerungen nur begrenzt: Im April 1939 urteilte er, die Daladier-Regierung übe schärfere Kontrollen über den Transit aus als frühere Regierungen ${ }^{136}$.

${ }^{135}$ Bullitt an Hull, 11.2., Gilbert an Hull, 7.1., Peck an Hull, 8.2., 18.2.1939 (FRUS 1939, III, S. 104f., S. 737; S. 729f., S. 740f.); Headquarters, Fourth Marines, R-2 report, 3.1., 13.1., Jarvis an Hull, 13.1.1939 (SD 793.94/14762, 14722); Meyer an Hull, 31.1.; Southard an Hull, 11.2.1939 (SD 893.24/540, 851g.1561/2); Brévié an Mandel, T 235-42, 14.2.1939 (CAOM FM Tel 80).

${ }^{136}$ Bullitt an Hull, 9.5.1938 (FRUS 1938, III, S. 164); Note de la sous-direction d'Asie-Océanie pour le ministre, 7.4.1938 (MAE Ac 136); Barnes an Hull, 9.6.1938 (SD 793.94/13285); Daladier an Bonnet, L 1858, 27.7.1938 (SHAT $7 \mathrm{~N}$ 3311); Undatierte Briefentwürfe, die Daladier nicht unterzeichnen wollte: Daladier an Delbos, Transit de matériel de guerre par l'Indochine [vor dem 10.3.1938] (SHAT 7 N 3313); Daladier an Bonnet [Februar 1939] (SHAT 7 N 3311); Daladier an Air, L 63, 22.1.1940 (MAE Chine 560); TUNG, V.K. Wellington Koo, S. 45; Bullitt an Hull, 6.2., 5.6., 4.4.1939 (SD 740.00/568, FRUS 1939, I, S. 269f., III, S. 746f.). 
Eine weitere Änderung der Transitpolitik bahnte sich an, als Japan Hainan am 10. Februar 1939 besetzte und damit seine stillschweigende Gegenleistung für das französische Transitverbot annullierte. Einerseits hätte Paris den Transit offiziell freigeben können, andererseits konnte Japans Luftwaffe nun von Hainan aus Indochina attackieren. Chungking, London und die Verwaltung in Hanoi drängten, den Transit freizugeben. Weil der Antrag eines Exporteurs vorlag, 44 Maschinen zur Waffenherstellung mit einem Gewicht von 316 Tonnen über die Yunnanbahn zu transportieren - wohl identisch mit Chinas Bitte, Maschinen einer »Fabrik für optische Geräte« per Bahn ins Land zu bringen -, fand der Quai d'Orsay eine elegante Lösung: Bei der Definition, was Kriegsmaterial sei, halte man sich nicht mehr an die Aufzählung des französischen Regierungserlasses vom 3. September 1935 über den Waffenexport, sondern an die Nomenklatur der Genfer Konvention vom 17. Juni 1925 über den Kriegswaffen- und Munitionshandel, teilte Léger dem Kolonial- und dem Verteidigungsministerium sowie den Botschaften Japans und Chinas mit. Die Konvention war von Japan und Frankreich unterzeichnet worden und deshalb von Tokio nicht zu beanstanden. Einziger Unterschied zwischen beiden Vorschriften war, daß die Genfer Konvention keine Maschinen umfaßte. Paris war damit China entgegengekommen, hatte das grundsätzliche Verbot eines Waffentransits aber nicht in Frage gestellt. Gegenüber dem britischen Diplomaten Campbell betonte der Politische Direktor Charvériat, die bisherige, strikte Haltung werde nur wenig aufgeweicht. Die Grenze bleibe für Waffen strikt geschlossen. Die Äußerung Mandels Ende Februar gegenüber Bullitt, es gebe keine Restriktionen für den Transit mehr - selbst Mandels Erzfeind Bonnet behauptet dies in seinen Memoiren -, war ohne Basis ${ }^{137}$.

Der Umschlag nichtmilitärischer Güter in Haiphong wuchs enorm. Mandels Anordnung von Mitte Dezember 1938, Lastwagenverkehr durch Haiphong unbegrenzt zuzulassen, machten den Hafen in Tonkin zum zentralen Umschlagplatz für Importe nach China. Von Anfang März bis zum Herbst 1939 meldeten britische und amerikanische Diplomaten, aber auch Japans Presse, einen dramatischen Anstieg der Importe über Yunnanfu und vor allem Langson. Im

\footnotetext{
${ }^{137}$ Brévié an Mandel, T 129, 27.1., T 147, 31.1., T 218-19, 13.2.1939 (CAOM FM Tel 80); Notes de la sous-direction d'Asie-Océanie, 17.2, 3.2., 4.2., Exporterlaubnis für Fa. Somua, 24.2.1939 (DDF XIV, 136; MAE Chine 554); Bullitt an Hull, 16.2., 22.2.1939 (FRUS 1939, III, S. 110, S. 741); Diplomatie an Défense nationale, L 587, 22.2 .1939 (SHAT 7 N 3311); Mandel an Bonnet, T 52, 19.2.1939; Note, Réactions françaises à la suite de l'occupation de Hainan [ohne Datum] (MAE SDN 366; Papiers 1940, cabinet Bonnet 8); Léger an Knobel, T 78-79, 20.2., T 84-85, 24.2.1939 (DDF XIV, 148; MAE Japon 128); Bullitt an Hull, 6.3.1939 (SD 793.94/14781); Howe an Phipps, 2.3.; Phipps an Halifax, 8.3.1939 (FO 371/23426, F 1364/28/10, 371/23437, F 2364/28/10); BONNET, De Munich à la guerre, S. 277. Für die Angabe von HAAS (Französisch-Indochina, S. 36) und ROTH (Japans Strikes South, S. 127f.), als Reaktion auf die Besetzung Hainans habe Paris für zwei Wochen das Transitverbot für Waffen und Munition nach China aufgehoben, gibt es keinen Beleg.
} 
Mai wurden je 9000 Tonnen über Langson und Yunnanfu nach China gebracht, bis Mitte Juli waren 3500 Lastwagen nach China gelangt. Schneller als die abtransportierte Menge wuchsen die Lager. Zwischen 80000 und 150000 Tonnen Material, so Schätzungen, lagen am Hafen. Paris drängte Chungking, den Umschlag der Waren zu beschleunigen, chinesische Beamte verlangten aber Schmiergeld für schnelles Abfertigen. Mandel, der noch im Winter Brévié für seine liberale Transitpolitik gescholten hatte, tönte Mitte April 1939, er entlasse alle Beamten in Indochina, die sich dem raschen Warentransit widersetzen. Einer Statistik der Behörden in der indochinesischen Grenzstadt Langson zufolge wurden 1939 in den sieben Monaten von April bis Oktober 13100 Tonnen Benzin, 2000 Tonnen Petroleum, 9100 Tonnen Zement, 6500 Tonnen Öle und Schmierstoffe, 3600 Kraftfahrzeuge und 450 Tonnen Autoteile sowie 290 Tonnen Medikamente nach China gebracht. Die Statistik nennt auch 3500 Tonnen Metallwaren, 3000 Tonnen Baumwollstoffe, 950 Tonnen Eisen- und Kupferdraht sowie 240 Tonnen Bücher, Deklarierungen, hinter denen Kriegsgerät zu vermuten is ${ }^{138}$.

Paris bemühte sich, die Kapazität der Yunnanbahn zu erhöhen. Von Jahresanfang bis Mitte Juli 1939 hatte sich die monatliche Kapazität bereits von 6000 auf 9000 Tonnen gesteigert. Investionen von 80 Millionen Francs, auch für den Kauf zusätzlicher Waggons und Lokomotiven, sollten die Kapazität auf 18000 Tonnen im Oktober und 30000 Tonnen im Januar 1940, das Fünffache des Vorjahreszeitraums, erhöhen. Bis Ende 1938 war der Umsatz der Yunnanbahn im Vergleich zu 1936 bereits um 117 Prozent gestiegen, im ersten Quartal legte er noch einmal um 48 Prozent zu. Die im Hafen von Haiphong, der auch modernisiert wurde, eingenommenen Gebühren waren zu Beginn 1939 im Vergleich zu den Vorjahren um 200 Prozent gestiegen ${ }^{139}$.

Warum die bis dahin so vorsichtige französische Regierung duldete, daß Haiphong zum Zentrum des zivilen Nachschubs für China wurde, hat verschiedenen Gründe. Zunächst durften die Franzosen hoffen, daß Tokio gegen

${ }^{138}$ Headquarters, Fourth Marines, R-2 report, 4.3.; Meyer an Hull, 26.4., 29.6., 15.8., Peck an Hull, 22.5.; Flood an Hull, 22.5., 2.6 .1939 (793.94/14943; 893.24/570, 585, 605, 577, 851g.1561/5, 851g.77/23); Walsh an Halifax, 11.3., 12.7., Broadmeat an Halifax, 21.4.1939 (FO 371/22921, C 4185, 10342, 8244/249/17); STS-bulletin, 1.4., 1.8.1939 (MAEN Chine 535); Crépin an Cosme, L 49, 24.4.1939 (MAEN Tchonging 7); Yvon an Guerre, D 332, 1.6.1939 (DDF XVI, 332); Bullitt an Hull, 21.4.1939 (SD 651g.11251/14); Colonies an Diplomatie, L 3707, 28.6., Royère an Cosme, L 38, 12.5., L 52, 13.6., L 64, 13.7., L 76, 17.8., L 85, 14.9., L 90, 17.10., L 98, 14.11.1939 (MAE Indff 45).

${ }^{139}$ Bulletins Comparatifs des Recettes des Chemins, in: JO de l'Indochine Française, 8.1.1938, S. 122, 11.1.1939, S.107, 31.5.1939, S. 1516 (CAOM INF FM 104); Cosme an Bonnet, L 9, 16.6.; Brady an Hull, 8.4.; Wilson an Hull, 10.6.1939 (MAE Chine 949, SD 893.24/564, 893.51/6911); Kurt BLOCH, China's Lifelines and the Indo-China Frontier, in: Far Eastem Survey (1940), S. 47f. HuLot, Les Chemins de Fer, Bd. 1, S. 56f.; Young, China and the Helping Hand, S. 109; »L'Indochine apprend à se défendre elle-même«, »Le Petit Parisien«, 17.8.1939 (CAOM Fonds Mandel 17/PA/1). 
die zivilen Exporte, die zum überwältigenden Teil aus den USA stammten, mit Rücksicht auf Amerika nicht protestierte. Washington machte Paris im Juni 1939 klar, für wie wichtig die USA das Offenhalten der Verkehrswege in Indochina für China hielten. Einen Konflikt mit der US-Regierung wollten die Franzosen vermeiden. Zudem hatte der Präsident der Handelskammer Hanoi Baffeleuf Ende März mit seiner Forderung nach liberalem Transit die breite Zustimmung des Kolonialausschusses der Kammer erhalten. Das Kolonialministerium fürchtete, daß sich der Chinahandel von Indochina ab- und Birma zuwenden könnte; und die Transporte waren für die französische Staatskasse profitabel. Die französische Regierung machte China, Großbritannien und den USA im Sommer 1939 deutlich, daß sie die Verbote weniger rigid anwandte. Léger, Charvériat und Botschafter Saint-Quentin betonten gegenüber britischen und US-Diplomaten jedoch, daß sich Paris auf diese Linie nicht würde festlegen lassen und daß ein sichtbarer Waffenexport über Indochina nur bei einer Garantie beider Mächte in Frage käme ${ }^{140}$.

Französische Waffen durften seit Oktober 1938 nur noch über die BirmaStraße nach China gebracht werden. Der erste Konvoi konnte die von 160000 zwangsverpflichteten Männern, Frauen und Kindern hergestellte, 1144 Kilometer lange Verbindung zwischen Yunnanfu und Lashio in Nordostbirma Mitte Dezember 1938 befahren und transportierte bereits 60 Tonnen französisches Kriegsmaterial. Weitere 700 Tonnen französischer Waffen warteten in Singapur auf den Abtransport nach Rangun. Die auch mit Expertise des französischen Ingenieurs Maux erbaute schmale Straße in gebirgigem Gelände war nicht für größeren Güterverkehr geeignet. Kein französischer Beobachter vertraute der Kapazität der $S$ traße $\mathrm{e}^{141}$. Doch der Quai d'Orsay dirigierte die französischen Waffen- und Munitionsexporte weiter nach Rangun, weil sie dort, anders als in Indochina, nicht für Friktionen mit Japan sorgten, aber dennoch irgendwann in Yunnanfu ankamen.

${ }^{140}$ Brady an Hull, 2.3., Hull an Bullitt, 2.6., Wilson an Hull, 15.6., 10.6., Bullitt an Hull, 3.6.1939 (FRUS 1939, III, S. 742, S. 756f., SD 893.51/6911, 6902); Walsh an Halifax, 22.3.1939 (FO 371/22921, C 5008/249/17); Bullitt an Hull, 4.4., 31.7., Welles, Memorandum of Conversation, 21.7.1939 (FRUS 1939, III, S. 746f., S. 698, S. 541f.); Notes de la sous-direction d'Asie-Océanie, 14.4., 17.5.1939 (MAE Chine 761, 664); Charvériat, Note, 5.4., Charvériat an Phipps, L, 15.6.1939 (DDF XV, 268; XVI, 440); Phipps an Halifax, 6.4.1939 (FO 371/23437, F 3441/28/10).

${ }^{141}$ Bames an Hull, 19.7.1938 (SD 893.154/219); SEH, Reinseignement, 28.10.1938 (CAOM CabMil 81); SEH, renseignement, 30.11.1938, 12.4., 10.5., 15.6.; 20.7., 10.10.1939 (CAOM CM 94, 78); Naggiar an Bonnet, T 1790-92, 22.11.1938 (DDF XII, 353); Naggiar an Bonnet, T 1713-14, 12.11., T 1790-92, 22.11., Etablissement Edgar Brandt an Diplomatie, 15.12., Crépin an Bonnet, T 14, 16.12.1938 (MAE Chine 554); Guillermaz, Note No. 17, 7.2., Crépin an Cosme, D 20, 7.3.1939 (DDF XIV, 63, 277); STS-bulletin, 1.4., 1.6.1939 (MAE Chine 535); Brévié an Mandel, T 644, 17.4.1939 (CAOM FM Tel 80); Bulletin quotidien des Affaires étrangères, 6.9.1939 (SHAT $7 \mathrm{~N} 3308$ ). 
Ausländische Rüstung wurde vom französischen Zoll weiter durchgelassen, wenn sie als zivile Ware deklariert war. Mit dem Hinweis an Bullitt Mitte September 1939, daß Waffen- und Munitionskisten die Grenze passierten, wenn sie nach dem Prinzip sthat a rose by any other name would smell as sweet« beschriftet seien, räumte der Quai d'Orsay ein, daß er die Praxis kannte. Von »un certain relachement dans les restrictions apportées au trafic par la frontière Indochinoise« berichtete Admiral Decoux im Mai 1939. Nach Informationen des US-Konsuls in Saigon, des US-Marine-Geheimdienstes in Shanghai und des US-Finanzberaters in Chungking bedeutete dies, daß sämtliches Kriegsmaterial (außer Material französischen Ursprungs) unbeschränkt die Grenze passierte. Von einem massiven Waffenschmuggel ging auch Tokio aus. Der neue Generalstabschef der Armee in Kanton, der ehemalige Militärattaché Tsushihashi, drohte Thiébaut am 1. August 1939 mit einem Angriff auf die Yunnanbahn im Laufe des Monats, wenn der Transit nicht ende ${ }^{142}$.

Wie von Chiang Kai-shek befürchtet, beschränkte Frankreich nach Ausbruch des Kriegs in Europa den Transit. Mitte September beschlagnahmte Catroux 30 für China bestimmte Lastwagen sowie Waren für fast elf Millionen Francs, die deutsche Bürger in China erhalten sollten. Drastische Maßnahmen verhängte der Kolonialminister - ohne Rücksprache mit dem Quai d'Orsay am 23. oder 26. September: Mandel verbot sämtliche Lieferungen von Lastwagen, Benzin und Waffen nach China, außer den Waren, die bereits in Indochina lagerten. Binnen zehn Tagen sollte das in Haiphong lagernde Material abtransportiert werden. Catroux erklärte Chinas Generalkonsul jedoch, er wolle die Anordnung nicht anwenden. Paris trieb die Chinesen nur zur Eile an. Die Unsicherheit über die Bestimmungen in Indochina sollte Chungking wohl auch dazu bringen, verstärkt die Birmastraße zu nutzen. Angesichts der Bemühungen um eine Annäherung an Tokio wollte Paris den Eindruck vermeiden, es unterstütze Chinas Kriegführung. Als Henry das Transitverbot in Tokio bekanntgab, sorgte dies dort für Zustimmung. Einen oder zwei Tage später erklärte Catroux jedoch, das Transitverbot gelte nur für Kriegsmaterial. Allem Anschein nach endete damit tatsächlich die Praxis, falsch deklarierte Waffen passieren zu lassen. Anfang Oktober verlangte der Generalgouverneur, deutsche Waren bis Monatsende aus Haiphong abzutransportieren. Weil Erdrutsche und ein Unfall die Yunnanbahn im Oktober blockierten, war dies jedoch unmöglich. Chiang Kai-shek bat Washington und London um Hilfe. Nach

${ }^{142}$ Cosme an Daladier, T 1176-79, 23.10., T 93-96, 4.12.1939 (MAE Chine 739, 677); Southard an Hull, 3.3., Bullitt an Hull, 9.9., 14.9., 5.10., Flood an Hull, 15.4.1939 (FRUS 1939, III, S. 145, S. 758f., SD 893.24/614, 566); FNEO, compte rendu, 5.5.1939 (SHM 1 BB4 74); Fourth Marines, R-2 report, 5.8.1939 (SD 793.94/15423); YouNG, China and the Helping Hand, S. 108; Henry an Bonnet, T 436-37, 1.8.1939 (DDF XVII, 377); Diplomatie an Guerre, L 3298, 3.8.1939 (SHAT 7 N 3313). 
Paris entsandte Chiang seinen persönlichen Emissär Li Yu Ying. Im Oktober schätzten US-Beobachter, in Haiphong lagerten 220000 Tonnen Ware ${ }^{143}$.

Das Chaos im Hafen wuchs, als Japan im November Nanning besetzte und den Nachschubweg über Langson abschnitt. Zuletzt waren nach US-Schätzungen monatlich zwischen 13000 und 18000 Tonnen, dem französischen Militärattaché zufolge 3000 Tonnen und 1200 Lastwagen, auf diesem Weg nach China gelangt. Einige amerikanische und chinesische Firmen verlagerten ihren Warenumschlag nach Birma. Den Franzosen gelang es, die Kapazität der Yunnanbahn im November und Dezember auf je 18000 Tonnen zu steigern. Nach dem Angriff auf Nanning bewilligte Paris 16 Millionen Francs für den Ausbau der parallel zur Yunnanbahn verlaufenden Straße Haiphong-Laokai.

Nach Beginn der Bombardements auf die Yunnanbahn sank die Transportkapazität deutlich: Im Januar und Februar 1940 kamen nur noch 5000 und 7500 Tonnen Waren nach Yunnanfu. Seit Anfang Januar wurde zusätzlich eine enge Straße über Caobang genutzt. Auf diesem Weg wurden bis 1000 Tonnen monatlich transportiert, auch wenn er ständig von Japan bombardiert wurde. Die Menge der gelagerten Waren in Haiphong reduzierte sich dennoch: Es kamen weniger Waren in Haiphong an; ab März wurden monatlich zwischen 3500 und 7000 Tonnen von Haiphong nach Rangun gebracht. Zudem transportierte die Yunnanbahn im April und Mai wieder jeweils 17000 Tonnen nach China. In Haiphong lagerten Anfang Juni »nur« noch 135000 Tonnen Waren. Erstmals seit eineinhalb Jahren sah US-Konsul Charles S. Reed die Lage wieder mit Optimismus. Am 28. Mai forderte China die französische Regierung auf, den Transit über Indochina zu beschleunigen ${ }^{144}$.

${ }^{143}$ Catroux an Mandel, T 1632, 19.9.; Cosme an Daladier, T 1176-79, 23.10., 26.10., Léger an Cosme, T, 26.10.1939 (CAOM FM Tel 82, MAE Chine 739); Auriti an Ciano, 14.11.1939 (DDI Serie 9, II, 210); Johnson an Hull, 10.9., Bullitt an Hull, 20.10., 4.12., 13.12., 14.12.1939 (FRUS 1939, III, S. 240, S. 295f., S. 768f., S. 769f., SD 751.93/67); Hull an Bullitt, 4.10., Johnson an Hull, 27.9., 29.9., Flood an Hull, 29.9., Brady an Hull, 16.9., Meyer an Hull, 20.10., Reed an Hull, 27.10., 10.11., Flood an Hull, 7.11.1939 (SD 893.24/610-612, 629, 632, 652, 653, 637); Flood an Hull, 9.10.; Reed an Hull, 9.11.1939 (SD 611.51g9/4, 851g.156/8, 851g.77/26); Cadogan, Memorandum, 27.9., Chinesische Botschaft, aide-mémoire, 9.10., Clark Kerr an Halifax, 13.10., Howe an Campbell, 31.10.1939 (FO 371/23428, F 10481, 10912, 10999, 11215/28/10); Clark Kerr an Halifax, 18.9., 23.10.1939 (FO 371/23461, F 10301, 11196/87/10); Clark Kerr an Halifax, 28.9., Campbell an Howe, 16.11.1939 (FO 371/23444, F 10579/69/10, FO 371/23462, F 11986/87/10). Die Mitteilung des US-Konsuls, einer glaubwürdigen Quelle zufolge seien vier Tonnen Dynamit auf Lastwagen über Caobang nach China gebracht worden, ist der einzige Hinweis, daß nach dem September 1939 weiter Kriegsmaterial über Indochina geschmuggelt wurde (Reed an Hull, 20.4.1940, SD 893.24/735).

144 Reed an Hull, 6.12.1939, 3.1., 4.1., 12.1., 20.2., 4.3., 10.3., 5.4., 9.4., 20.4., 8.5., 12.6.1940 (SD 893.24/675, 691, 692, 694, 709, 713, 716, 715, 727, 736, 740, 773); Reed an Hull, 4.12.1939, 30.1., 3.4.; Note Penfield, 6.12., Reed an Hull, 4.12.1939, 6.4., 6.2., 20.4.1940, Johnson an Hull, 8.12.1939, 4.3., Peck an Hull 14.1.1940 (SD 851g.77/27, 851g.154/12, 16, 851g.1561/9, 11, 14, 793.94/15717, 15866, 15569, 15726, 15599); Yvon an EMA.2, Note, 5.12.1939; Crépin an Cosme, L 48, 22.3.; Chinas Botschaft, aide-mémoire, 28.5.1940 (SHAT 7 N 3292, MAEN Tchongking 7, MAE Indfr 45). 
Im Juni 1940 erklärten Henry und Chiang Kai-shek den US-Botschaftern, es habe seit 1937 keine Waffentransporte über Indochina gegeben. Catroux' Angabe gegenüber britischen Offizieren, "seit einiger Zeit« habe es keine Waffentransporte mehr gegeben, entsprach schon eher den Tatsachen. Im Herbst 1940 fielen Japans Truppen ihren Angaben zufolge 150000 Tonnen Nachschub und 2200 Lastwagen in die Hände. Die Franzosen schätzten die Beute auf 100000 Tonnen Fracht, darunter $1000 \mathrm{Lkw}^{145}$.

Einer Statistik der Stadt Yunnan zufolge kamen von Ende 1937 bis Anfang 19401355 Flugzeuge, 176000 Fliegerbomben, 178 Panzer, 4284 Maschinengewehre, 360 Maschinenpistolen, 520 Mörser mit 252000 Geschossen, 320 Geschütze mit 263000 Granaten, 23,6 Millionen Patronen sowie 5600 Lkw über die Yunnanbahn nach China. Cosme hielt die Statistik für exakt ${ }^{146}$. Die hohe Zahl an Flugzeugen und Panzern, wo doch Beobachter keinen Waffentransit über die Bahn sahen, darf aber bezweifelt werden. Französische Waren waren kaum darunter. Französische Firmen verkauften von Juli 1937 bis zum Sommer 193924 Panzer, 2000 Maschinengewehre, 400 Geschütze mit 14000 Granaten, 600 Mörser mit 910000 Geschossen sowie 3,9 Millionen Patronen. Zwei Drittel davon gelangte über Hongkong oder Birma nach China - nämlich fünf Panzer, 1650 Maschinengewehre, 300 Geschütze mit mindestens 10000 Granaten, 540 Mörser mit mehr als 400000 Geschossen, der Rest kam legal über Indochina ${ }^{147}$. Der Wert französischer Lieferungen ohne Flugzeuge betrug rund 300 Millionen Francs. Die USA verkauften doppelt soviel Kriegsgerät an China $^{148}$, die Sowjetunion und das Deutsche Reich offenbar noch mehr.

Führte der immense Waffentransport und der uneingeschränkte Transit von Benzin und Fahrzeugen durch Indochina dazu, daß Tokio Indochina attackierte, wie Pierre-Étienne Flandin, Henri Cosme und der Kolonialbeamte Georges Gautier beklagen? Oder hätte Japan die Gelegenheit des französischen $\mathrm{Zu}$ sammenbruchs in Europa auch ausgenutzt, wenn Paris China nicht unterstützt hätte, wie Militärattaché Camille Sabattier annimmt ${ }^{149}$ ? Die Frage läßt sich

${ }^{145}$ Grew an Hull, 18.6., Johnson an Hull, 24.6.1940 (SD 893.24/745, FRUS 1940, IV, S. 34); C in C China an War Office, 28.6.1940 (FO 371/24328, C 7405/7327/17); ROTH, Japan Strikes South, S. 53.

${ }^{146}$ Cosme an Vichy, L 153, 19.7.1940 (MAE Vichy-Asie 124).

${ }^{147}$ Für diese Schätzung wurden französische, britische und amerikanische Quellen abgeglichen. Die Exporterlaubnisse des Außen- und des Verteidigungsministeriums sind in SHAT 7 N 3312-3313 sowie MAE Chine 553, 554 und 558 archiviert. Bestätigungen der französischen Konsulate in Longtchéou und Yunnanfu über aus Frankreich importiertes Material finden sich in MAEN Pékin A 394. Die Berichte, die US-Konsul Brady ab Mai 1939 aus Rangun über die Transporte auf der BurmaStraße nach Washington lieferte, sind in SD 893.24/571-708 abgelegt; Erkenntnisse der britischen Behörden über den französischen Waffenexport über Hongkong und Burma wurden den Akten FO 371/22072-22075, FO 371/23428 und 23437 entnommen.

${ }^{148}$ State Department, Division of Controls, Memorandum, 2.2.1940, SD 893.24/697.

${ }^{149}$ FLANDIN, Politique française, S. 137; Cosme an Chauvel, L 135, 19.7.1940, L 35, 31.3.1941 (MAE Vichy-Asie 124); GAUTIER, La fin de l'Indochine, S. 25; SABATTIER, Le destin, S. 27. 
nicht entscheiden. Ohne den Transit hätte Japan jedenfalls im Juni 1940 keine Beobachter nach Hanoi entsandt. Daß Indochina später auf Japans Wunschliste geraten wäre, ist möglich. Sicher ist, daß der Quai d'Orsay und Édouard Daladier einen Konflikt mit Japan erwarten mußten, als sie eine liberale Transitpolitik duldeten. Sie gingen das Risiko ein, von dem vor allem deutsche und insbesondere amerikanische Exporteure profitierten, ohne eine Garantie Londons oder Washingtons zu verlangen, die Paris noch im Herbst 1937 als unabdingbar bezeichnet hatte. Gegenüber den Briten stritt der Quai d'Orsay ja sogar den Transit ab, vermutlich, um nicht auch britische Exporte in Haiphong abfertigen zu müssen. Warum ging Paris für China dieses Risiko ein?

Fünf Gründe scheinen dafür maßgeblich. Moralische Motive befinden sich nicht darunter. Grundsätzlich hatte Paris ein Interesse daran - vor allem, wenn dies heimlich geschehen konnte -, daß Japan in China ausblutete. Dies erhöhte die Sicherheit Indochinas und schwächte das Gewicht, das Japan als Deutschlands Verbündeter gegen Großbritannien oder die Sowjetunion in die Waagschale werfen konnte. Je schwächer Japan war, desto leichter konnte sich auch Frankreich mit Japan über einen modus vivendi in China einigen; eine in China versinkende japanische Armee konnte kaum gegen Indochina vorgehen. Der großzügige Transit bot, zweitens, die Chance, Südchina wirtschaftlich auf Haiphong auszurichten und damit die französische Einflußsphäre zu stärken. Es dürfte, drittens, in Paris und in Haiphong genug Franzosen gegeben haben, die direkt von den umfangreichen Transporten profitierten und auf Daladier Einfluß nahmen. Viertens ließ sich angesichts der starken französischen wirtschaftlichen Interessen und des dringenden Bedarfs Chinas ein Transitembargo praktisch kaum durchsetzen. Fünftens wußten Daladier und Léger, wie wichtig Washington die Versorgung Chinas war. Über Bullitt erfuhren sie eventuell sogar, daß der Transit ein Herzensanliegen Roosevelts persönlich war, der am Wohlergehen Chinas ebenso interessiert war wie an dem der USExporteure. Daladier und Léger riskierten also einen begrenzten Konflikt mit Japan, weil sie Sympathien in Washington gewinnen wollten, die in Europa so wichtig waren. Dafür spricht auch, daß die großzügige Transportpolitik begann, als für Paris nach Österreichs "Anschluß« die Luft in Europa dünn wurde. Die persönlichen Interessen der am Transit Beteiligten ließen den von Paris grundsätzlich geduldeten Waffenschmuggel dann aufblähen.

In letzter Konsequenz ging Paris also für seine Beziehungen zu den USA ein gehöriges Risiko für Indochinas Integrität ein. Paradoxerweise widersetzte sich während des Zweiten Weltkriegs ausgerechnet die US-Regierung dem Wiederaufleben der französischen Herrschaft in Indochina. 


\subsection{Frankreich verliert die Kontrolle über die Konzessionen}

Als Deutschlands Truppen im Mai 1940 Frankreich überrannten, bemühte sich Japans Militär in Tientsin, die sich seit Monaten hinziehenden Verhandlungen über das Silber, die Währung und Japans Rechte in den Konzessionen zu beenden. Tokio wollte wegen der unklaren Entwicklung in Europa seine Hegemonie in Nordchina förmlich absichern und die Lage klären, ehe es seine Ambitionen auf den Süden richtete, wo die Kolonien der Niederlande, Frankreichs und Großbritanniens Japan beinahe schutzlos ausgeliefert waren.

Anfang Juni sagte Henry in Tokio grundsätzlich zu, daß Frankreich in Tientsin die gleichen Zugeständnisse machen werde wie Großbritannien. Mit Genehmigung des Quai d'Orsay veröffentlichten Henry und Außenminister Arita am 20. Juni Noten, die dem entsprachen, was Craigie mit Tokio vereinbart hatte. Demnach wurde das in der französischen Konzession lagernde Silber, nach der Entnahme von 200000 Pfund für humanitäre Zwecke, von Franzosen und Japanern versiegelt. Das Geld wurde von einer gemischten Kommission verwaltet. Frankreichs Konzession verpflichtete sich, die Währung der Federal Reserve Bank anzunehmen und die chinesischen Wechselstuben japanischer Kontrolle zu unterwerfen. Henry versprach, für Tientsin ein Abkommen zur Zusammenarbeit der japanischen und der französischen Polizei abzuschließen. Schließlich gab Henry eine von Japans Armee schon im Januar 1940 verlangte Erklärung $a b$, in der die französische Regierung die besonderen Rechte der japanischen Armee in Nordchina anerkannte. Diese Verlautbarung glich aufs Wort der Stellungnahme Craigies vom 22. Juli 1939. Offenbar um zu demonstrieren, daß er nur dem britischen Beispiel folgte, gab Henry diese Erklärung auf Englisch ab, während die anderen Bestandteile der Vereinbarung mit Arita auf Französisch formuliert waren. Als Craigie und Henry die Verträge unterzeichnen, hob Japans Militär am 20. Juni um $18 \mathrm{Uhr}$ japanischer Zeit nach 372 Tagen die Blockade auf. Frankreichs Regierung, die unmittelbar vor der Kapitulation stand, dürfte das Ereignis kaum registriert haben. Das Foreign Office hingegen gratulierte Craigie zu dem Abschluß ${ }^{150}$.

Mit Italiens Kriegserklärung vom 10. Juni hatte sich die Lage aller französischen Konzessionen in China erheblich verschärft. Dies lag aber nicht an den Italienern. Unmittelbar nach Mussolinis Kriegserklärung suchte Botschafter Taliani in Shanghai Cosme auf und erklärte ihm, er wünsche, Zwischenfälle zu vermeiden und auf keinen Fall Japan hineinzuziehen. In Shanghai, Peking

\footnotetext{
${ }^{150}$ Henry an Cosme, T 194-97, 6.6.; Corbin an Reynaud, T 2492, 12.6.; Craigie an Halifax, 17.6., 18.6., 25.6., Halifax an Craigie, 21.6.1940 (MAEN Pékin A 311, Londres C 482, FO 371/24652-53, F 3420, 3423/5/10, F 3890/5/10); Armee-Aufzeichnung, 12.1.1940 (JA, S 1.1.1.0-28, S. 550).
} 
und Tientsin vereinbarten französische und italienische Kommandeure, ihre Truppen zu trennen: Diese erhielten an verschiedenen Tagen Ausgang und durften bestimmte Zonen nicht mehr betreten. Im Settlement patrouillierten britische, amerikanische und italienische Militärpolizisten gemeinsam ${ }^{151}$.

Tokio nutzte jedoch den Kriegseintritt Italiens, dem Japans Kriegsminister Hata einen ruhmreichen Sieg wünschte, um Briten, Franzosen und Italiener zum Abzug ihrer Truppen und Schiffe aufzufordern. Vize-Außenminister Tani erklärte den Botschaftern, er erwarte diesmal eine rasche Antwort. Botschafter Corbin riet zum Nachgeben, weil sich Frankreich keinen Streit in Asien leisten könne. Man solle die USA um Hilfe bitten. Die französische Regierung, die vollends mit ihrer eigenen Kapitulation beschäftigt war, ermächtigte Cosme am 23. Juni, gemeinsam mit Henry über die Zukunft der französischen Truppen zu entscheiden. Aus Washington war nichts zu erwarten. Saint-Quentin fragte am 27. Juni Sumner Welles, ob US-Truppen im Falle einer Forderung Japans nach Räumung der Konzession die Franzosen bei der Verteidigung unterstützen oder das Gebiet übernehmen könnten. Der undersecretary antwortete Frankreichs Botschafter, die USA übernähmen keine Verantwortung. Japans Militär reichte es dann aber, in Frankreichs Konzession gemeinsam mit französischen Beamten Polizeigewalt auszuüben ${ }^{152}$.

Am 25. Juni eröffnete die japanische Gendarmerie Büros in beiden westlichen Konzessionen in Tientsin. Zwei Tage später vereinbarten Henry und Arita eine Zusammenarbeit der französischen und der japanischen Polizei in Tientsin, die die Konzession praktisch japanischer Kontrolle unterwarf: Die japanische Polizei durfte zehn, unter besonderen Umständen bis zu 25 Gendarme als zivile Beobachter in die französische Konzession entsenden. Die Gendarme durften alle Aktivitäten der französischen Polizei verfolgen und um Festnahmen bitten. Antijapanischer Aktivitäten verdächtige Chinesen wurden, wenn es Beweise gab, sofort an ein örtliches Gericht übergeben. Gab es keine Beweise, durften die Japaner die Verdächtigen verhören. Durch Folter erpreßte Geständnisse blieben gültig, solange die Folter keine körperlichen Spuren hinterließ. Ähnliche Abkommen galten in Shanghai und Hankou. Für die winzige Konzession in Kanton hielten beide Seiten eine Vereinbarung

${ }^{151}$ FTFC, EM.2., compte rendu, 16.6.1940 (SHAT 11 H 63); Fletcher an Hull, 11.6., Smyth an Hull, 12.6.1940 (FRUS 1940, IV, S. 348, S. 352); Noble an Halifax, 13.6., 14.6.1940; Despatch on Shanghai Emergency, 1.1. to 27.8.1940 (FO 371/24655, F 3392, F 5662/16/10).

${ }^{152}$ Henry an Cosme, T 204, 11.6.; Boissezon an Reynaud, T 137-38, 11.6., Charles-Roux an Cosme, T 2 BX, 23.6.1940 (MAEN Pékin A 312; MAE Vichy-Asie 124); Craigie an Halifax, 11.6., 12.6., mit Note Cadogan, 15.6., White an Halifax, 12.6., Halifax an Lothian, 18.6., Lothian an Halifax, 22.6.1940 (FO 371/24655, F 3392/16/10); Grew an Hull, Butrick an Hull, 12.6., 2.7.1940 (FRUS 1940, IV, S. 350, S. 751); Corbin an Reynaud, T 2535, 14.6.1940 (MAEN Londres C 486); LANGER, Gleason, The Challenge, S. 599f.; Memorandum of Conversation, 27.6.1940 (SD 893.24/828). 
offenbar für unnötig. Das Entgegenkommen ging so weit, daß Cosme seiner Regierung versichern mußte, die rechtliche Lage der Konzessionen bleibe unverändert. Henry und Arita äußerten, die Zusammenarbeit sei nur vorübergehender Natur, die Extraterritorialität der Franzosen bleibe unangetastet ${ }^{153}$. Japan hatte die Konzessionen als Fluchtstätte für chinesische Widerstandskämpfer und Hindernis seiner wirtschaftlichen Hegemoniepläne ausgeschaltet, und beherrschte die westlichen Niederlassungen auch im Innern. Lediglich der Zugriff auf ausländische Staatsbürger blieb Japan theoretisch versagt.

Mit der Zulassung japanischer Polizisten in den Konzessionen vollendeten Henry und Cosme eine Entwicklung: Seit dem Herbst 1938 hatte Frankreich immer mehr Eingriffe in die Konzessionen zugelassen, aber den Schein der Souveränität verteidigt. Im Juni 1940 übergaben die Franzosen die faktische Kontrolle über die Konzessionen, sie verteidigten nur die formelle Herrschaft über die Konzessionen. Frankreich und Japan bestätigten damit die förmliche Fortexistenz französischer Rechte, die in der Praxis bis auf eine leere Hülle ausgehöhlt waren. Nach dem gleichen Muster sollten Vichy und Tokio später im August 1940 die Präsenz japanischer Truppen in Indochina vereinbaren.

Mit der Neuordnung der Herrschaft über die französischen Konzessionen wurden auch zwei territoriale Fragen in Shanghai neu geregelt. Die 400 Hektar, die französische Truppen im November 1937 unmittelbar westlich von der französischen Konzession besetzt hatten, gaben die Franzosen an Japan heraus. Am 23. Juni zogen sich die französischen Truppen aus dem ohne rechtliche Grundlage besetzten Gebiet zurück. Auch die »Jacquinot-Schutzzone« von Nantao, die Frankreichs Prestige so genutzt hatte, wurde aufgelöst. Die noch verbliebenen 19000 Flüchtlinge wurden, mit der Lebensmittelration für einen Monat, sich selbst überlassen ${ }^{154}$.

\subsection{Das Ende der französischen Souveränität in Indochina}

Trotz des seit September 1939 in Europa herrschenden Krieges hatte Frankreich bis ins Frühjahr 1940 seine Position im Fernen Osten behauptet. Tokio hatte zwar massiv Druck auf die Beendigung des Transits durch Indochina

${ }^{153}$ Cosme an Vichy, T 499-504, 20.7., Cosme an Gandon, L 94, 23.7.1940 (MAE Vichy-Asie 124, MAEN Tchongking 3); WASSERSTEIN, Secret War, S. 74; ROTH, Japan Strikes South, S. 51.

${ }^{154}$ Cosme an Chauvel, T 499-504, 20.7.1940 (MAE Vichy-Asie 124); Memorandum/Despatch by Major General F. Keith Simmons, 10.7., 27.8.1940 (FO 371/24655, F 3392, 5662/16/10); QUIGLEY, The Far Eastern War, S. 143; WASSERSTEIN, Secret War, S. 61. 
nach China ausgeübt und die Reduzierung französischer Kontingente in China erreicht, doch Frankreichs Rolle in Ostasien stand nie in Zweifel. Entscheidend ins Rutschen geriet die französische Position durch die deutsche Offensive in Europa.

Japan war im Frühjahr 1940 bestrebt, seine Kontrolle über den Südpazifik zu verstärken. Eine Woche nach Deutschlands Angriff auf Dänemark und Norwegen erklärte Außenminister Arita am 15. April Japans Interesse am Erhalt des Status quo in Niederländisch-Indien, da er ein Protektorat der USA oder Großbritanniens über das ölreiche Borneo befürchtete. Tokio hatte bereits im Januar das Schiedsgerichtsabkommen mit Den Haag gekündigt und im Februar 1940 höhere Ölexporte der Niederländer verlangt. Den französischen Vorschlag eines gemeinsamen Auftritts der drei westlichen Mächte in Tokio lehnte Hull zwar ab, doch er rief Japan die Verpflichtungen des Vier-MächteVertrages von 1921 in Erinnerung. Am Tag nach dem Beginn der deutschen Offensive gegen Frankreich wiederholte Arita am 11. Mai gegenüber den Botschaftern Frankreichs, Großbritanniens und Deutschlands den Wunsch, den Status quo in Niederländisch-Indien zu erhalten. Aritas Sorge vor einem alliierten Vorgehen im Pazifik war gestiegen, weil britische und französische Truppen am 10. und 11. Mai auf Den Haags Bitte die niederländischen Inseln Curaçao und Aruba in der Karibik besetzt hatten, um einen deutschen Handstreich zu verhindern. London und Paris, aber auch Den Haag, Washington und zuletzt Berlin sicherten zu, den Status quo in der niederländischen Kolonie zu bewahren. Zeitgleich mit Aritas Erklärung erhielt Japans Vierte Flotte die Weisung, sich für eine eventuelle Operation gegen die niederländische Kolonie bereit zu halten. Vom 11. bis 21. Mai spielte die Marineführung in Tokio zudem in einem großangelegten Planspiel die Möglichkeit eines längeren Konflikts mit Großbritannien und den USA über Niederländisch-Indien durch. Danach beschloß der Generalstab, für alle Eventualitäten einen Plan zur Eroberung der niederländischen Kolonie auszuarbeiten ${ }^{155}$.

Das Foreign Office nahm Anfang Juni an, daß Japan Frankreichs prekäre Lage in Europa nicht für ein Unternehmen gegen Indochina ausnutzen werde, da Tokio die Entwicklung in der Sowjetunion, in den USA und in China nicht absehen könne. Von der Erklärung des japanischen Kolonialministers General

\footnotetext{
${ }^{155}$ Hull, The Memoirs, S. 888f.; Langer, Gleason, The Challenge, S. 585f.; MuraKami, Japan's Thrust, S. 49f.; KREBS, Japans Deutschlandpolitik, S. 409f.; SATO, Japan and Britain, S. 55f.; Tsunoda Jun, The Navy's Role in the Southern Strategy, in: MORLEY (Hg.), The Fateful Choice, S. 241-295 (S. 241f.); PELZ, Race to Pearl Harbor, S. 213; FEIS, Road to Pearl Harbor, S. 51f.; Muhammed Abdul AZIZ, Japan's Colonialism and Indonesia, Den Haag 1955, S. 106f.; War Office an Foreign Office, Weekly Summary, 14.5.1940 (FO 371/24654, F 3131/15/10); Grew an Hull, 14.4., Bullitt an Hull, 15.4.1940 (SD 740.0011 Eur. War 1939/2206, 2244); Arita an Sawada, 2.5.1940 (JA, S 1.1.1.0-28, S. 123f., S. 446f.); LEGRAND, L'Indochine, S. 18.
} 
Kiosi, Japan wolle wirtschaftlich in den Süden expandieren, hielt der britische Geheimdienst Indochina für nicht betroffen. Nur britische Kreise in Hongkong hielten ab Anfang Juni einen Angriff Japans auf Indochina für denkbar ${ }^{156}$.

In Europa kollabierte Frankreich allerdings viel schneller, als alle Beobachter annahmen. Schon fünf Tage nach Beginn der deutschen Offensive fürchtete General Gamelin eine schwere Niederlage; am 16. Mai nahm er an, die Deutschen könnten noch am selben Tag in Paris einrücken. Um die Franzosen zu mobilisieren, bildete Reynaud am 18. Mai die Regierung um: Marschall Philippe Pétain, der Sieger von Verdun, den Reynaud schon am 6. Mai in die Regierung aufnehmen wollte, wurde vice-président $d u$ Conseil, Georges Mandel, der im Ersten Weltkrieg den Defätismus so wirksam bekämpft hatte, wechselte vom Kolonial- ins Innenministerium. Der bisherige Handelsminister Louis Rollin übernahm das Kolonialressort. Daladier, der am 21. März trotz des Rücktritts als Regierungschef Verteidigungsminister geblieben war, wurde Außenminister. Reynaud übernahm das Militärressort selbst ${ }^{157}$.

Unmittelbar vor der Übergabe des Quai d'Orsay an Daladier entließ Reynaud, wie er seit Anfang Mai geplant hatte, Generalsekretär Alexis Léger und berief den Botschafter am Heiligen Stuhl, François Charles-Roux, zu Légers Nachfolger. Reynaud nannte keine Gründe für den Schritt, doch die Umbesetzung erleichterte die Annäherung an Italien; sie brachte Reynaud bei der politischen Rechten, die Léger ablehnte, Sympathien; und Charles-Roux war kein Generalsekretär, der Reynaud widersprechen würde. Zudem fürchtete Reynaud Légers Machtfülle und dessen Nähe zu Daladier, den Reynaud haßte. Hinter den Kulissen intrigierte auch Reynauds Mätresse, Hélène de Portes, heftig gegen Léger ${ }^{158}$. Nicht zuletzt wollte Reynaud in der dramatischen Lage der französischen Öffentlichkeit einen Sündenbock liefern. Frankreichs Fernostpolitik verlor damit den Kopf, der sie seit Mitte der zwanziger Jahre gelenkt hatte. Alexis Légers Grundüberzeugungen wurden aber von Charles-Roux und Chauvel geteilt, so daß Frankreichs Ostasienpolitik nach dem 18. Mai zunächst unverändert blieb. Einen Kurswechsel konnte sich Paris in der dramatischen Lage ohnehin nicht leisten. Am 5. Juni bildete Reynaud die Regierung

${ }^{156}$ Corbin an Daladier, T 2384-85, 5.6.1940 (MAEN Londres C 486); Far East Combined Bureau, Intelligence Summary, 15.5.1940 (WO 208/864); Southard an Hull, 6.6.1940 (SD 793.94/15911).

${ }^{157}$ PertinaX, Les fossoyeurs, Bd. 1, S. 87f.; Baudouin, Neuf mois, S. 55; Villelume, Journal, S. 327; GATES, End of the Affair, S. 81; CRÉmieuX-BrilhaC, Les Français, Bd. 1, S. 548.

${ }^{158}$ VILLELUME, Joumal, S. 320f; HARVEY, Diplomatic Diaries, S. 362; DARIDAN, Le chemin, S. 196; DU RÉAU, Édouard Daladier, S. 426; SACOTTE, Alexis Léger, S. 157f;; PERTINAX, Les fossoyeurs, Bd. 1, S. 258f.; Chauvel, Commentaire, S. 98; Stefan GrüNER, Paul Reynaud (1878-1966). Biographische Studien zum Liberalismus in Frankreich, München 2001 (Quellen und Darstellungen zur Zeitgeschichte, 48), S. 335; MAY, Strange Victory, S. 337; KAMMERER, La vérité sur l'armistice, S. 29f. De Crouy-Chanel (Alexis Leger, S. 148) und Villelume (Jounal, S. 339) machen hingegen Daladier für die Entlassung verantwortlich. 
erneut um und übernahm von Daladier auch das Außenministerium. Der Brigadegeneral Charles de Gaulle, ein alter Freund Reynauds, wurde Staatssekretär im Kriegsministerium.

Die Lage im Fernen Osten schien weiter stabil. Im April und Mai kamen Gerüchte auf, Japan wolle Indochina angreifen. Seine Flotte habe starke Kräfte in Amoy und auf Formosa konzentriert. Doch bei Nachforschungen stellten sich die Berichte als falsch heraus. Dies galt auch für die von China Anfang Juni verbreitete Information, Tokio konzentriere Schiffe vor Hainan. Weder französische noch britische Aufklärer stellten verdächtige Bewegungen in Südchina fest ${ }^{159}$. Der Quai d'Orsay gewann Mitte und Ende Mai sogar den Eindruck, Japans Regierung, die fürchte, von Berlin in den Krieg gezogen zu werden, bemühe sich intensiver um Frankreichs Freundschaft. Dafür sprach auch, daß der frankophile Sato Naotake, ehemaliger Botschafter in Paris, eine japanische Mission nach Europa anführte. Henry und der Quai d'Orsay glaubten Ende Mai, daß in Tokio zwei Fraktionen um die Macht rangen: Die Extremisten wollten eine Expansion in den Süden und ein Bündnis mit Berlin und Rom, die Moderaten wollten nicht mit London, Paris und Washington brechen. Unter der aktuellen Regierung habe Indochina nichts von Japan zu befürchten. Um die gemäßigten Kräfte in Japan zu stärken, von denen der Erhalt des Status quo in Ostasien abhing - nicht aus unmittelbarer Angst vor einer eventuellen japanischen Aggression gegen Indochina -, wies der Quai d'Orsay Ende Mai oder Anfang Juni Henry an, im Gaimusho über die Verlängerung des Handelsvertrags, den Nickelexport aus Neukaledonien sowie den Überflug Indochinas durch eine japanische Fluglinie zu sprechen. Die Gespräche sollten zu einem rapprochement an Japan führen. Auch die Briten, so Reynauds Vorstellung, sollten Japan im Handelsbereich entgegenkommen. Auf Anraten des Foreign Office, das vor einer Verärgerung der Amerikaner über das französische Angebot warnte, verzichtete er jedoch darauf, Washington über seine neuen Vorschläge zu informieren ${ }^{160}$.

Vize-Außenminister Tani lehnte die französische Offerte am 4. Juni nicht $a b$, doch Nickellieferungen seien Vorbedingung für die Verlängerung des Handelsvertrags. Wenn Frankreich aufhöre, Lastwagen und Treibstoff nach

${ }^{159}$ DEcoux, À la barre de l'Indochine, S. 65; Halifax an Craigie, 15.5., Militärattaché Tokio an War Office, 16.5.1940 (FO 371/24730, F 3276/66/23); Cosme an Reynaud, T 417, 6.6.1940 (MAEN Londres C 486); Southard an Hull, 1.6., Grew an Hull, 3.6., Johnson an Hull, 7.6., Grew an Hull, 11.6.1940 (SD 793.94/15890, 15899, 15914, 15926).

${ }^{160}$ Charvériat an François-Poncet, T 914, 22.5.1940 (MAE Japon 129); Bullitt an Hull, 22.5., Hull an Bullitt, 23.5., Grew an Hull, 24.5.1940 (SD 740.0011 Eur. War 1939/3237, 3297); Henry an Reynaud, T 419--23, 11.6.1940 (MAE SDN 2143); Cosme an Daladier, T 382, 26.5., Henry an Daladier, T 38991, 30.-31.5., note de la sous-direction d'Asie-Océanie, 25.5., Corbin an Daladier, T 2310-14, 3.6., Reynaud an Corbin, T 2376-78, 6.6., Corbin an Reynaud, T 2405, 6.6.1940 (MAEN Londres C 486). 
Chungking zu schicken, trage dies zur Entspannung bei. Die Äußerung war, anders, als im Tokioter Kriegsverbrecherprozeß angenommen, keine Drohung. Henry sagte nach dem Gespräch, das sich ähnlich zwischen Botschaftsrat Fain und dem Leiter der Europa-Abteilung im Gaimusho Nishi wiederholte, er glaube, Japan wolle wirklich eine Verständigung mit Frankreich und England.

Reynaud bat Japan sogar um Waffenlieferungen. Frankreichs Regierung hatte bereits im Januar 1940 in Tokio angefragt, ob sie Waffen kaufen könne. Ende Mai und am 4. Juni im Außenministerium in Tokio sowie am 5. Juni in Paris gegenüber der japanischen Handelsfirma Showa baten die Franzosen um die Lieferung von Flugzeugen und Munition, für Indochina wolle man Uniformen und Gewehre kaufen. Tokio versuchte, die Bitte zu nutzen, um von Paris einen Handelsvertrag, den Verkauf größerer Nickelmengen aus Neukaledonien und vor allem ein Ende des Transits in Indochina zu erreichen, und verzögerte die Antwort. Von einem starken Druck Japans auf Frankreich läßt sich aber nicht sprechen. Noch am 13. Juni, einen Tag, bevor deutsche Truppen in Paris einmarschierten, hielt Cosme die Situation in Asien für stabil ${ }^{161}$.

Frankreichs Lage verdüsterte sich. Am 25. Mai hatte das Comité de guerre der Regierung erstmals die Möglichkeit einer Kapitulation erwogen, seit dem 26. Mai zogen sich die britischen Truppen aus Frankreich zurück. Am 10. Juni verließ die Regierung Paris in Richtung Tours, Italien erklärte Frankreich den Krieg. Am 14. Juni zog die Regierung weiter nach Bordeaux, deutsche Truppen rückten in Paris ein. Reynaud, der in der Regierung keine Mehrheit für die Fortsetzung des Kampfes fand, gab am 16. Juni auf. Pétain wurde Regierungschef. Am 17. Juni - 125 Jahre nach der Schlacht von Waterloo vom 18. Juni 1815, wie Jean-Louis Crémieux-Brilhac bemerkt - bat der Marschall Hitler und Mussolini um einen Waffenstillstand ${ }^{162}$.

Nicht nur politisch, sondern auch technisch waren nach der Abreise der Regierung aus Paris die Möglichkeiten des Außenministeriums begrenzt, auf die Entwicklung Einfluß zu nehmen. Angesichts katastrophaler Telegrammund Telefonverbindungen war die Diplomatie größtenteils von der Außenwelt abgeschnitten. In den nur kurz bezogenen Büroräumen bei Tours und Bor-

${ }^{161}$ Henry an Daladier, T 397-98, 4.6., Henry an Reynaud, T 200, 6.6., Cosme an Reynaud, L 137, 13.6.1940 (MAEN Londres C 486, Pékin A 312, Tchongking 5); TWTC, XX, Urteil, S. 48922; Bericht über Treffen Tani-Henry, 4.6., Bericht über Treffen Nishi und Fain, 6.6., Arita an Sawada, 7.6., Sawada an Arita, 7.6. 1940 (JA, S 1.1.1.0-28, S. 127f., S. 131f., S. 453f., S. 456f.).

${ }^{162}$ Baudourn, Neuf mois, S. 138, S. 145, S. 175f.; François ChaRLes-Roux, Cinq mois tragiques aux Affaires étrangères (21 mai-1 ${ }^{\text {er }}$ novembre 1940), Paris 1949, S. 5, S. 22f.; AZÉMA, 1940, l'année terrible, S. 60, S. 187; Duroselle, L'Abîme, S. 201 f.; Heimsoeth, Der Zusammenbruch, S. 347f; P.M.H. BELL, The Breakdown of the Alliance in 1940, in: Neville WAITES (Hg.), Troubled Neighbours. Franco-British Relations in the Twentieth Century, London 1971, S. 200-227 (S. 201f.); CRÉMIEUX-BrILHAC, Les Français, Bd. 1, S. 615. 
deaux spielten sich chaotische Szenen $a b^{163}$. Ab dem 12. Juni spitzte sich die Lage in Indochina zu: Die japanische Armee in Kanton drohte öffentlich mit dem Einmarsch in die Kolonie. Henry glaubte nicht, daß Japans Regierung das Vorgehen des Militärs unterstützte, aber sie stehe unter Druck. Japans Truppen in Südchina setzten sich nach Indochina in Marsch, Gerüchte über die Präsenz japanischer Flottenverbände vor Hainan bestätigten sich nicht. Am 15. Juni sagte ein japanischer Diplomat Botschafter Cosme, die japanisch-französischen Differenzen lösten sich auf, wenn Frankreich den Benzintransport nach China einstelle. Cosme riet Catroux, der japanischen Bitte zu folgen. Am gleichen Tag verlangte General Tsushihashi in Tokio die sofortige Einstellung des Transports von Benzin und Lastwagen nach China. Am 16. Juni erhielt die Armee in Indochina Hinweise aus Tokio, wonach Japan die Schließung der Grenze notfalls mit Gewalt durchsetzen wolle. Catroux stoppte am 16. Juni den Benzintransit. Am folgenden Tag unterbrach Catroux auch den Transit von Lastwagen. In der Praxis, so die Beobachtung des US-Konsuls in Hanoi, gelangte allerdings noch bis zum 20. oder 22. Juni Benzin über die Grenze. Dem US-Konsul in Saigon zufolge endete der Benzin- und Lastwagentransit am 20. Juni, am 22. Juni wurde der gesamte Transit unterbrochen ${ }^{164}$.

Als Pétain am 17. Juni einen Waffenstillstand anstrebte, ahnte Catroux, daß weitere japanische Forderungen folgten. Ebenso mußte dem Generalgouverneur klar geworden sein, daß er die Herrschaft in Indochina ohne Hilfe aus Paris würde behaupten müssen. Craigie schloß keine japanischen Militärmaßnahmen gegen Indochina mehr aus, wenn auch der Stop des Benzintransits die Atmosphäre entspanne. Am 18. Juni bat Catroux Saint-Quentin, die US-Regierung zu fragen, wie sie sich verhalte, falls Japan Indochina angreife. Anlaß der japanischen Drohungen sei immerhin der Transit von Lastwagen und Benzin aus den USA nach China. Einen Tag später bat Catroux die Amerikaner um die Lieferung von Flugzeugen und Flugabwehrgeschützen, damit Indochina den Status quo im Pazifik bewahren könne. Am 18. und am 20. Juni informierte ein Mitarbeiter Catroux' US-Konsul Charles Reed über die Notlage. Am 19. Juni sprach Saint-Quentin mit Sumner Welles, am 20. Juni mit dem Diplomaten Hornbeck. Beide hielten einen japanischen Angriff für möglich,

\footnotetext{
${ }^{163}$ Chauvel, Commentaire, S. 111f.; HaRveY, Diplomatic Diaries, S. 386f.; Claude LÉVY, Le département à l'heure de Vichy, in: BAILLOU (Hg.), Les affaires étrangères, Bd. 2, 1870-1980, Paris 1984, S. 541-561 (S. 541); CRÉMIEUX-BRILHAC, Les Français, Bd. 1, S. 587.

${ }^{164}$ Henry an Cosme, T 216, 13.6., Cosme an Catroux, T 98-99, 15.6.1940 (MAEN Pékin A 312); Southard an Hull, 1.6.1940 (SD 793.94/15890); Cosme an Reynaud, T 417, 6.6.1940 (MAEN Londres C 486); Grew an Hull, 17.6., 20.1940 (SD 793.94/15954; FRUS 1940, IV, S. 30f.); Henry an Cosme, T 222, 15.6., Catroux an Cosme, T 1035, 16.6.1940 (MAEN Pékin A 395); Reed an Hull, 17.6., 18.6., Grew an Hull, 18.6.1940 (FRUS 1940, IV, S. 25f., SD 893.24/746, 745); DECOUX, Ȧ la barre de l'Indochine, S. 65; Catroux, Deux actes, S. 54; Pedrazzani, La France en Indochine, S. 16; Reed an Hull, 21.7., Flood an Hull, 6.8.1940 (SD 893.24/844, 819).
} 
doch Amerika wolle über Indochina keinen Krieg riskieren. Privat riet Welles, die Grenze für den Transit zu schließen. Diesen Rat könne er weder offiziell noch offiziös geben. Bezeichnenderweise fertigte Welles von dem Gespräch keine Niederschrift an. Die einzige Maßnahme, die die US-Diplomatie für Indochina ergriff, war am 22. Juni der Vorschlag eines Notenaustausches, in dem Japan und die USA ihr Interesse an der Bewahrung des Status quo im Pazifik ausdrückten. Arita lehnte die Anregung ab, Washington insistierte nicht. Anfang Juli erklärte der Sprecher des Weißen Hauses sogar, über Indochinas Schicksal sollten allein die asiatischen Staaten entscheiden ${ }^{165}$.

Amerikas Passivität in diesem entscheidenden Moment stellen die französischen Beteiligten in ihren Memoiren als wichtigen Grund für Frankreichs Nachgeben dar, während die US-Diplomaten in ihren Erinnerungen die französische Anfrage schlicht unterschlagen ${ }^{166}$. Ob Catroux wirklich auf Hilfe aus Amerika hoffte, ist fraglich. Zwar waren die Vereinigten Staaten das einzige Land, das helfen konnte. Doch weil auch Henry sich am 20. Juni bei Grew für Frankreichs Zusammenarbeit mit Japan entschuldigte, liegt die Vermutung nahe, daß Catroux mit seiner Anfrage in Washington vor allem Kritik der USA verhindern wollte ${ }^{167}$.

Über die Schließung der indochinesischen Grenze für Lastwagen und Treibstoff informierte Henry Vizeaußenminister Tani noch am 18. Juni. Zu diesem Zeitpunkt hatte sich Japans Regierung auf ihre Haltung zu Indochina geeinigt. Die Europa/Asien-Abteilung im Außenministerium hatte Ende Mai einen Plan für den Fall eines raschen Endes des Krieges in Europa entworfen. Sie empfahl, Japans wirtschaftliche und politische Beziehungen zu den Ländern in Ost- und Südostasien zu stärken und zu versuchen, den westlichen Einfluß zurückzudrängen. Der Stabsoffizier Nishiura Susuma vom Armeeministerium,

\footnotetext{
${ }^{165}$ Craigie an Halifax, 17.6.1940 (FO 371/24674, F 3422/57/10); CATROUX, Deux actes, S. 54f.; Reed an Hull, 20.6., 19.6.; Hombeck, Memoranda, 20.6., 22.6.; Saint-Quentin an Corbin, T 1213, 20.6.1940 (SD 851g.01/12, FRUS 1940, IV, S. 26, S. 29, SD 851g.01/26, MAE Vichy-Asie 27); BAUDOUIN, Neuf mois, S. 217; William DUIKER, Les États-Unis et l'Indochine française 1940-1945, in: BRocheuX u.a. (Hg.), L'Indochine française, S. 177-213 (S. 179); ROTH, Japan Strikes, S. 54.

${ }^{166}$ DeCouX, À la barre de l'Indochine, S. 97f.; Catroux, Deux actes, S. 54f.; Chauvel, Commentaire, S. 228f;; CharLes-RouX, Cinq mois tragiques, S. 70f.; BaUdouIN, Neuf mois, S. 217; HULL, The Memoirs, Bd. 1, S. 896; Fers, Road to Pearl Harbor, S. 67; Welles, The Time for Decision, S. 289; DERS., Seven Decisions, S. 289. Georges BONNET macht die USA indirekt für den Verlust Indochinas verantwortlich. In drei Memoiren-Bänden wirft er Washington vor, 1938 und 1939 die Bildung einer westlichen Front gegen Japan verhindert und die Bedrohung durch Japan unterschätzt zu haben (Defénse de la paix, Bd. 2, S. 57; De Munich à la guerre, S. 240, S. 276f., S. 522; Dans la tourmente, 1938-1948, S. 108). An anderer Stelle begründet er den Vorwurf damit, die US-Regierung habe im Herbst 1939 eine mögliche Annäherung an Japan blockiert (Le Quai d'Orsay, S. 309).

${ }^{167}$ Grew an Hull, 20.6.1940 (FRUS 1940, IV, S. 30f.). Auch die Bitte am 11. Juni um die Hilfe der USA in Europa hatte, so Reynauds Mitarbeiter Paul DE VILLELUME, der das Telegramm an Roosevelt verfaßte, das Ziel, sich mit Amerikas Einverständnis mit Hitler zu einigen (Journal, S. 405).
} 
der am 19. Mai den Auftrag erhielt, wegen des deutschen Vorstoßes eine neue Strategie zu entwerfen, riet Mitte Mai und Anfang Juni zu großer Vorsicht bei der Planung eines Südstoßes. Den Vorschlag des Kabinettsberaters Kuhura Fusanosukem vom 6. Juni, Maßnahmen gegen die Länder zu ergreifen, die Chiang Kai-shek unterstützten, wies Regierungschef Yonai zurück. Auch der Armee-Generalstab drang mit seinen Forderungen nicht durch: Am 1. Juni legten die Generäle einen Plan vor, wonach man von Indochina die Einstellung aller Transporte auf der Yunnanbahn, ein Durchmarschrecht für japanische Truppen durch Indochina sowie die Abtretung eines Teils Nordindochinas fordern solle. Falls Paris ablehne, solle man zur Gewalt greifen. Das Kriegsministerium schwächte den Plan ab: Zunächst solle man auf diplomatischem und friedlichem Weg französische Zugeständnisse erreichen. Erst wenn dies scheitere, sei der Einsatz militärischer Mittel zu erwägen. Am 18. Juni beschloß das Innere Kabinett in Tokio, von Paris die Schließung der Grenze zu fordern. Nach Henrys Erklärung, daß Catroux den Lastwagen- und Benzintransit gestoppt habe, erhöhte Tokio seine Forderung: Am 19. Juni verlangte Tani von Henry, Frankreich müsse sämtliche Transporte nach China stoppen. Japanische Inspekteure müßten den Transportstop vor Ort beobachten; bis zum 20. Juni abends habe Frankreich den japanischen Forderungen nachzugeben. Die gleichen Forderungen übergab der japanische Generalstab an Militärattaché Thiébaut. Begleitet wurden die Ultimaten von neuen Drohungen der japanischen Armee in Kanton gegen Frankreich ${ }^{168}$.

Henry und Catroux hielten die Befolgung der japanischen Forderungen für den einzigen Weg, Zeit zu gewinnen und einen unmittelbar drohenden japanischen Angriff abzuwenden. Thiébaut erklärte, die Annahme des Ultimatums sei nur eine Chance, aber keine Sicherheit, um Indochina zu retten. Einen Konflikt mit Japan könne Indochina wegen seiner mangelhaften Rüstung nicht bestehen, waren sich die Verantwortlichen einig. Catroux beriet sich mit General Martin und dem Asienexperten Grandjean aus der Kolonialverwaltung und stimmte Tanis Forderung zu. Noch am 19. Juni schloß Catroux die Grenze für alle Transporte und akzeptierte japanische Beobachter. Eine Einschränkung der französischen Souveränität durch die Kommission sei dem sicheren

\footnotetext{
${ }^{168}$ Murakami, Japan's Thrust, S. 44f.; TsunOda, The Navy's Role, S. 241f.; HatA, The Army's Move, S. 159; FeIS, Road to Pearl Harbor, S. 66; SOMMER, Deutschland und Japan, S. 338; KrEBS, Japans Deutschlandpolitik, S. 418f; CATrouX, Deux actes, S. 47f.; GaUTIER, La fin de l'Indochine, S. 20; Plädoyer Oneto (TWTC Bd. XVI, S. 38550); Craigie an Halifax, 20.6.1940 (FO 371/24730, F 3400/66/23); Canadian Legation (Washington) an Hull, 20.6.1940 (SD 893.24/781); GOC Hongkong an War Office, 19.6.1940 (FO 371/24654, F 3410/15/10). DREIFORTS (bisweilen unpräziser) Darstellung zufolge verlangte Tani bereits am 17. Juni vor der Presse die Einstellung des Waffentransits durch Indochina (Japan's Advance, S. 279).
} 
Verlust Indochinas im Krieg mit Japan vorzuziehen gewesen, argumentiert Catroux in den Memoiren. Henry informierte Tokio von der Entscheidung ${ }^{169}$.

In der kurzen Zeit hielt es Catroux für unmöglich, die Regierung in Bordeaux an der Entscheidung zu beteiligen. Erst in der Nacht zum 20. Juni informierte er telegraphisch den neuen Kolonialminister, den sozialistischen Abgeordneten Albert Rivière, der in die Regierung eintrat, nachdem Amtsinhaber Rollin aus Protest gegen Pétains Waffenstillstandsgesuch zurückgetreten war. Am 20. Juni setzte Henry sein Außenministerium von der Befolgung des japanischen Ultimatums in Kenntnis. Generalsekretär Charles-Roux stimmte Catroux' Entscheidung zu. Immerhin hatte ja auch Léger zu Jahresbeginn Japan einen Transitstop und die Akzeptanz einer Kontrollkommission in Indochina angeboten. Doch Rivière hielt japanische Inspekteure auf französischem Boden für inakzeptabel, wie er Catroux am 21. Juni telegraphierte. Die Japaner, so Rivières weltfremder Vorschlag, sollten auf chinesischem Boden kontrollieren. Der Generalgouverneur wies am 24. Juni die Kritik des Ministers zurück: Die Befolgung des Ultimatums sei die einzige Möglichkeit gewesen, um Indochina für Frankreich zu bewahren. Gleichzeitig verlangte Catroux, daß ihm die Regierung Handlungsfreiheit gebe. Rivière beharte auf seiner Position, die, wie er Catroux schrieb, mit dem Außenministerium abgestimmt sei. Da Catroux am 20. Juni zudem nach Bordeaux telegraphiert hatte, er wolle trotz des Waffenstillstandsgesuchs der Regierung den Kampf an Englands Seite fortsetzen, und er London uneingeschränkte Unterstützung angeboten hatte, griff der Kolonialminister durch: In der Kabinettssitzung am 25. Juni verlangte Rivière, Catroux abzulösen. Admiral Darlan schlug Vize-Admiral Decoux, Chef der Fernostflotille, als neuen Generalgouverneur vor. Dieser sei bereits vor Ort. Darlan verbürgte sich für Decoux' Gehorsam. Das Kabinett stimmte Darlans Vorschlag zu. Henry versicherte Tokio am 26. Juni, der personelle Wechsel bedeute keine Veränderung der Politik. In dieser Krise für Frankreich und sein Kolonialreich war ein ungehorsamer Generalgouverneur, der ankündigte, weiter unabhängig von Bordeaux zu handeln, für die Regierung kaum zu dulden ${ }^{170}$. Catroux beruft sich in seinen Memoiren darauf, er habe für den Fall, daß die Verbindung zur Metropole abreißen sollte, von Kolonialminister

\footnotetext{
${ }^{169}$ Henry an Cosme, T 237-38, 19.6., Catroux an Cosme, T 1069, 19.6., Grew an Hull, 20.6.1940 (MAEN Pékin A 312, A 395; FRUS 1940, IV, S. 30f.); LEGRAND, L'Indochine, S. 26; CATrouX, Deux actes, S. 58f.; DECOUX, Ȧ la barre de l'Indochine, S. 66; VALETTE, Indochine, S. $22 \mathrm{f}$.

${ }^{170}$ Charles-Roux an Cosme, T 1 BX, Saint-Quentin, T 8-BY, 23.6., Rivière an Catroux, T 1S, 21.6., Rivière an Catroux, T 11R, 1.7.1940 [sic, richtig wohl 24.6.1940] (MAE Vichy-Asie 27); CATROUX, Deux actes, S. 46f.; Allied Expeditionary Force an State Dpt, 8.11.1944 (SD 851 g.00/11-844); Note de la sous-direction d'Asie-Océanie, 26.6.1940 (MAE Vichy-Asie 27); DECOUX, À la barre de l'Indochine, S. 66; GaUTIER: La fin de l'Indochine, S. 21f.; LeGRAND, L'Indochine, S. 26f.; Baudoun,, Neuf mois, S. 216; MARTIN DU GARD, La carte impériale, S. 419f;; LERNER, Catroux, S. 138f.
} 
Rollin eine Handlungsvollmacht erhalten. Daran sind aber Zweifel erlaubt, denn im Konflikt mit Rivière erwähnte Catroux Rollins Blankoscheck nicht. Zudem berichtete Chauvel am 20. Juni von Plänen, daß die Regierung dem Generalgouverneur für alle Eventualitäten eine Vollmacht erteilen wolle, wofür der Ministerrat dann aber keine Zeit fand. Chauvel schreibt in seinen Memoiren, Rivière habe diese Vollmacht verweigert. Decoux nahm am 20. Juli die Arbeit als Generalgouverneur auf und blieb Chef der Forces navales d'Extrême-Orient, die er im August 1940 auflöste ${ }^{171}$.

Ihre Interessen bedroht sahen nun die Chinesen. Einerseits hatten die Franzosen ihren wichtigsten Nachschubweg abgeschnitten, andererseits waren 125000 bis 150000 Tonnen Material in Haiphong, darunter 2200 Lastwagen, unmittelbar in Gefahr. Tatsächlich beschlagnahmte Japan das Material im September. Chinas Regierung protestierte in Hanoi und in Shanghai gegen die französische Unterwerfung, was die Franzosen kaum zur Kenntnis nahmen; Cosme meldete gar, China habe nur pro forma der Zulassung japanischer Beobachter in Indochina widersprochen. Zudem versuchte Chungking, die USA für eine Demarche zugunsten der Unabhängigkeit Indochinas und des freien Warentransits zu gewinnen. Dies scheiterte aber ebenso wie Chinas Versuch, die deutsche Regierung von der Bedeutung des Versorgungsweges Indochina zu überzeugen. Um zu verhindern, daß Japan die Yunnanbahn für die Invasion Südchinas nutzte und die Franzosen Waggons nach Indochina brachten, zerstörte China am 22. Juni eine Eisenbahnbrücke ${ }^{172}$.

Auf einem anderen Weg versuchte China, Einfluß auf Indochina zu nehmen. Am 28. Mai 1940 bekräftigte Finanzminister Kung das frühere, zuletzt Ende September 1939 wiederholte Angebot seiner Regierung, 100000 Mann für Indochinas Verteidigung abzustellen. Eine Woche später erneuerte Außenminister Wang Cheng Hui in Chungking gegenüber Konsul André Gandon die Offerte; um den 10. Juni sprach auch Wellington Koo Staatssekretär Paul Baudouin und Generalsekretär François Charles-Roux an und regte zusätzlich ein diskretes Treffen beider Generalstäbe $a^{173}$. Kein französischer Diplomat

${ }^{171}$ Catroux, Deux actes, S. 43, S. 106; Biddle an Hull, 20.6., 21.6.1940 (SD 851g.01.13, 16); CHAUVEL, Commentaire, S. 230f.; ANTIN DE VAILLAC, Les canonnières, S. $227 \mathrm{f}$.

${ }^{172}$ Reed an Hull, 19.7.1940 (SD 893.24/843); COGNIET, BÜHRER, Histoire et épopée, S. 256; Cosme an Chauvel, T 499-504, 20.7.1940 (MAE Vichy-Asie 124); Johnson an Hull, 21.6., 23.6., 24.6.1940 (SD 893.24/749, 753; FRUS 1940, IV, S. 34); Hornbeck, Memorandum of Conversation, 28.6.1940 (SD 893.51/7096); LANGER, GLEASON, The Challenge, S. 599; Aufzeichnung, von Weizsăcker, 28.6.1940 (AA Pol VIII 60, 2); Meyer an Hull, 25.6., Note, Division of Far Eastern Affairs, Note, 6.8., Perkins an Hull, 2.7.1940 (SD 793.94/15985, 16068); Reed an Hull, 21.7.1940 (SD 893.24/844).

${ }^{173}$ Phipps an Halifax, 29.9.1939 (FO 371/23517, F 10586/2882/10); Cosme an Daladier, T 385-87, 28.5., Charles-Roux an Cosme, T 244, 30.5.1940 (MAE Chine 677); Cosme an Daladier, L 331, 3.10.1939 (MAE Chine 739); Cosme an Reynaud, T 411-16, 6.6., note d'audience, cabinet du soussecrétaire d'État, 10.6.1940 (MAE Vichy-Asie 124); ChARLES-RouX, Cinq mois tragiques, S. 70. 
sah in Chinas Angebot, das kam, als Frankreich die Hilfe starker Freunde brauchte, wirklichen Beistand. Cosme warnte, China versuche, Frankreich in Tokio zu kompromittieren und in einen Krieg gegen Japan zu ziehen. Die chinesische Armee sei militärisch für Indochina wertlos, dafür gefährdeten $100000 \mathrm{Kulis}$ in Indochina die Kolonie. Eine Allianz mit China helfe Frankreich gegen Japan nicht. Ohne Beistand der USA müsse Paris eine Übereinkunft mit Tokio suchen, das immerhin an der Grenze Indochinas und vor Frankreichs Konzessionen Truppen unterhalte. Die Präsenz chinesischer Truppen in Indochina müsse man unbedingt verhindern. Schon im Oktober 1939 hatte er ein ähnliches Angebot Chiangs mit der Bemerkung kommentiert, der Möglichkeit, daß 100000 Kulis ohne Waffen, Munition und Offiziere nach Indochina gesandt werden, sehe er mit Schrecken entgegen ${ }^{174}$.

Ebensowenig sah Generalsekretär Charles-Roux einen Grund, Chinas Angebot anzunehmen. Er bat Cosme, Kung zu antworten, daß man für Chinas Geste danke. Staatssekretär Baudouin beschränkte sich auf Zuhören, als Koo die Vorschläge wiederholte ${ }^{175}$. Warum die Franzosen Chinas Angebot ablehnten, wird auch in den Memoiren von Charles-Roux und Militärattaché Sabattier deutlich. Dem Generalsekretär zufolge schlug Koo vor, Indochina von chinesischen Truppen besetzen zu lassen, um es vor einer japanischen Aggression zu schützen. Hinweise auf aggressive Absichten Japans habe der Botschafter aber nicht besessen. Die Chinesen nach Indochina zu lassen, hätte einerseits einen japanischen Angriff erst heraufbeschworen, andererseits wäre dies wegen der alten Ansprüche des Reichs der Mitte auf Vietnam sehr riskant gewesen, so Charles-Roux. Militärattaché Sabattier glaubt, daß Chinas Truppen, von Indochina einmal zu Hilfe gerufen, vermutlich nicht gegen Japan gekämpft, sondern »als gierige Horden « das Land geplündert hätten ${ }^{176}$.

Als Reaktion auf die Zulassung der japanischen Beobachter wiederholte Chinas Regierung am 22. oder 23. Juni in Chungking das Angebot einer militärischen Kooperation und bestand darauf - gleichsam als Ausgleich zu den in Haiphong erwarteten japanischen Offizieren -, Vertreter ihres Generalstabs nach Hanoi zu entsenden. Cosme solle nach Chungking kommen. Am 25. Juni wiederholte Wellington Koo in Bordeaux die Bitte. Am 19. Juni hatte er Charles Rochat bereits erklärt, wie wichtig China der Erhalt des Status quo in Indochina sei. Alle chinesischen Vorschläge wurden abgelehnt ${ }^{177}$. Die

\footnotetext{
${ }^{174}$ Cosme an Daladier, L 331, 3.10.1939, T 385-87, 28.5.1940 (MAE Chine 739, 677); Cosme an Reynaud, T 461-66, 6.6., Cosme an Charles-Roux, T 463-65, 23.6.1940 (MAE Vichy-Asie 124).

${ }^{175}$ Charles-Roux an Cosme, T 244, 30.5.1940 (MAE Chine 677); Note d'audience, cabinet du soussecrétaire d'État, 10.6.1940 (MAE Vichy-Asie 124).

${ }^{176}$ Charles-Roux, Cinq mois tragiques, S. 70; SABATTIER, Le destin, S. 30.

${ }^{177}$ Note de la Direction des affaires politiques, 19.6., Cosme an Charles-Roux, T 463-65, 23.6.1940 (MAE Vichy-Asie 124); DuRoselle, L'Abîme, S. 323.
} 
Präsenz chinesischer Soldaten in Indochina hätte mit Sicherheit einen kriegerischen Konflikt zwischen Japan und Frankreich provoziert - genau das hatte Catroux mit der Zulassung der japanischen Beobachter verhindern wollen.

Um sich Japans Kontrolle zu entziehen, hätte Indochina noch auf britische Unterstützung bauen können. Doch die Briten standen seit dem 19. Juni unter ähnlichem Druck wie die Franzosen. An diesem Tag drohte Japans Armee mit Krieg, falls London nicht sofort die Nachschubwege über Birma und Hongkong schließe und seine Truppen aus Shanghai abziehe. Japans Außenministerium lehnte die Kriegsdrohung der Armee ab, schloß sich aber der Forderung an. Einen Krieg mit Japan mußte die britische Regierung verhindern. Um Indochina trotz der Kapitulation der Regierung in Bordeaux im Krieg - gegen Deutschland! - zu halten, versprach London Catroux deshalb diplomatische, wirtschaftliche und finanzielle Hilfe, aber dies half Catroux nicht gegen die unmittelbare Bedrohung. Der General hatte auch Angst bekommen, daß Japan gegen Indochina vorgehe, falls er den Briten folge $^{178}$. Damit waren sich, außer Kolonialminister Rivière, alle französischen Entscheidungsträger in Europa und Ostasien einig: Allein die prompte Erfüllung aller japanischen Wünsche konnte die Fortdauer der französischen Souveränität über seine fernöstliche Kolonie noch gewährleisten.

Selbst nachdem sich die Franzosen am 19. Juni den japanischen Forderungen gefügt hatten, fürchtete das Militär in Indochina einen japanischen Angriff binnen Tagen. Die Städte wurden weiter verdunkelt. Ab dem 21. Juni löste sich die Spannung in Indochina. Am 22. Juni teilte Tani Henry die Zusammensetzung der $» B e o b a c h t e r g r u p p e \ll$, so der offizielle Titel, mit. Diese umfaßte 30 Soldaten, 23 Offiziere und Unteroffiziere der Armee sowie sieben Marineangehörige, und zehn Beamte des Außenministeriums, darunter drei Mitarbeiter des Generalkonsulats in Hanoi. Die Japaner träten in zivil und diskret auf, versprach Tani. Um Transporte nach China zu unterbinden, kämen sieben Inspekteure bereits am 25. Juni auf einem Minenleger in Haiphong an. Chef der Mission war General Nishihara Issaku, der an der Botschaft in Paris gearbeitet sowie bei zwei Gelegenheiten Japan vor dem Völkerbund in Genf vertreten hatte. Nishihara sprach französisch und galt als gemäßigt. Am 28. Juni erreichten japanische Verbände aus Südchina die indochinesische Grenzstadt Chennankuan, um zu vermeiden, daß Nachschub in letzter Minute doch noch nach China kam. Für kurze Unruhe sorgte am 25. Juni die Meldung, Japan habe

${ }^{178}$ Grew an Hull, 19.6., 24.6.1940 (SD 793.94/15946, 15962, 893.24/757); Corbin an Baudouin, T 2607-8, 20.6., T 2620, 21.6.1940 (MAEN Londres C 486); War Cabinet, FCP (40), $2^{\text {nd }}$ meeting, 21.6.1940 (FO 371/24719, F 3474/3429/61); C in C China an War Office, 28.6.1940 (FO 371/24328, C 7405/7327/17); DECouX, À la barre de l'Indochine, S. 37; Nicholas TARLING, The British and the First Japanese Move into Indo-China, in: Journal of Southeast Asian Studies 21.1 (1990), S. 35-65 (S. 36f.); DREIFORT, Japan's Advance, S. $284 f$. 
Schiffe nach Haiphong entsandt ${ }^{179}$. Aus Europa drohte Frankreichs Herrschaft über Indochina nun keine Gefahr mehr. Die Waffenstillstände mit Deutschland und Italien, die am 25. Juni um 0.35 Uhr in Kraft traten, erwähnten die Kolonien nicht. Baudouin und Charles-Roux hofften, daß sich die französische Macht in Asien bis zu einem Friedensschluß behaupten lassen werde ${ }^{180}$.

Die Anklage im Kriegsverbrecherprozeß in Tokio behauptete, darin von einem Teil der Literatur gefolgt, Japan habe schon lange, spätestens seit 1939, die Absicht gehabt, Indochina zu besetzen ${ }^{181}$. Tatsächlich besaß Japan bis zum Juni 1940 keine Pläne für eine Eroberung Südostasiens, weder für die Besetzung Indochinas noch die einer anderen westlichen Kolonie. Das Ultimatum vom 19. Juni blieb ja im Rahmen bisheriger Forderungen, wenn es auch diesmal von massiven militärischen Drohungen begleitet war. In Tokio beklagte der deutsche Botschafter Ott den freundschaftlichen Geist, in dem sich Außenminister Arita und Botschafter Henry über den Transit in Indochina und die Beendigung der Tientsinkrise geeinigt hätten. Japan bemühte sich erst am 21. Juni in Berlin, von Hitler freie Hand für den Zugriff auf Futsuin (Französisch-Indochina) zu erhalten. Daß Tokio viel zu spät ins Lager der »Achse« umgeschwenkt war, sorgte zunächst für scharfe Kritik in der japanischen Presse und Mitte Juli 1940 für den Sturz der Regierung Yonai ${ }^{182}$.

Nach den Waffenstillstandsgesuchen Frankreichs in Europa verbreitete Tojo Hideki, der im Juli 1940 Kriegsminister wurde, das Wort, man dürfe »den Bus

\footnotetext{
${ }^{179}$ Reed an Hull, 20.6., 23.6., 26.6., 21.6.1940 (SD 851g.01/12, 19, 24; FRUS 1940, IV, S. 31); Flood an Hull, 23.6., Grew an Hull, 25.6.1940 (SD 851g.01/18; FRUS 1940, IV, S. 38); Henry an Cosme, T 245-46, 23.6.1940 (MAEN Pékin A 395); KAMMERER, La vérité sur l'armistice, S. 265; YOSHIZAWA Minami, The Nishihara Mission in Hanoi, July 1940, in: SHIRAISHI, FURUTA (Hg.), Indochina in the 1940s, S. 9-54 (S. 18f.); Hata, The Army's Move, S. 160; MURAKAMI, Japan's Thrust, S. 107; Myers (Canton) an Hull, 28.6.1940 (SD 793.94/15995); Foreign Office, Weekly Political Intelligence Summary No. 38, 25.6.1940, in: Great Britain, Foreign Office, Weekly Political Intelligence Summaries [October 1939-November 1947], New York, London, Schaan 1983.

${ }_{180}$ Charles-Roux an Cosme, T 10-13 CF, Henry, T 2-5 CF, Lépissier, T 10-13 CF, 1.7.1940 (MAE Vichy Asie 124); Baudouin an Corbin, T 17-19, 4.7.1940 (MAEN Londres C 486).

${ }^{181}$ Anklage Robert Oneto (TWTC, Bd. III, S. 6708); BUTTINGER, Vietnam, Bd. 1, S. 234; HATA, Continental Expansion, S. 309f.; CROWLY, Japan's Quest, S. 296f.; KURUSU Nitz Kiyoko, Japanese Military Policy towards French Indochina during the Second World War: The Road to Meigo Sukusen (9 March 1945), in: Journal of Southeast Asian Studies 14.2 (1983), S. 328-353 (S. 331). Ohne Quellenangabe schreibt LU, am 28. Dezember 1939 hätten Außenminister Nomura, Marineminister Yoshida und Kriegsminister Hata vereinbart, eine Besetzung Indochinas zu planen (From the Marco Polo Bridge, S. 67). HaTANo Sumio und ASADA Sadao zufolge beschlossen die Minister bei dem Treffen jedoch ausdrücklich, nicht in den Süden zu expandieren (The Japanese Decision to Move South [1939-1941], in: Robert BOYCE, Esmonde M. ROBERTSON [Hg.], Path to War: New Essays on the Origins of the Second World War, London, New York 1989, S. 383-407 [S. 386]).

${ }^{182}$ Ott an Ribbentrop, 19.6., 21.6., Aufzeichnung des Staatssekretärs, 21.6.1940 (ADAP, Serie D, IX, 484, 514, 511); KREBS, Japans Deutschlandpolitik, S. 421f.; SOMMER, Deutschland und Japan, S. 342f.; KREBS, Von Hitlers Machtergreifung, S. 19; Craigie an Halifax, 22.6.1940 (FO 371/24730, F $3400 / 66 / 23)$.
} 
nicht verpassen«. Am 25. Juni erklärte Kriegsminister General Hata Shonroku, die Nachwelt werde es nicht verzeihen, wenn man die Gelegenheit nicht nutze. $\mathrm{Ab} 21$. Juni entwickelte der Generalstab eine neue Strategie, die Generalstab und Kriegsministerium am 3. Juli beschlossen. Die "Skizze der Hauptprinzipien zum Umgang mit der verändernden Weltsituation« wurde am 27. Juli vom Kabinett und den Oberkommandos übernommen. Diese Hauptprinzipien bestimmten bis Pearl Harbor das japanische Vorgehen: Japan sollte demnach notfalls mit Gewalt - in Südostasien eine ihm untergeordnete Wirtschaftssphäre schaffen. Mitte Juli forderte die Armee den Bau von Flugplätzen in Südindochina als Voraussetzung für einen Angriff auf britische und niederländische Kolonien. Am 30. Juli bezog Außenminister Matsuoka intern Indochina in Japans Interessensphäre ein; am 1. August forderte der Generalstab der Marine die Stationierung japanischer Truppen in Indochina als ersten Schritt des Südstoßes; Indochina sollte auch Basis in einem Krieg gegen Großbritannien und die USA sowie Lieferant wichtiger Rohstoffe werden. Erst Frankreichs Niederlage in Europa hatte also den Expansionisten in Japan eine goldene Gelegenheit gegeben und die Südstrategie in Japan durchsetzungsfähig gemacht $^{183}$. Japans Vorstoß nach Indochina war Ergebnis günstiger Umstände nicht einer langen Planung. Catroux' Nachgeben hatte kurzfristig die Lage beruhigt, aber vor allem den Appetit der Japaner geweckt ${ }^{184}$.

Der 29. Juni, ein Samstag, schloß einige Prozesse ab. Gleichzeitig begannen Entwicklungen, die die Folgejahre prägen sollten: Die französische Regierung begann an diesem Tag den Umzug von Bordeaux nach Vichy. Einen Tag zuvor hatte die britische Regierung Charles de Gaulle als »Chef der freien Franzosen« anerkannt. Die Beamten und Offiziere in Ostasien, mit Ausnahme von General Catroux, der de Gaulle schon seit gemeinsamer Kriegsgefangenschaft von 1916 bis 1918 kannte, dem Gesandten in Bangkok, Paul Lépissier, sowie dem Vize-Polizeichef der Konzession in Shanghai, Robert Jobez, setzten ihre Tätigkeit für das Regime unter Marschall Pétain fort. In London trat Botschafter Corbin zurück, Geschäftsträger Cambon folgte Anfang Juli ${ }^{185}$.

\footnotetext{
${ }^{183}$ CoOX, The Pacific War, S. 324; Langer, Gleason, The Challenge, S. 603; TsunOda, The Navy's Role, S. 247f.; Hata, The Army's Move, S. 155; BarNHART, Japan Prepares for Total War, S. 158f.; WANG Xi, China and the U.S.Japanese Relations, in: IRIYE Akira (Hg.), Pearl Harbor and the Coming of the Pacific War. A Brief History with Documents and Essays, Boston, New York 1999, S. 184-194 (S. 193); Hatano, Asada, The Japanese Decision, S. 389, S. 393; LAFEBER, The Clash, S. 193.

${ }^{184}$ MURAKAMI Sachiko, Indochina: Unplanned Incursion, in: CONROY, WRAY (Hg.), Pearl Harbor Reexamined, S. 141-149 (S. 142); MURAKAMI, Japan's Thrust, S. 65, S. 542; DECouX, À la barte, S. 93. ${ }^{185}$ De Gaulle, Mémoires de Guerre, Bd. 1, S. 72f;; Peter SCHUNCK, Charles de Gaulle. Ein Leben für Frankreichs Größe, Berlin 1998, S. 41, S. 169f.; LERNER, Catroux, S. 68f.; Crosby an Foreign Office, 9.11.1940 (FO 371/24345, C 12394/7328/17); WASSERSTEIN, Secret War, S. 75; ChARLES-RouX, Cinq mois tragiques, S. 94, S. 63, S. 129.
} 
Außenminister Arita verkündete am 29. Juni im Radio den Anspruch Japans auf die Schaffung einer asiatischen Wohlstandssphäre unter japanischer Führung. In dieser Zone habe Japan eine Mission und eine Verantwortung als stabilisierende Macht. Dies war die erste Äußerung, die auf die neuen Ziele der japanischen Expansion hindeutete ${ }^{186}$.

In Hanoi landeten am 29. Juni, begleitet von Militärattaché Thiébaut, 30 Mitglieder der japanischen Überwachungskommission auf dem Flugplatz, auf dem sie mit drei Beamten ihres Generalkonsulats und den sieben Soldaten des Vorauskommandos zusammentrafen. Rasch reisten japanische Inspekteure in sechs Grenzstädte. Die Kommissionsmitglieder wohnten im Gästehaus des Generalgouverneurs; ihre Ausgaben wurden von den Franzosen getragen. Im Gepäck hatte General Nishihara den Auftrag von Armee und Marine in Tokio, mit den Franzosen über die Passage japanischer Truppen durch Indochina sowie die Nutzung französischer Flugplätze und Häfen zu verhandeln ${ }^{187}$. Die Tage von Frankreichs Herrschaft über Indochina waren gezählt.

Die Phase der drôle de guerre war in Asien durch Japans »aggressive Neutralität ${ }^{188}$ charakterisiert. Während sich Paris - mit Rücksicht auf die USA aber nicht vollends entschlossen - um Japans Freundschaft bemühte, wartete Tokio den Verlauf des Krieges in Europa ab und schüchterte Paris mit 14 Bombardements der Yunnanbahn ein. Japan nutzte die französische Schwäche aus, um seine Kontrolle über China zu vergrößern. Daß der $\mathrm{Zu}-$ sammenbruch Frankreichs eine Gelegenheit sein könnte, nach Indochina vorzustoßen, erkannte das japanische Militär erst, als deutsche Truppen bereits in Paris einmarschiert waren.

${ }^{186}$ LANGer, Gleason, The Challenge, S. 603; MuRakami, Japan's Thrust, S. 48; IEnaGa, The Pacific War, S. 130.

${ }^{187}$ Reed an Hull, 14.7., 21.7.1940 (SD 851g.01/34, 893.24/844); HaTA, The Army's Move, S. 155; MURAKamI, Japan's Thrust, S. 104f.; PEDRAZZANI, La France en Indochine, S. 47f. Die vom Generalsekretär der Kolonialverwaltung in Indochina genannte Zahl von 60 Kontrolleuren, die am 29. Juni angekommen seien (GAUTIER, La fin de l'Indochine, S. 25), umfaßt das Militär, das am 29. Juni und am 3. Juli landete (Decoux an Rivière, T 1860-67, 23.7.1940, MAE Vichy-Asie 27).

${ }^{188}$ VIÉ, Le Japon et le monde, S. 208. 